\title{
THE PLANT BUG TRIBE ORTHOTYLINI IN JAPAN (HETEROPTERA: MIRIDAE: ORTHOTYLINAE)*
}

\begin{abstract}
Yasunaga, T., 1999. The plant bug tribe Orthotylini in Japan (Heteroptera: Miridae: Orthotylinae). - Tijdschrift voor Entomologie 142: 143-183, figs. 1-155. [ISSN 0040-7496]. Published 22 September 1999.

The plant bug tribe Orthotylini of Japan is revised: 33 species are recognized in 11 genera. Two new genera, Malacocorisella and Pseudoloxopidea, and a new subgenus of the genus Orthotylus, Yamatorthotylus, are described. Thirteen new species are described: Orthotylus (O.) fuscipennis, O. (O.) japonicus, O. (Yamatorthotylus) xanthopoda, Blepharidopterus striatus, Dryophilocoris lucidus, D. miyamotoi, Zanchius quercicola, Z. nakatanii, Z. ryukyuensis, Z. takahashii, Z. gigantoculus, Malacocorisella endoi, and Pseudoloxopidea pinicola. Other known taxa are diagnosed and/or redescribed, and three species, Orthotylus (O.) kurilensis Kerzhner, O. (Melanotrichus) parvulus Reuter and Pseudoloxops imperatorius Distant, are reported from Japan for the first time. The female of Mecomma japonica Miyamoto is also documented. Brief notes on biology are given for 26 species. Photographs of 23 species and a key are also provided.

Correspondence: Tomohide Yasunaga, Biological Laboratory, Natural Sciences Department, Hokkaido University of Education, Ainosato 5-3-1, Sapporo, 002-8075 Japan. E-mail: yasunaga@atson.sap.hokkyodai.ac.jp.

Key words. - Miridae; Orthotylinae; Orthotylini; monographic revision; new genera; new subgenus; new species; Japan.
\end{abstract}

*Contribution from the Russia/Japan Cooperative East Asian Entomological Program, No. 53.

Although the plant bug tribe Orthotylini is a large group including numerous described genera and species throughout the world, the Japanese fauna has been hitherto represented only by 17 species in 8 genera. Because the Japan Archipelago lies from $46^{\circ} \mathrm{N}$ to $24^{\circ} \mathrm{N}$ and contains cold temperate zone to subtropical islands, the Japanese fauna of the tribe is in great need of investigation.

My continuing studies of the Japanese Orthotylini have recognized a total of 33 species in 11 genera. Of these, 13 species were found to be undescribed, and 3 have not been previously recorded from Japan. In addition, 2 undescribed species were confirmed to be not accommodated by any known genera, and an undescribed species belonging to the genus Orthotylus also could not be placed in any known subgenera of the genus.

This paper is the first monographic revision documenting the Japanese fauna of the Orthotylini comprehensively, with descriptions of two new genera, a new subgenus of Orthotylus, and 13 new species. Three species are also recorded from Japan for the first time. All known taxa are diagnosed and/or redescribed. The female of Mecomma japonica Miya- moto is described. Brief notes on plant association, habit and/or habitat are given for 26 species. A key is provided to distinguish the Japanese genera, subgenera and species of the tribe Orthotylini.

\section{MATERIAL AND METHODS}

More than 2,000 dried specimens of 65 species (including exotic ones) were examined. Depositories of the material are abbreviated as follows:

BMNH Department of Entomology, the Natural History Museum, London

ELKU Entomological Laboratory, Faculty of Agriculture, Kyushu University, Fukuoka

HUES Biological Laboratory, Hokkaido University of Education, Sapporo

IC Mr. Ichita's personal collection, Aomori

MC Dr. Miyamoto's personal collection, Fukuoka

NIAS National Institute of Agro-Environmental Sciences, Tsukuba, Ibaraki

NSMT Department of Zoology, National Science Museum, Tokyo

SEHU Systematic Entomology, Faculty of Agriculture, Hokkaido University, Sapporo 
USNM U. S. National Museum of Natural History, Washington, D. C.

ZMAS Zoological Institute, Russian Academy of Sciences, St. Petersburg

ZMUH Zoological Museum, University of Helsinki, Finland

Nymphs of 15 Japanese species preserved in $80 \%$ ethyl alcohol (HUES) were also observed. Photographs of live material were made with Olympus OM-System $(\mathrm{OM}-4 \mathrm{Ti} 35 \mathrm{~mm}$ camera with T10 Ringflash, Auto Extension Tube, and either $38 \mathrm{~mm}$ or $50 \mathrm{~mm}$ macro lenses).

All measurements in the text are given in millimeters. In the synonymic listings, only selected references are cited for each taxon; for detailed synonymic lists, see Carvalho (1958) and Schuh (1995). New distributional records for known species are each indicated by an asterisk $\left(^{*}\right)$ after the name of a region.

\section{Checklist of Orthotylini in Japan}

Blepharidopterus Kolenati, 1845

B. striatus sp. $\mathbf{n}$.

B. ulmicola Kerzhner, 1977

Cyllecoris Hahn, 1834

C. nakanishii Miyamoto, 1965

C. vicarius Kerzhner, 1988

Cyrtorhinus Fieber, 1858

C. caricis (Fallén, 1807)

C. lividipennis Reuter, 1884

Dryophilocoris Reuter, 1875

D. lucidus sp. $\mathbf{n}$.

D. miyamotoi sp. $\mathbf{n}$.

D. saigusai Miyamoto, 1966

Malacocorisella gen. $\mathbf{n}$.

M. endoisp. n.

Mecomma Fieber, 1858

M. japonica Miyamoto, 1966

Mecommopsis Kerzhner, 1979

M. cruciata Kerzhner, 1979

Orthotylus Fieber, 1858

Subgen. Kiiorthotylus Yasunaga, 1993

O. (K.) gotohi Yasunaga, 1993

Subgen. Melanotrichus Reuter, 1875

O. (M.) flavosparsus (C. R. Sahlberg, 1841)

O. (M.) parvulus Reuter, 1879

Subgen. Orthotylus s. str.

$O$. (O.) fuscipennis sp. $\mathbf{n}$.

O. (O.) interpositus Schmidt, 1938

$O$. (O.) japonicus sp. n.

O. (O.) kurilensis Kerzhner, 1997

O. (O.) pallens (Matsumura, 1911)

Subgen. Pseudorthotylus Poppius, 1914

O. (P.) bilineatus (Fallén, 1807)

Subgen. Yamatorthotylus subgen. $\mathbf{n}$.
O. (Y.) xanthopoda sp. $\mathbf{n}$.

Pseudoloxopidea gen. n.

P. pinicola sp. n.

Pseudoloxops Kirkaldy, 1905

P. imperatorius (Distant, 1904)

P. miyamotoi Yasunaga, 1997

P. miyatakei Miyamoto, 1966

P. takaii Yasunaga, 1997

Zanchius Distant, 1904

Z. gigantoculus sp. $\mathbf{n}$.

$Z$. nakatanii sp. $\mathbf{n}$.

$Z$. quercicola sp. $\mathbf{n}$.

Z. ryukyuensis sp. $\mathbf{n}$.

Z. takahashii sp. n.

Z. tarasovi Kerzhner, 1988

\section{Systematic PART}

\section{Tribe Orthotylini Van Duzee, 1916}

Judging from the conspicuously variable structures exhibited in the external body and genitalia, it is somewhat difficult to consider the tribe as a monophyletic group. Although Linnavuori (1994) provided rather detailed characters for the tribe, only a few consistent key characters were documented. The most distinctive and reliable feature defining the Orthotylini is the presence of a pair of K-structures in the female genitalia (Schuh 1974). Further world level revision is required to redefine this enormous tribe properly.

The Japanese orthotyline members are primarily recognized by the usually elongate body, and fleshy, apically convergent parempodia between the claws. Most species are associated with certain plants, whereas predation on other insects is frequently observed in laboratory tests as well as in the field.

\section{Orthotylus Fieber}

Orthotylus Fieber, 1858: 315, type species: Cimex nassatus Fabricius sensu Fieber 1858 (= Orthotylus marginalis Reuter, 1883: 380), subsequent designation by Kirkaldy 1906: 127; Schuh 1995: 147.

This is one of the largest genera among the Miridae, with approximately 300 described species worldwide. Only 5 species, $O$. (O.) pallens, $O$. (O.) interpositus, O. (Kiiorthotylus) gotohi, O. (Melanotrichus) flavosparsus and $O$. (Pseudorthotylus) bilineatus, were previously recorded from Japan (Miyamoto 1969, 1977, Miyamoto \& Yasunaga 1989, Todo \& Yasunaga 1996, Yasunaga 1993).

Orthotylus appears not to be a monophyletic group, and has not been defined by any consistent diagnostic characters. Some authors (Southwood 1953, Wagner 1952, 1973) proposed several subgenera and species 
groups for the classification of Orthotylus, but a further world level revision is required to correctly redefine these subgenera and species groups. As pointed out by Southwood \& Leston (1959), several subgenera and species groups will be upgraded to the generic level.

Most species of the genus are plant-feeders and several are of economic importance, whereas predation on psyllids, aphids, and lepidopteran and dipteran larvae has been frequently observed during my continuous surveys and also reported by some authors (Wheeler \& Henry 1992, Yasunaga 1996, etc.).

\section{Subgenus Orthotylus s. str.}

Because the members of this subgenus exhibit great interspecific variation in the genitalia, several species groups have been proposed as mentioned above. However, these species groups were proposed mainly for European species, and are not always applicable to the members from other regions. Therefore, I do not use any of them here. Japanese species placed in the subgenus are recognized by the elongate or elongate oval body, principally green general coloration, dense, simple vestiture on the dorsal surface, peculiar shape of the parameres, 3 sclerotized appendages of the vesica (figs. $13,17,21,25,31$, sclerites I-III), and developed female K-structure. The greenish coloration of the body is easily fading to yellow or brown after death.

In Japan the subgenus Orthotylus s. str. has been represented only by two species, pallens and interpositus, but the present study adds 3 species to the Japanese fauna.

\section{Orthotylus (Orthotylus) pallens (Matsumura)}

(figs. 1-2, 7-13, 32)

Calocoris pallens Matsumura, 1911: 39; Yasunaga et al. 1996: 92 (lectotype designated).

Orthotylus (O.) pallens - Miyamoto 1977: 232; Kerzhner 1988b: 833; Schuh 1995: 166; Todo \& Yasunaga 1996: 43; Yasunaga 1996: 48.

Diagnosis. - Recognized by the moderate size, widely darkened head, pronotum, scutellum and hemelytra (fig. 1), striate frons, widened and flattened right paramere, and simple form of the K-structure. Very variable species in coloration; females are paler than males. This species is sometimes confused with Stenotus binotatus of the subfamily Mirinae, inhabiting gramineous grasses, but Orthotylus pallens is easily distinguished from it by the reduced pronotal collar and fleshy, apically convergent parempodia between the claws. The final instar nymph is recognized by the generally yellowish green body with a yellowish orange spot at the dorsal scent gland opening on the abdomen (fig. 2).

Redescription. - Body elongate, subparallel-sided; dorsal surface pale green but usually widely darkened, uniformly clothed with silky, suberect pubescence. Head pale green, weakly granulated, not strongly shining, vertical, with silky, upright pubescence; vertex usually darkened mesally, with basal transverse carina; frons usually widely darkened, striolate by 3-4 pairs of transverse grooves; tylus dark brown. Antennae dark brown; segments I, II and basal part of III sometimes pale in $q$; lengths of segments I-IV (ठ/ 0.96-1.11/0.96-1.04, 0.57-0.60/0.50-0.58. Rostrum pale brown, reaching but not exceeding apex of middle coxa; apical half of segment IV infuscate. Pronotum pale green, usually widely darkened by symmetrical paired markings (that are sometimes reduced and becoming a pair of spots or stripes), shallowly and transversely rugose, uniformly clothed with silky, suberect pubescence; mesoscutum and scutellum varying from pale green to entirely dark brown, shagreened, bearing silky, suberect pubescence; pleura pale green, but partly infuscate in $\hat{\delta}$. Hemelytra pale green, uniformly clothed with silky, suberect pubescence; corium and clavus usually widely (or sometimes entirely) dark brown; inner margin and apex of cuneus sometimes darkened; membrane sombre greyish brown. Legs pale green; tibial spines pale brown; tarsi (especially tarsomeres III) darkened; lengths of hind femur, tibia and tarsus ( $\delta /$ o ): 1.70-1.92/1.84-2.00, 2.64-2.86/2.64-2.84, 0.52-0.53/0.52-0.56; lengths of hind tarsomeres I-III ( $\delta / \%): 0.16-0.21 / 0.18-0.20$, $0.25-0.27 / 0.26-0.27,0.25-0.28 / 0.24-0.28$. Abdomen widely dark brown in $\hat{0}$, unicolorously pale green in ․ Male genitalia (figs. 7-13): Genital segment without any spines (7); left paramere with long, apically curved hypophysis (fig. 12); right paramere variable in general shape, widened and flattened, with minute teeth dorsally (figs. 8-11); vesical sclerite I with strongly curved and toothed apex; sclerite II strongly curved and twisted subapically; sclerite III toothed and 2-branched (fig. 13). Female genitalia (fig. 32): $\mathrm{K}$-structure simple, gradually narrowed towards apex.

Dimensions. - o / 9 : Body length 5.28-5.91/5.425.62; head width including eyes $0.99-1.01 / 1.00$ 1.01 ; vertex width $0.36-0.39 / 0.45-0.46$; rostral length 1.48-1.66/1.60-1.68; mesal pronotal length $0.81-0.89 / 0.87-0.89$; basal pronotal width 1.48 1.52/1.51-1.55; width across hemelytra 1.80 1.90/1.84-1.92.

Distribution. - Japan (Hokkaido, Honshu, Shikoku*, Rishiri Is., Rebun Is., Yagishiri Is.*), S. Kuril Isls., Russia (S. Sakhalin).

Biology. - This is one of the commonest species among the willow-inhabiting mirid bugs in Hokkaido (Todo \& Yasunaga 1996). It seems to have a univoltine life cycle, and the adults usually emerge in late June. The eggs are laid in shoots of willow (Salix spp., 

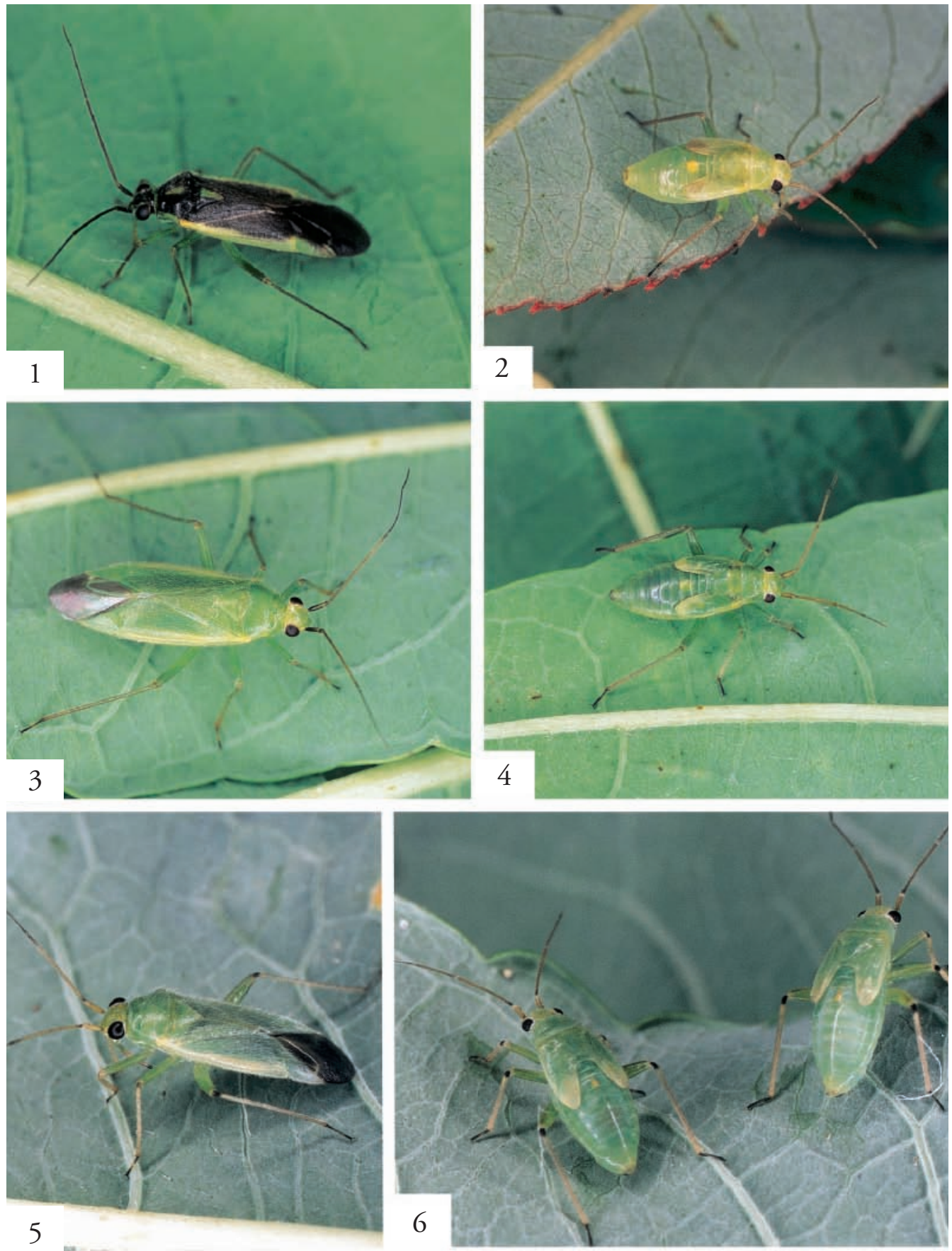

Figs. 1-6. Adults $(1,3 \& 5)$ and final instar nymphs $(2,4,6)$ of Orthotylus spp. on willow in Hokkaido. - 1, 2, O. pallens; 3 , 4, O. interpositus; 5, 6, O. japonicus. 
Salicaceae) and hibernate. Predation on lepidopteran and dipteran larvae by the adults and final instar nymphs were frequently observed in laboratory tests (Yasunaga 1996).

Material examined. - More than 350 specimens (HUES, NSMT, SEHU, ZMAS) were examined from the following localities: JAPAN: Hokkaido: Soya: Kutsukata, Rishiri Is.; Kafukai, Rebun Is. - Rumoi: Yagishiri Is. - Kamikawa: Nakagawa T.; Moshiri \& Shirakaba, Horokanai T.; Etanbetsu, Asahikawa C.; Mt. Asahidake, 200-800 m alt. \& Tenninkyo Valley, Mts. Taisetsu; Katsurazawa Park, Ashibetsu C. - Sorachi: Sunagawa C.; Higashi-Naie, Naie T. - Ishikari: Aoyama, Tobetsu T.; Yausuba, Ishikari C.; Hokkaido Univ. Campus, Sapporo C.; Jozankei, Sapporo C. - Shiribeshi: Asari Pass, Otaru C.; Mt. Chisenupuri, 500-600 m alt., Niseko. - Iburi: Hokkaido Univ. Exp. Forest, Tomakomai C.; Kimundo Waterfall, Toya Lake. - Hidaka: Urakawa T. - Tokachi: Tokachi-Mitsumata, Kamishihoro T.; Rakko Riv., Hiroo T.; Obihiro C.; Kyushu Univ. Exp. Forest, Ashoro T.; Kimonto, Churui Vil. - Honshu: Ozegahara, Gunma Pref. (NSMT); Daimonzawa, Mt. Akadake, 2,0002,500 m alt., Mts. Yatsugatake, Yamanashi Pref.; Minoto, Mt. Akadake, 2,000-2,500 m alt., Nagano Pref. - Shikoku: Haruno T., Kochi Pref. - KURIL ISLS.: Alekhino \& Dubovoe, Kunashiri Is. (ZMAS) - RUSSIA, Sakhalin: Tunnaicha Lake, S. Sakhalin (lectotype + , SEHU); $12 \mathrm{~km} \mathrm{~S}$ of Kholmsk (holotype $\hat{\sigma}$ of $O$. emiliae Kerzhner, ZMAS).

\section{Orthotylus (Orthotylus) interpositus Schmidt} (figs. 3-4, 14-17, 33)

Orthotylus (O.) interpositus Schmidt, 1938: 469; Kerzhner 1978: 43; Kerzhner 1988b: 833; Yasunaga 1993: 57, fig. 2G; Schuh 1995: 160.

Orthotylus interpositus? - Todo \& Yasunaga 1996: 43.

Orthotylus (O.) sp. 1 - Endo et al. 1998: 17.

Diagnosis. - Recognized by the elongate body, immaculate pale green general coloration, usually darkened antennal segment I (fig. 3), and shape of the genitalia. The specimens from the eastern Palearctic Region are somewhat different from those from Europe in the larger body, longer antennae and legs, and developed and not conspicuously bifurcate female Kstructures mesally overlapping each other (figs. 3233). These different forms are considered to represent zoogeographical variation (Kerzhner pers. comm.). The final instar nymph resembles that of pallens, from which it is separable by the slender body and more deep greenish coloration (fig. 4).

Redescription. - Body generally pale green, elongate, parallel- ( $\widehat{0}$ ) or subparallel-sided ( + ); dorsal surface uniformly clothed with silky, suberect pubescence. Head somewhat tinged with yellow, weakly shining, subvertical, bearing silky, erect pubescence; vertex transversely carinate basally; frons smooth, not striolate; tylus somewhat raised. Antennae pale brown; segment I, apex of II, and entire III and IV sometimes darkened especially in $\delta$; lengths of segments I-IV
(ઠ /ㅇ ): $0.55-0.60 / 0.55-0.62,2.08-2.16 / 1.89-2.21$, 1.03-1.23/1.00-1.18, 0.62-0.70/0.62-0.75. Rostrum pale brown, short, reaching but not exceeding middle coxa; apical half of segment IV infuscate. Pronotum transversely and very narrowly wrinkled, uniformly clothed with silky, upright pubescence; mesoscutum and scutellum shagreened, bearing silky, suberect pubescence; pleura unicolorously pale. Hemelytra weakly shagreened, uniformly clothed with silky, suberect pubescence; embolium tinged with yellow; membrane pale greyish brown, with greenish veins. Legs rather long; tibial spines pale brown; tarsi dark brown; lengths of hind femur, tibia and tarsus ( $\delta / \%$ ): 2.06-2.16/2.16 $2.23, \quad 2.85-3.20 / 3.00-3.12, \quad 0.62-0.68 / 0.60-0.65$; lengths of hind tarsomeres I-III $(\delta / \%)$ : 0.18 0.20/0.20-0.22, 0.27-0.35/0.32-0.34, 0.27-0.34/0.300.35 . Abdomen unicolorously pale; apex of $q$ ovipositor infuscate. Male genitalia (figs. 14-17): Genital segment with a pointed process above base of left paramere (14); right paramere broadened and toothed apically (fig. 15); vesica moderately curved in general shape; sclerite I smooth, gradually tapered towards apex; sclerite II with a branch at middle; sclerite III toothed and 3-branched (fig. 17). Female genitalia (fig. 33): K-structures well developed, somewhat asymmetrical and mesally overlapping each other.

Dimensions. - o/ 9 : Body length 6.29-6.58/6.626.72; head width including eyes 1.03-1.08/1.031.08 ; vertex width $0.40-0.46 / 0.46-0.53$; rostral length 1.68-1.71/1.68-1.78; mesal pronotal length 0.90-0.94/0.94-0.96; basal pronotal width 1.561.61/1.63-1.68; width across hemelytra 1.891.97/2.06-2.24

Distribution. Japan (Hokkaido), Kuril Isls, Palearctic Region. A typical Euro-Siberian species.

Biology. - This species is associated with willow, Salix spp., and is occasionally attracted to light. One generation per year is assumed for this mirid, and the final instar nymphs appear in mid July in Hokkaido.

Material examined. - 148 specimens (BMNH, HUES, MC, NSMT, ZMAS, ZMUH) from the following localities: JAPAN, Hokkaido: Kitami C., Abashiri (MC); Mitsumata, Kamishihoro T., Tokachi (NSMT); Ya'usuba, Ishikari C., Ishikari; Aoyama, Tobetsu T., Ishikari (HUES, ZMAS). - AUSTRIA: Pernitz (BMNH). - GERMANY: Passau \& Halbendorf (ZMUH) RUSSIA, Primorskij Kraj: $17 \mathrm{~km}$ SW of Krounovka, near Mt. Medvezh'ja; Ussurijsk Natural Reserve; near Sergeevka; Rjazanovka, Khasanskij Dist.; Mt. Oblachnaja, 600-700 m alt.(HUES, ZMAS).

\section{Orthotylus (Orthotylus) kurilensis Kerzhner} (figs. 18-21, 35)

Orthotylus (O.) kurilensis Kerzhner, 1997a: 212.

Diagnosis. - Recognized by the slender body, nar- 


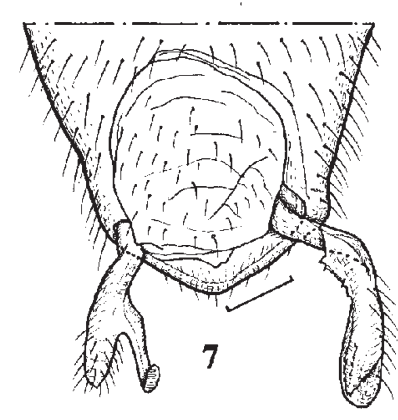

\section{4}

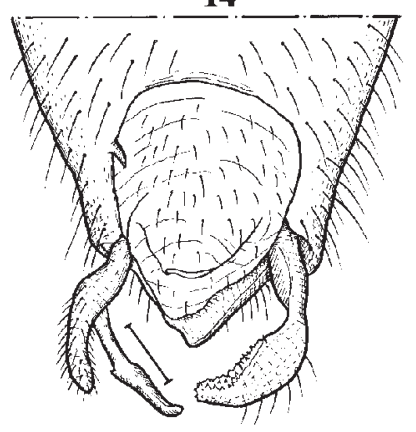

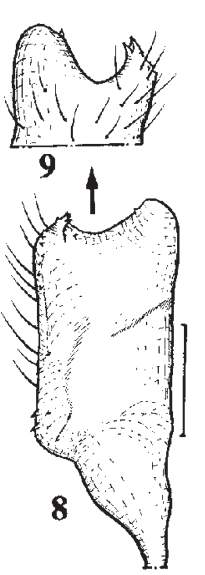
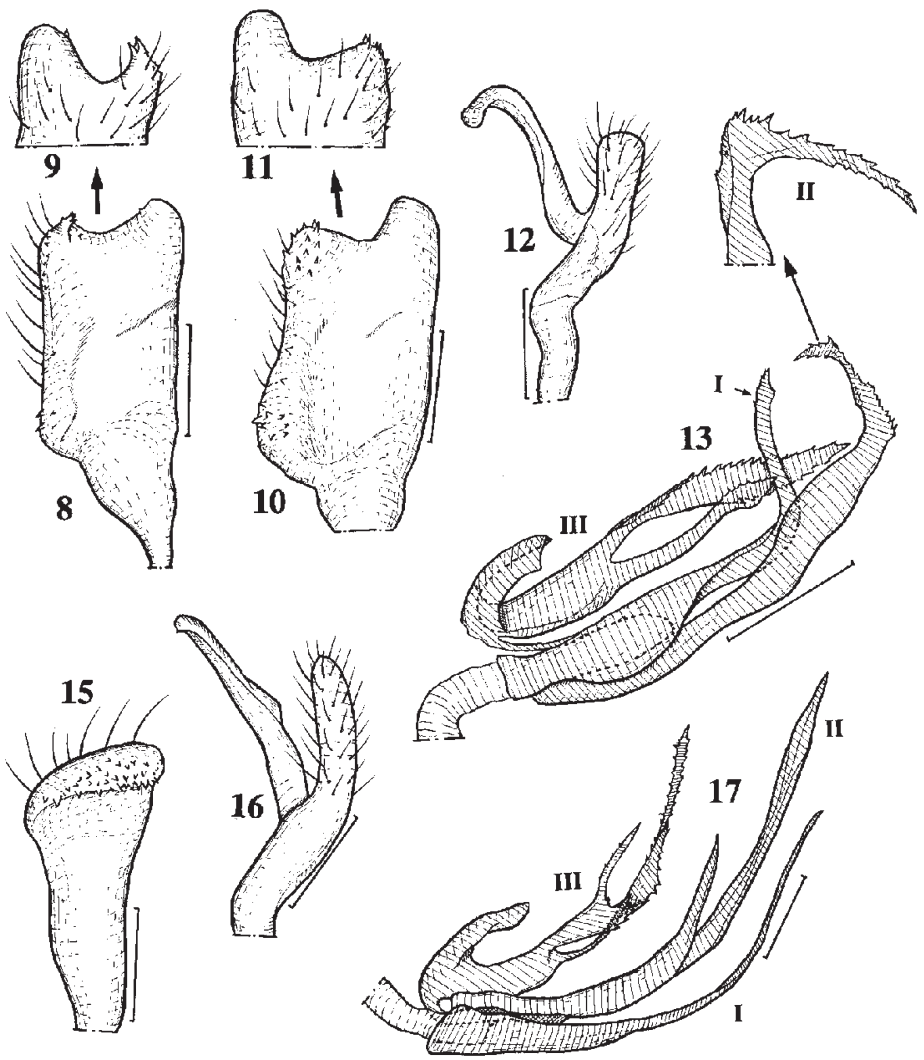

Figs. 7-17. Male genitalia of Orthotylus pallens (7-13) and O. interpositus (14-17). - 7, 14, genital segment with parameres in dorsal view; $8,10,15$, right paramere in left lateral view; 9, 11, apex of right paramere in right lateral view; 12, 16, left paramere; 13,17 , vesica. Scales: $0.2 \mathrm{~mm}$.

row head, vertex and pronotum, noticeably darkened antennae, anterior margin of the scutellum and $\hat{o} \mathrm{ab}-$ domen, and peculiar shape of the right paramere. Similar in external appearance to $O$. interpositus, from which it is readily distinguished by the darkened anterior margin of the scutellum, and dark membrane veins. The yellow parts of the body described below may be pale green when alive although I have not seen live material.

Redescription. - Body slender, parallel- ( $\hat{\sigma})$ and subparallel-sided ( $q$ ); dorsal surface pale green, partly tinged with yellow, uniformly clothed with silky, slender, suberect pubescence. Head yellow, weakly shagreened, narrow, bearing sparse, silky, erect pubescence; vertex with a basal transverse carina. Antennae fuscous; segment I and basal part of II sometimes pale brown in $q$; lengths of segments I-IV $(\delta / \%)$ : 0.48/0.45-0.48, 1.92-2.02/1.84-2.04, 0.93-0.96/0.88$0.96,0.57-0.63 / 0.55-0.58$. Rostrum pale brown, reaching apex of hind coxa; apical half of segment IV infuscate. Pronotum uniformly clothed with silky, suberect pubescence; calli tinged with yellow; mesoscutum yellow, with narrowly infuscate mesal part and posterolateral margin, bearing sparse, silky pubescence; scutellum yellow, darkened along anterior margin, somewhat shagreened, with sparse, silky pubescence; pleura entirely yellow. Hemelytra somewhat shagreened, uniformly clothed with silky, suberect pubescence; embolium and cuneus tinged with yellow; membrane sombre greyish brown, darkened along veins. Legs pale brown; tibial spines pale brown; tarsi, especially tarsomeres III, darkened; lengths of hind femur, tibia and tarsus ( $\delta / \%)$ : 1.80-1.92/1.84-2.01, 2.68-2.96/2.71-2.98, 0.52-0.60/0.57-0.60; lengths of hind tarsomeres I-III ( $\mathrm{o} / \mathrm{q}$ ): $0.18-0.20 / 0.19-0.20$, $0.24-0.26 / 0.27-0.32,0.25-0.27 / 0.25-0.29$. Abdomen pale brown, widely darkened except for genital segment in $\delta$; apices of $q$ valvulae infuscate. Male geni- 


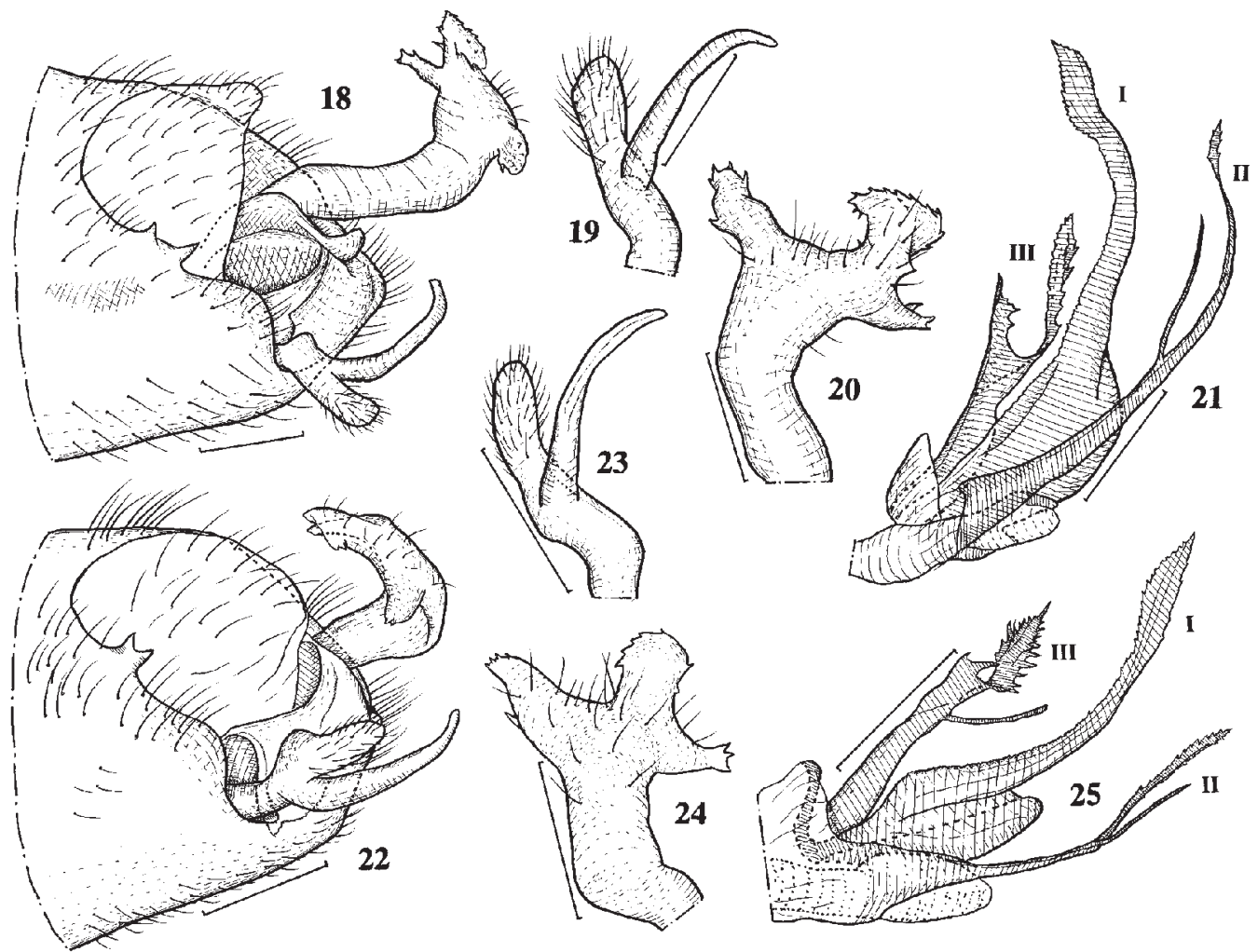

Figs. 18-25. Male genitalia of Orthotylus kurilensis (18-21) and O. fuscipennis (22-25). - 18, 22, genital segment with parameres in left dorsolateral view; 19, 23, left paramere; 20, 24, right paramere; 21,25 , vesica. Scales: $0.2 \mathrm{~mm}$.

talia (figs. 18-21): Genital segment with two pointed processes above base of left paramere (fig. 18); hypophysis of left paramere slender and tapered apically (fig. 19); right paramere 3-branched apically, each branch provided with pointed teeth (fig. 20); vesical sclerite I developed basally; sclerite II with a median slender branch; sclerite III toothed and 2-branched (fig. 21). Female genitalia (fig. 35): K-structure squared, weakly divided into two apical lobes.

Dimensions. - o/ 9 : Body length 5.23-6.00/5.185.91; head width including eyes 0.92-0.94/0.91-0.96; vertex width $0.31-0.36 / 0.40-0.44$; rostral length 1.44 1.49/1.51-1.61; mesal pronotal length 0.740.84/0.76-0.89; basal pronotal width 1.39-1.44/1.461.56; width across hemelytra 1.70-1.92/1.68-1.92.

Distribution. - Japan* (Hokkaido, Honshu), Kuril Isls. (Urup Is.).

Material examined. - Hokkaido: 20ิ, 1 우, Tokachi-Mitsumata, Kamishihoro T., Tokachi, 22.vii.1984, M. Tomo- kuni (NSMT). - Honshu: 10, Hakuho Valley, Minamikoma-gun, Yamanashi Pref., light trap, 20.viii.1987, S. Nomura (HUES); 10, Ozegahara, Gunma Pref., 28 31.viii.1978, M. Sato (NSMT); 10ิ, same locality, 20-24.viii.1979, M. Sato (NSMT); 10, 1 온, Yamanohana, Ozegahara, Gunma Pref., 20.viii.1979, M. Owada (NSMT).

Orthotylus (Orthotylus) fuscipennis sp. n. (figs. 22-25, 36)

Type material. - Holotype ô, Utsumata, Maki Vil., Higashi-kubiki, Niigata Pref., Honshu, Japan, 5.vii. 1997, S. Sakurai (HUES). - Paratypes: $20^{\dagger}, 1$ 우, same data as for holotype (HUES).

Diagnosis. - Recognized by the small, slender and widely darkened body, and relatively shagreened dorsum. This new species resembles $O$. pallens, from which it is easily distinguished by the even smaller body. Judging from the similarity of the male genital 
structure, fuscipennis is a close relative of kurilensis.

Description. - Body small, slender, parallel-sided; dorsal surface widely dark brown, shagreened, uniformly clothed with simple, pale, suberect setae. Head widely dark brown, granulated, bearing sparse, silky, erect pubescence; median part of vertex and lateral margin of frons sometimes pale brown; weak basal transverse carina of vertex darkened in ${ }^{*}$; frons shallowly striolate with 3-4 transverse rows of minute punctures. Antennae dark brown; segment I pale brown; basal part of segment II pale in $\delta$; lengths of segments I-IV (§/\%): $0.43-0.46 / 0.46,1.75$ 1.88/1.80, 0.86-0.94/0.96, 0.60-0.70/0.67. Rostrum pale brown, reaching apex of middle coxa; apical half of segment IV infuscate. Pronotum dark brown, shagreened, with pale mesal stripe and calli, uniformly clothed with simple, pale, suberect setae; mesoscutum and scutellum dark brown, sometimes partly or widely pale brown, bearing sparse, suberect setae; pleura usually widely darkened and irregularly pale brown. Hemelytra dark brown, shagreened, uniformly clothed with simple, suberect setae; embolium, cuneus and narrow lateral margin of corium pale green; membrane dark greyish brown, with dark veins. Coxae and legs yellow; tibial spines pale brown; tarsomeres III dark brown; lengths of hind femur, tibia and tarsus ( $\delta /$ o ) : 1.60-1.66/1.73, 2.40-2.55/2.59, $0.48-0.57 / 0.50$; lengths of hind tarsomeres I-III (o/ $/$ ) : $\quad 0.15-0.17 / 0.16, \quad 0.24-0.28 / 0.24, \quad 0.24-$ $0.27 / 0.24$. Abdomen dark brown. Male genitalia (figs. 22-25): Genital segment with a bifurcate process above base of left paramere (fig. 22); parameres similar in general shape to kurilensis; median apical branch of right paramere narrow (fig. 24); vesical sclerite I developed basally; sclerite II slender, with a median branch; sclerite III strongly twisted apically, with a smooth, slender branch subapically (fig. 25). Female genitalia (fig. 36): K-structure rather flat, inwardly toothed, with slender extension at apex.

Dimensions. - ô/ 9 : Body length 4.46-4.76/4.80; head width including eyes $0.81-0.84 / 0.86$; vertex width $0.30-0.32 / 0.38$; rostral length $1.44-1.52 / 1.56$; mesal pronotal length $0.69-0.72 / 0.77$; basal pronotal width 1.12-1.20/1.30; width across hemelytra 1.36-1.44/1.63.

Distribution. - Japan (Honshu).

\section{Orthotylus (Orthotylus) japonicus sp. n.}

(figs. 5-6, 26-31, 37)

Orthotylus (O.) sp. 2 - Todo \& Yasunaga 1996: 43; Endo et al. 1998: 17 .

Type material. - Holotype ô, Etanbetsu, Asahikawa C., Kamikawa, Hokkaido, Japan, on willow, 25.vii. 1998, T. \& M. Yasunaga (HUES). Paratypes: 202 specimens from the following localities in Japan: Hokkaido: Otoineppu Vil., Kamikawa; Moshiri-Shirakaba, Horokanai T., Kamikawa; Engaru
T., Abashiri (ZMAS); Mt. Arashiyama, Asahikawa C.; same as holotype; Pin'neshiri, Shin-totsugawa Vil., Sorachi; Hassamu, Sapporo C., Ishikari (MC); Ya'usuba, Ishikari C., Ishikari; Hokkaido Univ. Campus, Sapporo C. (ZMAS); Seicha, Hidaka-horobetsu Riv., Urakawa T., Hidaka; Iwabokki-Suimon, Akkeshi T., Kushiro; Aoyama, Tobetsu T., Ishikari. - Honshu: Nishimeya Vil., Aomori Pref.; Kodera, Oe T., Yamagata Pref.; Ozegahara, Gunma Pref. (NSMT); Niitsu, Niigata Pref. (MC); Kakenoue, Muika T., Niigata Pref.; Myoko Plateau, Nagano Pref. (MC); Karuizawa, Nagano Pref. (MC); Nomugi-toge, Gifu Pref. (NSMT); Minamihizue-Shirami, Wakayama Pref. - Shikoku: Haruno T., Kochi Pref.; Hakawa, Ino T., Kochi Pref.

Diagnosis. - Recognized by the rather small and suboval body, immaculate pale green coloration, densely pubescent dorsum, a distinct dark spot at the base of each tibia (fig. 5), and significantly specialized form of the parameres. This new species is at first sight similar in general appearance to O. kerzhneri, from which it is easily distinguished by the smaller and more oval body. Judging from the peculiar male genital structure, O. japonicus has only a remote relationship with any known congeners. The final instar nymph is readily recognized by the generally pale green body with a dark knee spot at the base of each tibia (fig. 6).

Description. - Body generally pale green, small, suboval; dorsal surface densely covered with silvery or silky, suberect pubescence. Head tinged with yellow, somewhat rounded, bearing silvery, erect pubescence; basal transverse carina of vertex weak. Antennae pale brown; apical part of segment II, and entire III and IV dark brown; lengths of segments ( $8 / q)$ : $0.43-0.48 / 0.43-0.48, \quad 1.63-1.83 / 1.65-1.72, \quad 0.93-$ 1.01/0.93-0.96, 0.57-0.58/0.55-0.60. Rostrum pale brown, reaching apex of hind coxa; apical half of segment IV dark brown. Pronotum weakly shagreened, shining, rather tumid, densely clothed with silky, suberect pubescence; calli indistinct; mesoscutum and scutellum shagreened, densely pubescent. Hemelytra shagreened, densely clothed with silky, suberect pubescence; embolium somewhat tinged with yellow; membrane pale greyish brown. Legs pale green; extreme base (knee) of hind tibia infuscate; tarsi dark brown; lengths of hind femur, tibia and tarsus ( $8 / q)$ : $1.53-1.73 / 1.75-1.85, \quad 2.18-2.45 / 2.35-2.62, \quad 0.48$ $0.53 / 0.50-0.53$; lengths of hind tarsomeres I-III (ठ/ क ): $0.18-0.20 / 0.19-0.20,0.24-0.28 / 0.24-0.26$, $0.24-0.29 / 0.22-0.26$. Abdomen almost unicolorously pale green; apices of / valvulae darkened. Male genitalia (figs 26-31): Genital segment shortened, with a strong pointed projection near base of left paramere (fig. 26); parameres peculiar in shape; left paramere widened, with a hooked hypophysis, apical pointed process and dorsal bifurcate extension (fig. 27); right paramere with 3 pointed processes (fig. 28) and 


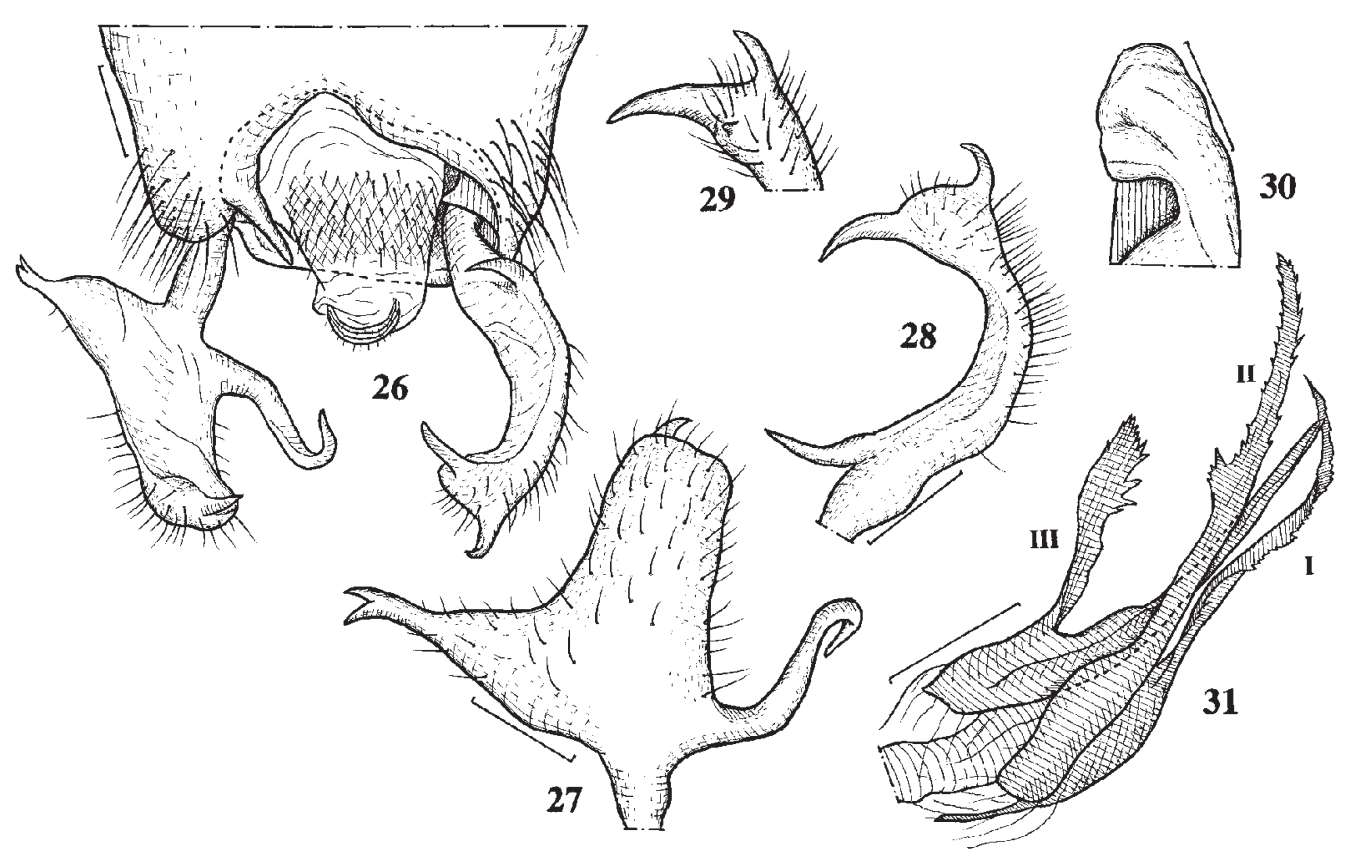

Figs. 26-30. Male genitalia of Orthotylus japonicus. - 26, Genital segment with parameres in dorsal view; 27, left paramere; 28 , right paramere; 29 , the same, apex of another specimen; 30, apex of theca; 31, vesica. Scales: $0.2 \mathrm{~mm}$.

sometimes with an apical small process ventrally (fig. 29); vesical sclerites I and II toothed but not branched; sclerite III bifurcate (fig. 31). Female genitalia (fig. 37): K-structure widened, with rounded inner lobe.

Dimensions. - o/ $/ 9$ : Body length 4.56-4.85/4.895.20; head width including eyes 0.91-0.94/0.980.99 ; vertex width $0.40-0.44 / 0.45-0.48$; rostral length 1.39-1.42/1.44-1.61; mesal pronotal length $0.72-0.80 / 0.81-0.82$; basal pronotal width 1.27 1.37/1.41-1.49; width across hemelytra 1.651.73/1.84-1.92. $\mathrm{ku})$.

Distribution. - Japan (Hokkaido, Honshu, Shiko-

Biology. - As pointed out by Todo \& Yasunaga (1996) and Endo et al. (1998), O. japonicus is associated with willow (Salix spp.) growing along rivers. It obviously has a univoltine life cycle, and hibernates as egg. Predation on dipteran and lepidopteran larvae by the final instar nymphs was observed in laboratory tests.

\section{Subgenus Kiiorthotylus Yasunaga}

Orthotylus (Kiiorthotylus) Yasunaga, 1993: 56, type species: O. gotohi Yasunaga, 1993, monotypic.

This subgenus is currently represented by a single Japanese species, O. gotohi, and is characterized by the small and slender body (fig. 39), long antennae, rostrum and legs, a mesal strong process and a smaller, left lateral blunt-tipped process on the male genital segment (fig. 46), unique shape of the parameres (figs. 47-48), 2-branched vesica that is curved at right angle (48), and asymmetrical K-structures (fig. 38).

Kiiorthotylus is represented by a single, unique species inhabiting an azalea, Rhododendron macrosepalum Maxim. (Ericaceae).

Orthotylus (Kiiorthotylus) gotohi Yasunaga (figs. 38, 39-40, 46-49)

Orthotylus (Kiiorthotylus) gotohi Yasunaga, 1993: 56.

Diagnosis. - Recognized by the slender body, immaculate pale green general coloration, uniformly distributed, pale brown, suberect setae on dorsum, long antennae, rostrum and legs (fig. 39), and unique shape of the genitalia (figs. 38, 46-49). Length 4.5-4.7; width 1.3-1.5. Detailed descriptions of the adult and final instar nymph were provided by Yasunaga (1993).

Distribution. - Japan (restricted areas of Honshu and Shikoku*, where the host, Rhododendron macrosepalum grows).

Biology. - This interesting mirid is associated strictly with a wild azalea, Rhododendron macrosepa- 

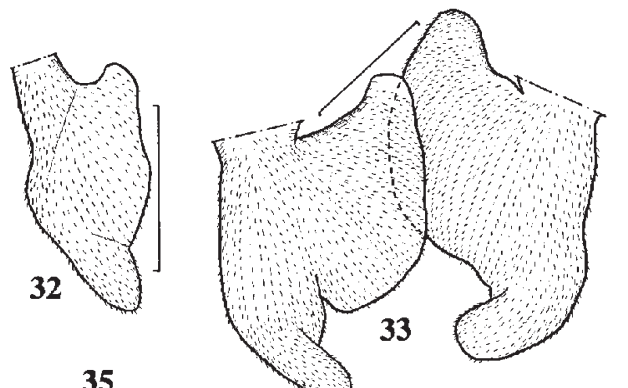

35

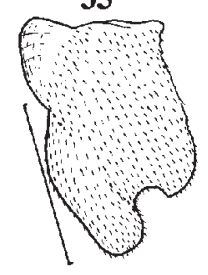

36
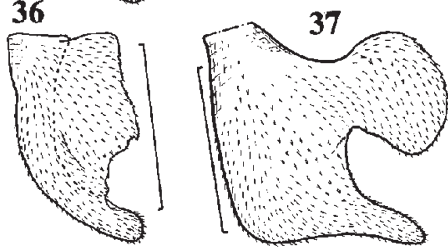

37

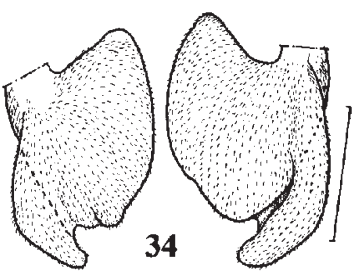

Figs. 32-38.

Female K-structures of $\mathrm{Or}$ thotylus spp. - 32, O. pallens, 33, O. interpositus from Hokkaido, Japan; 34, the same, from Germany; 35, O. kurilensis; 36, O. fuscipennis; 37, O. japonicus; 38, O. gotohi. Scales: $0.2 \mathrm{~mm}$. lum, which is endemic to southwestern Japan. Although the leaves and stems of this plant are densely covered with soft 'adhesive' hairs, the mirid can walk quickly on them (figs. 39-40). Many insects cannot walk or several are sometimes 'captured' by the adhesive hairs as observed by Yasunaga (1992). According to Mr. S. Gotoh (pers. comm.), this mirid frequently feeds on cadavers of other insects captured by the adhesive hairs of $R$. macrosepalum. One generation per year is assumed for O. gotohi. It seems to hibernate as egg, and the newly emerged adults are found from late May to early June.

Material examined. - More than 200 specimens including paratypes (ELKU, HUES, MC, ZMAS) from the following localities: Honshu: Mt. Yahiko, Niigata Pref.; Ayabe C., Kyoto Pref.; Oishi, Kanaya T., Wakayama Pref.; Tsubaki, Shirahama T., Wakayama Pref.; Doro Valley, Tamakiguchi, Wakayama Pref.; Yasukawa Valley, Ohtoh Vil., Wakayama Pref.; Hongu T., Wakayama Pref.; Ichie, Hikigawa T., Wakayama Pref.; Kotonotaki, Susami T., Wakayama Pref. Shikoku: Minaminoma, Tokushima Pref. Most specimens were collected on Rhododendron macrosepalum and some were attracted to light.

\section{Subgenus Pseudorthotylus Poppius}

Pseudorthotylus Poppius, 1914: 66 (as genus), type species: P. sordidus Poppius, 1914, a junior synonym of Capsus bilineatus Fallén, 1807, monotypic.

Orthotylus (Pseudorthotylus) - Linnavuori 1994: 31.

Orthotylus (Neomecomma) Southwood, 1953: 443, type species: Capsus bilineatus Fallén, 1807, original designation (syn. by Linnavuori 1994: 31).

This subgenus is characterized by the unique external appearance and genital structure. The male geni- talia significantly differ from those exhibited in other members of Orthotylus (figs. 50-53). It was actually treated as a full genus in the previous works (Poppius 1914, Southwood \& Leston 1959), but as the whole genus is in need of revision, the definitive treatment is beyond the scope of this study. Diagnostic characters were provided by Southwood (1953) as a synonym, Neomecomma.

\section{Orthotylus (Pseudorthotylus) bilineatus (Fallén)}

(figs. 50-53)

Capsus bilineatus, Fallén 1807: 102.

Orthotylus (Neomecomma) bilineatus - Southwood 1953: 433; Wagner \& Weber 1964: 313; Miyamoto 1969: 78;

Wagner 1973: 182; Kerzhner 1988b: 833; Schuh 1995:

151; Vinokurov \& Kanyukova 1995: 112.

Orthotylus (Pseudorthotylus) bilineatus - Linnavuori 1994: 31.

Diagnosis. - Easily recognized by the comparatively small size, oblong-oval body shape, pale whitish green general coloration, and noticeably darkened median part of the head, calli and posterior margin of the pronotum, mesal part of the scutellum and inner margins of the clavus and corium. Length 4.5-4.8; width 1.4-1.6. Detailed redescriptions were provided by Southwood (1953), Wagner (1952, 1973), Wagner \& Weber (1964), Miyamoto (1969), etc.

Distribution. - Japan (Hokkaido), Palearctic Region. Biology. - Butler (1923) and Kerzhner (1988b) indicated Populus spp. (Salicaceae) as its host plants in England and continental Eurasia. In Hokkaido, this species has been collected from Salix spp., and occasionally attracted to light. The breeding hosts in Japan remain unknown. 

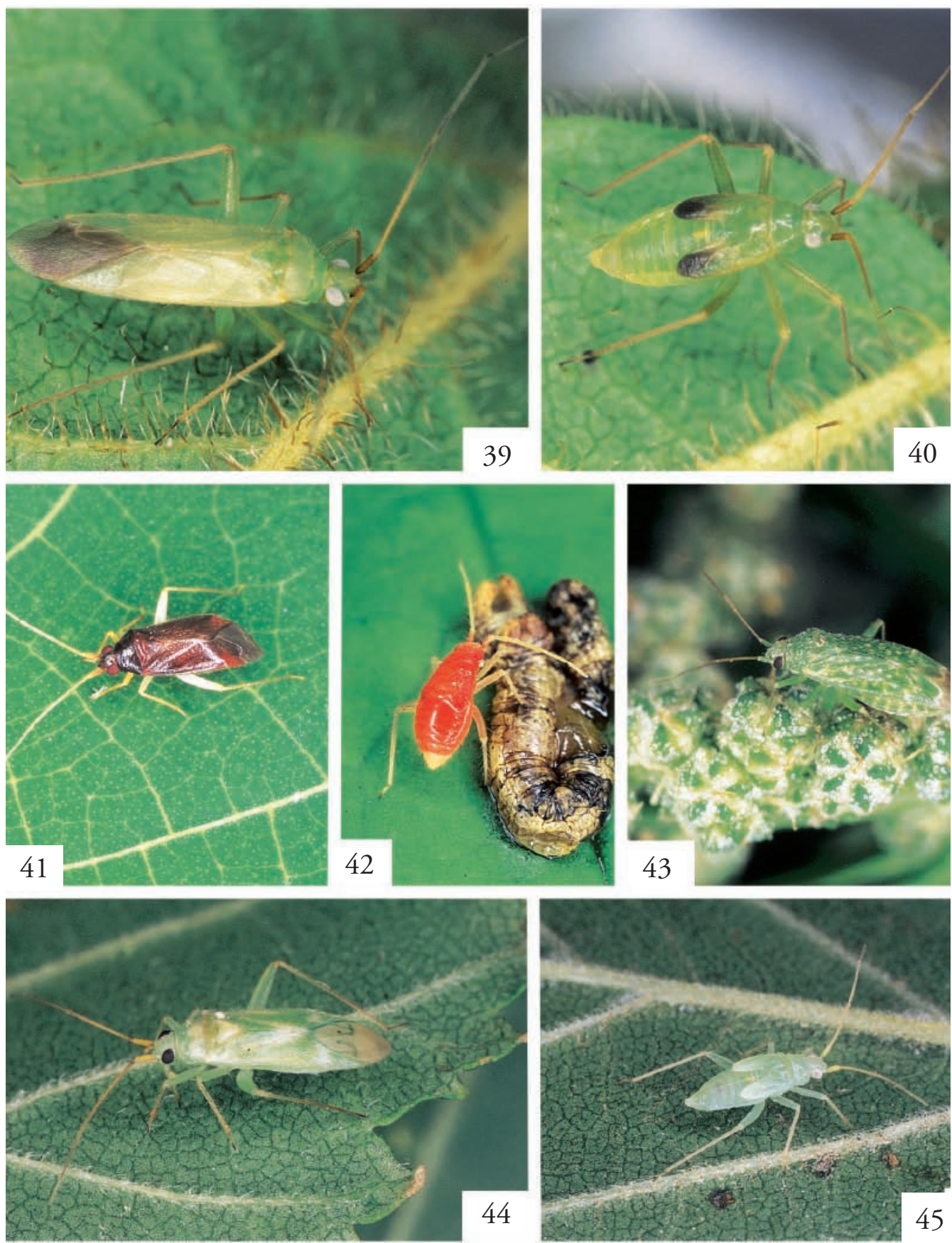

Figs. 39-45. Adults (39, 41, 43, 44) and final instar nymphs (40, 42, 45) of Orthotylus gotohi (39-40), O. xanthopoda (41-42), O. flavosparsus (43) and Blepharidopterus ulmicola (44-45). 


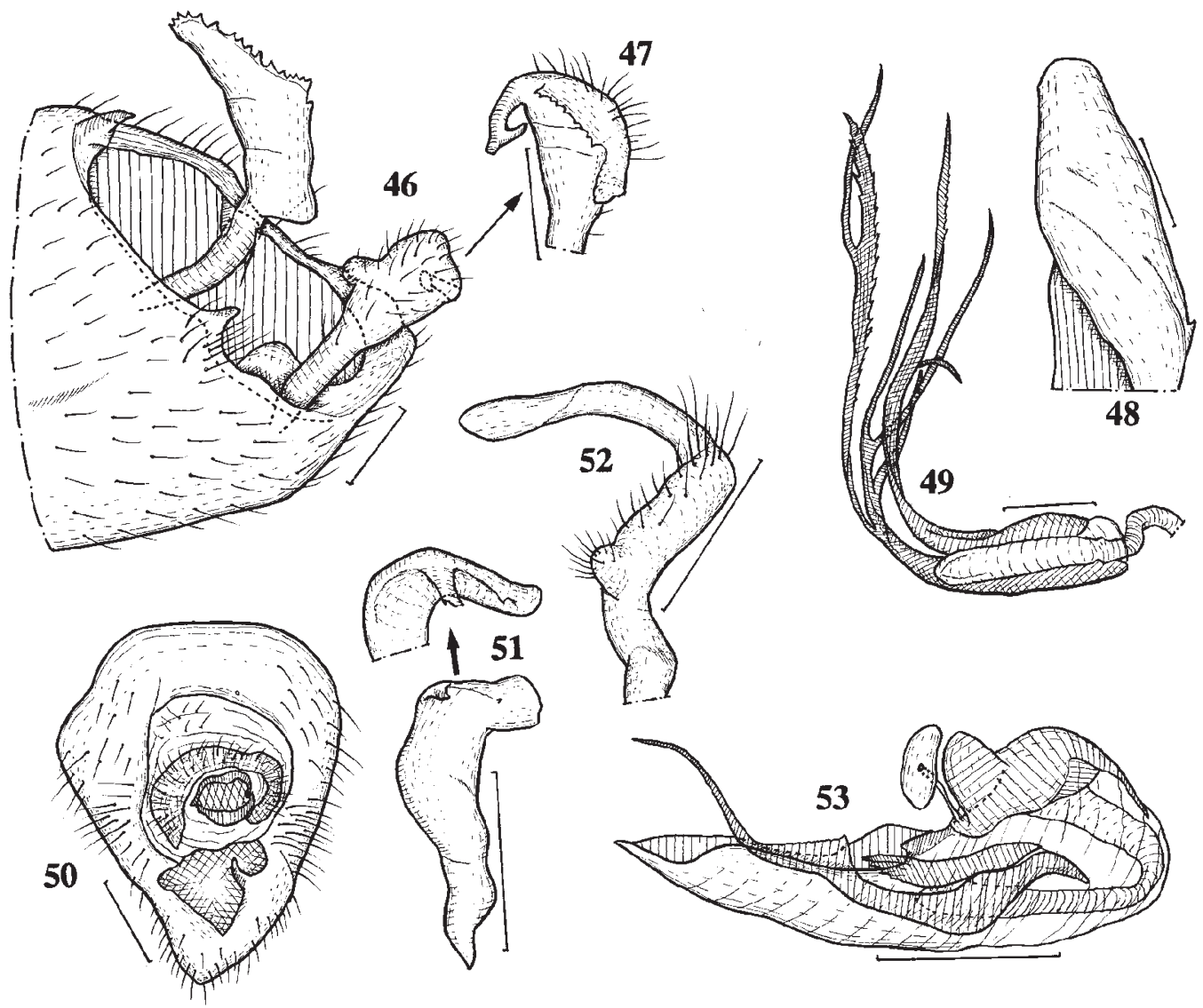

Figs. 46-53. Male genitalia of Orthotylus spp. - 46-49, O. gotohi; 50-53, O. bilineatus. - 46, genital segment with parameres in left dorsolateral view (tergite X removed); 50, the same, without parameres in dorsal view; 51, right paramere; 47, 52, left paramere; 49, 53, vesica in right lateral view; 48, phallotheca. Scales: $0.2 \mathrm{~mm}$.

Material examined. - JAPAN: Hokkaido: $10 \hat{0}, 1 \%$, Mitsumata, Kamishihoro T., Tokachi, 21-22.vii.1984, M. Tomokuni (NSMT); 1 đ, Oniwaki, Rishiri Is., Soya, on Salix sp., 28-29.vii.1994, Y. Todo (HUES); 30 ô, 16 \% , Moshiri, Horokanai T., Kamikawa, at light, 1-5.viii.1994, T. \& M. Yasunaga (HUES). - FINLAND: 19 , Ispois (BMNH). - ENGLAND: 1 \% , St. Beatenberg, viii. 1910 (BMNH); 1 \% , Chiltern Hills, viii. 1915 (BMNH).

\section{Subgenus Yamatorthotylus subgen. n.}

Type species. - Yamatorthotylus xanthopoda Yasunaga, sp. n.

Diagnosis. - Recognized by the small size, red to dark dorsum (fig. 41), strong processes of the male genital segment (fig. 54), highly modified form of the parameres (figs. 54-55), 2-branched vesica (fig. 56), and long, slender K-structure (fig. 57).
Description. - Body small, elongate oval, nearly parallel-sided; dorsal surface red to dark chestnut brown, shining, almost impunctate, densely clothed with simple, brown, suberect pubescence. Head short; eyes almost contiguous to pronotum; vertex transversely carinate basally. Antennal segment I shorter than head width, about as long as IV. Rostrum reaching apex of middle coxa. Pronotum less than half the length of basal width, with narrow collar; calli weak; scutellum flat. Hemelytra longer than abdomen. Legs moderate in length; tibia with pale brown spines. Male genitalia (figs. 54-56): Genital segment with a pointed process right-laterally and a strong, apically bifurcate and basally toothed process; left paramere widened, with 4 processes; right paramere with a broad mesial projection and a pointed, apical process (figs. 54-55); vesica 2-branched, each branch bifurcate 
and toothed apically (fig. 56). Female genitalia (fig. 57): K-structures remarkably elongate, slender, widely separated from each other.

Etymology. - 'Yamato' (= an old name of 'Japan') in combination with the generic name Orthotylus, gender masculine.

Discussion. - Yamatorthotylus is similar in external appearance, except in the reddish dorsum, to the nominotypical subgenus, but the genitalia are highly modified. Especially, the long, slender K-structure is unique, and considered to be an autapomorphy for the present new subgenus.

\section{Orthotylus (Yamatorthotylus) xanthopoda sp. n.} (figs. 41-42, 54-57)

Type material. - Holotype ô, Kuroson, 550 m alt., Nishitosa Vil., Kochi Pref., Shikoku, Japan, 26.vii.1996, T. Yasunaga (HUES). - Paratypes: 53 specimens (ELKU, HUES, USNM) from the following localities in Japan: Hokkaido: Aoyama, Tobetsu T., Ishikari; Takaoka, Tomakomai C., Iburi. - Honshu: Mt. Nekogatake, Suzu C., Ishikawa Pref.; Mt. Obokodake, Totsugawa Vil., Nara Pref.; Mt. Wasamata, Kamikitayama Vil., Nara Pref.; Kitamata, Kawakami Vil., Nara Pref.; Gyojagaeri, Tenkawa Vil., Nara Pref.; Saka'ashi, Nachi-katsu'ura, Wakayama Pref.; Yasukawa Valley \& Komori, Ohtoh Vil., Wakayama Pref.; Komori Riv., Kozagawa T., Wakayama Pref.; Chojabaru, Geihoku T., Hiroshima Pref. - Shikoku: Tsuchigoya, 1,400 m alt., Ehime Pref.; Omogo, Ehime Pref. (ELKU); Befu, Monobe Vil., Kochi Pref.; same as holotype. - Kyushu: Ohminami Pass, 500-600 $\mathrm{m}$ alt., Mt. Hikosan, Fukuoka Pref. (USNM).

Diagnosis. - Easily recognized by the small size, red to chestnut brown dorsum, and contrastingly creamy yellow legs (fig. 41). The reddish coloration enables us to distinguish it promptly from any of the east Asian congeners, but this new species resembles certain species of Phylus Hahn of the subfamily Phylinae, from which $O$. xanthopoda is distinguished by the fleshy, apically convergent parempodia between the claws. The final instar nymph is also readily recognized by the small, oval body, scarlet coloration and yellow apex of the abdomen (fig. 42).

Description. - Dorsal surface red to dark chestnut brown. Head dark brown. Antenna yellow; segments I and IV more or less tinged with red or sanguineous; lengths of segment I-IV ( $\delta / 9$ ): $0.31-0.38 / 0.34-0.42$, $1.58-1.67 / 1.37-1.57, \quad 0.52-0.57 / 0.55-0.64, \quad 0.36-$ $0.42 / 0.36-0.42$. Rostrum pale brown; apex of segment IV infuscate. Pronotum, scutellum, and hemelytra unicolorous, densely clothed with simple, brown, suberect setae. Leg creamy yellow; femur partly tinged with red; tarsus pale brown with dark apex of tar- somere III; lengths of hind femur, tibia and tarsus (ठ/ P): $1.26-1.43 / 1.26-1.41,1.86-2.06 / 1.82-2.06$, $0.31-0.32 / 0.31-0.32$; lengths of hind tarsomeres I-III (ㅎ/우): $0.11-0.13 / 0.12-0.15,0.15-0.17 / 0.14-0.17$, 0.18-0.22/0.17-0.19. Abdomen unicolorous, reddish brown to dark chestnut brown. Genitalia as mentioned in subgeneric description.

Dimensions. - o/ $/$ : Body length 4.05-4.23/4.204.50; head width including eyes 0.72-0.75/0.65-0.70; vertex width $0.28-0.31 / 0.31-0.32$; rostral length 1.25 1.27/1.25-1.32; mesal pronotal length; 0.460.48/0.46-0.51; basal pronotal width 0.95-1.02/1.021.06; width across hemelytra 1.25-1.33/1.29-1.40.

Distribution. - Japan (Hokkaido, Honshu, Shiko$\mathrm{ku}, \mathrm{Kyushu}$ ).

Biology. - This new species was collected by sweeping various broadleaved trees, such as Deutzia crenata Sieb. et Zucc. (Saxifragaceae), Fraxinus mandschurica Rupr., Syringa reticulata (Bl.) Hara (Oleaceae), Mallotus japonicus (Thunb. ex Murray) Muell. (Euphorbiaceae) and Acersp. (Aceraceae), and often attracted to light. The nymphs were found on Deutzia crenata in the Kii Peninsula and Fraxinus mandschurica in Hokkaido. Predation on unidentified lepidopteran larvae by both the adults and nymphs (fig. 42) was observed in laboratory tests. An univoltine life cycle is assumed for $O$. xanthopoda, and the newly emerged adults appear in early June in southern Japan and in mid July in Hokkaido.

\section{Subgenus Melanotrichus Reuter}

Orthotylus (Melanotrichus) Reuter, 1875a: 1: 92, type species: Phytocoris flavosparsus C. R. Sahlberg, 1841, subsequent designation by Kirkaldy 1906: 127; Schuh 1995: 148 .

This subgenus is primarily characterized by the small body, both dark setae and silvery pubescence on dorsum (fig. 43), shape of the parameres (figs. 58-63), and simple form of the vesica. This is treated as a full genus by some authors (e.g., Henry \& Wheeler 1988, Wheeler \& Henry 1992), but I treat it here as subgenus until a comprehensive revision will be accomplished.

\section{Orthotylus (Melanotrichus) flavosparsus (Sahlberg)} (Figs. 43, 58-60)

Phytocoris flavosparsus C. R. Sahlberg 1841: 411.

Orthotylus flavosparsus - Yasunaga et al. 1996: 93 (= Orthotylus nigropilosus Lindberg, 1934).

Orthotylus (Melanotrichus) flavosparsus - Reuter 1875b: 35; Wagner \& Weber 1964: 329; Miyamoto 1965: 98, pl. 49, fig. 22; Wagner 1973: 229; Kerzhner 1988b: 833; Lee \& Kwon 1991: 34; Schuh 1995: 157 (= Tuponia guttula Matsumura, 1917); Vinokurov \& Kanyukova 1995: 112.

Tuponia guttula Matsumura, 1917: 432; Yasunaga et al. 1996: 93 (lectotype designation). 


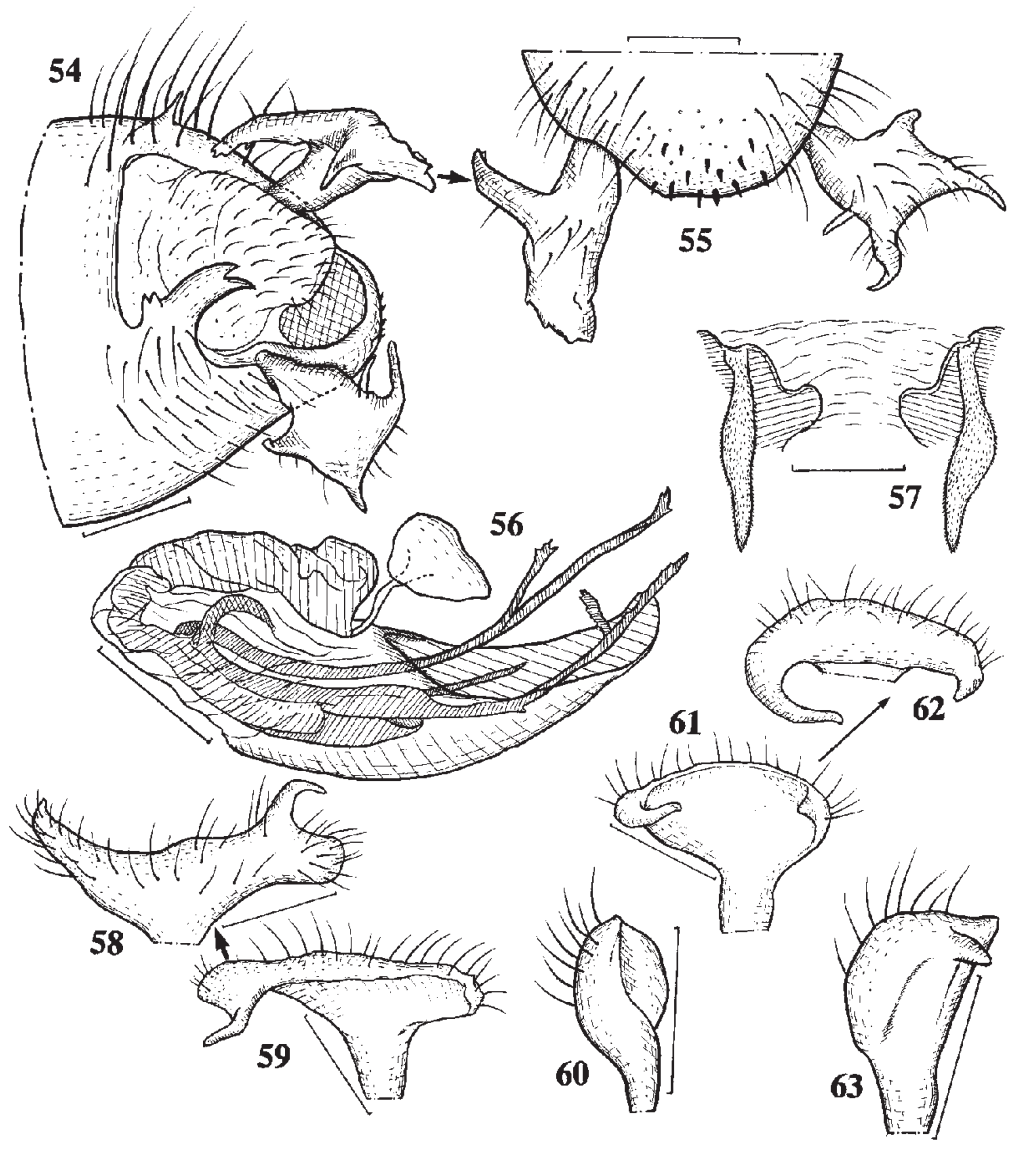

Figs. 54-63. Male and female (57) genitalia of $\mathrm{Or}$ thotylus spp. - 54-57, $O$. xanthopoda; 58-60, O. flavosparsus, 61-63, O. parvulus. 54, genital segment with parameres in left dorsolateral view; 55 , the same, in ventral view; 56, vesica with phallotheca in left lateral view; 58-59, 61-62, left paramere: 60, 63, right paramere. Scales: $0.2 \mathrm{~mm}$ for $54-57$, $0.1 \mathrm{~mm}$ for $58-63$.
Diagnosis. - Recognized by the small, elongate oval $(\delta)$ or oval ( $q$ ) body, shiny pale green general coloration, blackish setae on dorsum, patches of the silvery pubescence on the hemelytra (fig. 43), and shape of the parameres (figs. 58-60). Length 3.6-3.9; width 0.9-1.2. Because of its economic importance, this species has appeared in many papers, and redescriptions and/or figures were presented by Southwood (1953), Wagner $(1952,1973)$, Wagner \& Weber (1964), Miyamoto (1965), Kelton (1980), etc.

Distribution. - Japan (Hokkaido, Honshu, Kyushu), Holarctic Region.

Biology. - This common holarctic species is predominantly associated with Chenopodium spp. (Chenopodiaceae), and the coloration and dorsal vestiture are cryptic, harmonious with the flowers (fig. 43). It has bivoltine life cycles as reported by Southwood \& Leston (1959), and the adults appear in June and September in Hokkaido. Since it is a well known pest injurious to sugar beet (Beta vulgaris L., Chenopodiaceae), the ecology was studied by some workers as summarized by Wheeler \& Henry (1992). The chromosomes were also documented by Southwood (1957), Muramoto (1975), etc.

Material examined. - 163 specimens (BMNH, HUES, SEHU) from the following localities: JAPAN: Hokkaido: Etanbetsu, Asahikawa C., Kamikawa; Higashikawa T., Kamikawa; Ya'usuba, Ishikari C., Ishikari; Ainosato, Sapporo C., Ishikari; Maruyama, Sapporo C. (paralectotype $q$ of Tuponia guttula Matsumura, SEHU); Benkebetsu, Tobetsu T., Ishikari; Otarunai, Otaru C., Shiribeshi; Heiwa, Ashoro T., Tokachi; Kawayu, Teshikaga T., Kushiro; Takaoka, Tomakomai C., Iburi. - Honshu: Yamanouchi, Murayama C., Yamagata Pref.; Iwate Pref. (2 + , lectotype and paralectotype of Tuponia guttula, SEHU). - RUSSIA: Rjazanovka, Khasanskij Dist., S. Primorskij Kraj; Neryungri, Mts. Stanovoj, S. Yakutia, SE. Siberia. - SWITZERLAND: No further data (BMNH). - TURKEY: Kutahya (BMNH). 
Orthotylus (Melanotrichus) parvulus Reuter (figs. 61-63)

Orthotylus parvulus Reuter, 1879: 38.

Orthotylus (Melanotrichus) parvulus - Carvalho 1958: 117; Wagner 1973: 239; Kerzhner 1988a: 71; 1988b: 834; Lee \& Kwon 1991: 34; Vinokurov \& Kanyukova 1995: 112; Schuh 1995: 166

Orthotylus (Melanotrichus) namphoensis Josifov, 1976: 143 (synonymised by Kerzhner 1988a: 71).

Diagnosis. - Recognized by the tiny, oval body, pale green general coloration, brown setae on the dorsum, sparsely and uniformly distributed silvery pubescence on the hemelytra, and shape of the parameres (figs. 61-63). Length 3.0-3.2; width 1.1-1.3. Detailed redescriptions were provided by Wagner (1973) and Josifov (1976, as O. namphoensis). This is a close relative of flavosparsus, from which it can be distinguished by the even smaller body, brown setae and sparse silvery pubescence on dorsum, and different shape of the parameres.

Distribution. - Japan* (Tsushima Is.), Palearctic Region (from Mediterranean area to Korean Peninsula).

Biology. - Kerzhner (1988b) recognized Salicornia europaea L. (Chenopodiaceae) as its host plant. In Tsushima Island, Dr. M. Hayashi (pers. comm.) collected this mirid from Suaeda maritima (L.) Dumort. that also belongs to the Chenopodiaceae.

Material examined. - 10 ๙ 2 , Shushi, Kamiagata-gun, Tsushima Is., Nagasaki Pref., 16.vii.1995, M. Hayashi (HUES). - BULGARIA: $30 \hat{0}, 3$, Burgas, 8.x.1960, M. Josifov (ZMUH). - RUSSIA: 10, Ross. mer., Type no. 3442 (lectotype, Reuter (1879) indicated the locality as Astrakhan, see Kerzhner (1997b), ZMUH).

\section{Blepharidopterus Kolenati}

Blepharidopterus Kolenati, 1845: 107 (as subgenus of Polymerus of the Mirinae), type species: Lygaeus angulatus Fallén, 1807, subsequent designation by Kirkaldy 1906: 128; Schuh 1995: 83.

This genus has been liable to be confused with $O r$ thotylus Fieber, but is distinct in having the rather small and slender body, long antennae and rostrum, pale brown or dark brown suberect setae and silvery recumbent pubescence on the semitransparent hemelytra, ventral spine-like setae on the male genital segment, birdhead-shaped left paramere, slender right paramere, and simple form of the vesica. Judging from the male genital structure, relationship between Blepharidopterus and Orthotylus is only superficial.

Blepharidopterus currently contains 10 species in the Holarctic Region.
Blepharidopterus ulmicola Kerzhner, 1977

(figs. 44-45, 64-67)

Blepharidopterus ulmicola Kerzhner, 1977: 19; 1988b: 832;

Lee et al. 1994: 12; Schuh 1995: 85; Endo et al. 1998: 17.

Diagnosis. - Recognized by the small size, uniformly pale green general coloration (fig. 44, easily fading to yellow after death), pale suberect setae and silvery pubescence on the hemelytra, and shape of the male genitalia (figs. 64-67). The final instar nymph is recognized by the uniformly pale green, slender body (fig. 45). This species is closely related to the continental Palearctic B. diaphanus (Kirschbaum), from which it can be distinguished by the narrower head, shorter antennal segment III, long and sparse spinelike setae on the male genital segment, 3-4 apical teeth on the right paramere, and much shorter vesical appendage. In diaphanus, which may occur in Japan, the spine-like setae on the male genital segment are short and dense, the right paramere has 2-3 apical teeth, and the vesical appendage is much longer (figs. 71-73).

Redescription. - Body uniformly pale green, elongate oval, small; dorsal surface densely clothed with pale, suberect setae. Head vertical, bearing sparse, suberect, silky pubescence; vertex weakly margined by basal transverse carina. Antennae pale brown; segments III and IV brown; lengths of segments I-IV (o/ 우): $0.40-0.44 / 0.43-0.46,1.56-1.64 / 1.60-1.76$, 1.17-1.32/1.20-1.40, 0.45-0.53/0.48-0.54. Rostrum pale brown, reaching hind coxa; apex of segment IV dark brown. Pronotum, mesoscutum and scutellum weakly shagreened, clothed with pale, suberect setae. Hemelytra semitransparent, clothed with pale, suberect setae and silvery, recumbent pubescence; membrane pale brown, semitransparent, with pale green veins. Legs pale brown, tibiae tinged with brown, with pale brown spines; tarsi dark brown; lengths of hind femur, tibia and tarsus ( $\delta / 9$ ): 1.65-1.68/1.68-1.90, 2.562.64/2.64-2.76, 0.43-0.44/0.48-0.51; lengths of hind tarsomeres I-III $(ð / \bigcirc)$ : $0.13-0.15 / 0.14-0.17,0.20$ $0.22 / 0.21-0.24,0.20-0.21 / 0.22-0.24$. Abdomen uniformly pale green. Male genitalia (figs. 63-66): Spinelike setae on genital segment comparatively sparse (fig. 63); left paramere birdhead-shaped, provided with long setae (fig. 65); right paramere slender, with 3-4 apical teeth (fig. 64); vesica with a very short spine subapically (fig. 66).

Dimensions. - o / 9 : Body length 3.72-3.89/4.324.49; head width including eyes $0.76-0.77 / 0.72$ 0.75 ; vertex width $0.24-0.27 / 0.33-0.36$; rostral length 1.27-1.32/1.39-1.44; mesal pronotal length $0.48-0.51 / 0.57-0.60$; basal pronotal width 0.98 $1.02 / 1.20$; width across hemelytra 1.27-1.30/1.461.56 . 

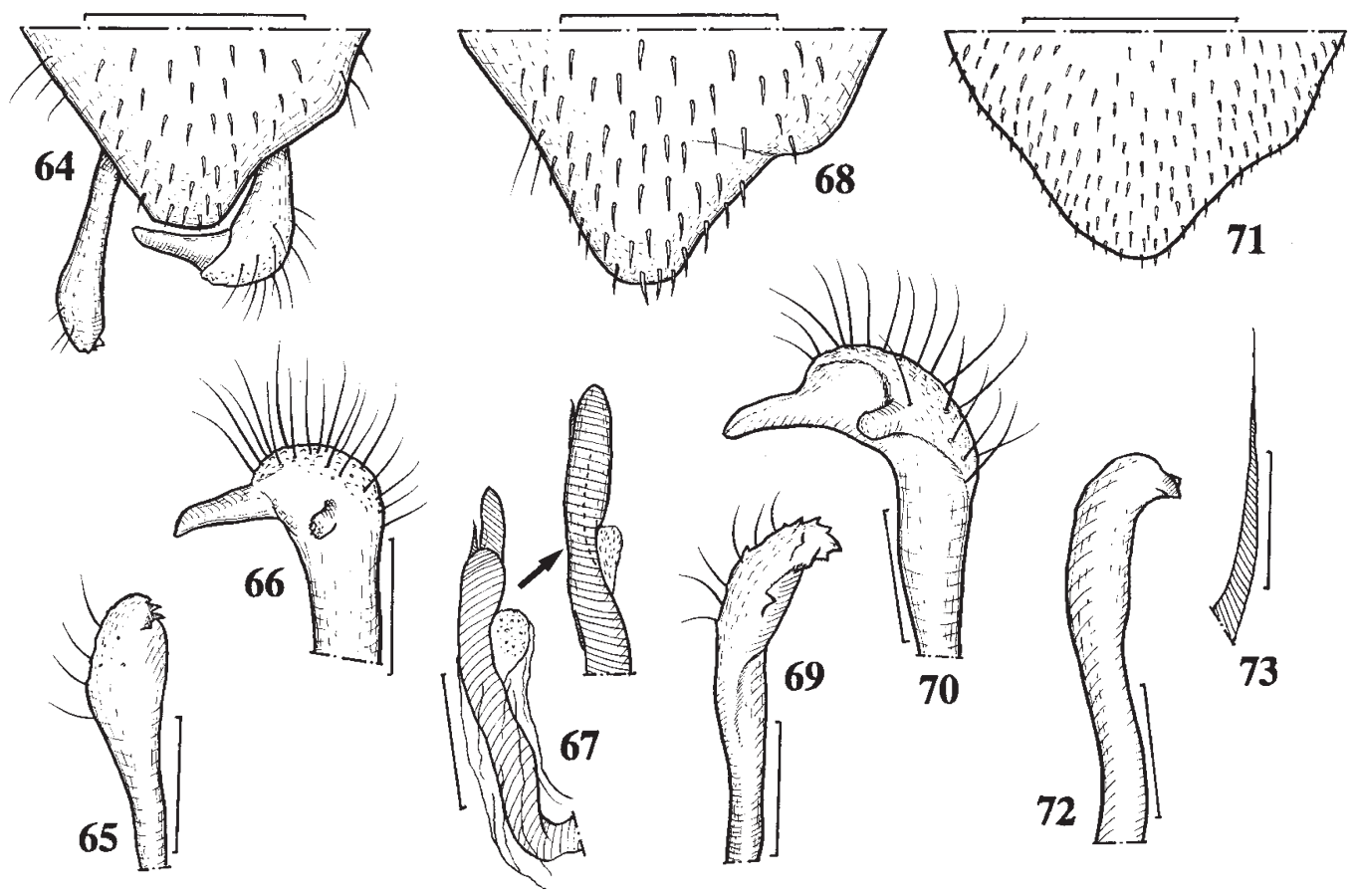

Figs. 64-73. Male genitalia of Blepharidopterus spp. - 64-67, B. ulmicola; 68-70, B. striatus; 71-73, B. diaphanus from Primor'je, Russia. $-64,68,71$, genital segment in ventral view; 65, 69, 72, right paramere; 66, 70, left paramere; 67, vesica; 73, vesical spine. Scales: $0.1 \mathrm{~mm}$ for $65-67,69-70,72-73,0.2 \mathrm{~mm}$ for $64,68,71$.

Distribution. - Japan (Hokkaido), S. Kuril Isls., Russia (Khabarovskij Kraj, Amur, Primorskij Kraj and Sakhalin), Mongolia.

Biology. - Kerzhner (1988b) indicated Ulmus spp. (Ulmaceae) as the host plants of B. ulmicola. Actually, in Japan most specimens examined in this study were collected from Ulmus japonica Nakai, but some were found on Juglans ailantifolia Carr. (Juglandaceae), Alnus spp. (Betulaceae), and Salix spp. (Salicaceae).

Material examined. - 155 specimens (HUES, ZMAS) from the following localities: JAPAN: Hokkaido: Mt. Asahidake, 500-800 m alt., Mts. Taisetsu, Kamikawa; Tenninkyo Valley, Mts. Taisetsu, Kamikawa; Aoyama, Tobetsu T., Ishikari; Ainosato, Sapporo C.; Berabonai-Takuhoku, Ashoro T., Tokachi; Takaoka, Tomakomai C., Iburi. - RUSSIA: Blagoveshensk, Amur (holotype, ZMAS); Khabarovsk (3 paratypes, ZMAS). - MONGOLIA: East Ajmak, Mt. DerkhinTsagan-Obo, $60 \mathrm{~km}$ ENE of Bajan Burd (3 paratypes, ZMAS).

\section{Blepharidopterus striatus sp. $\mathrm{n}$.}

(figs. 68-70)

Type material. - Holotype: $\delta^{\star}$, Mt. Wasamata, Kamikitayama Vil., Nara Pref., Honshu, Japan, 2425.vii.1992, Y. Nakatani (HUES). - Paratype: 10, same data as for holotype (HUES).

Diagnosis. - Recognized by the slender body, dark brown antennae and tibiae, darkened posterior part of the pronotum, dark spot near posterior corner of the membrane vein, and distinctly toothed apical part of the right paramere (fig. 68). This new species is related to $B$. diaphanus (Kirschbaum) and B. ulmicola Kerzhner, from which it is easily distinguished by the longer body and darkened posterior margin of the pronotum.

Description. - Male: Body slender, parallel-sided; dorsal surface yellowish green, clothed with pale brown, suberect setae. Head yellow, vertical, rounded at frons, with sparse, silky, suberect setae; basal transverse carina of vertex reduced. Antennae almost en- 
tirely dark brown, densely pubescent; segment I bearing a few, brown, suberect bristles; lengths of segments I-IV: $0.40-0.44,1.63-1.64,1.20-1.36,0.48$ 0.51 . Rostrum pale brown, reaching hind coxa; apical part of segment IV darkened. Pronotum yellow or yellowish green, shining, with darkened posterior margin, bearing pale brown, suberect setae; mesoscutum and scutellum yellow, weakly pruinose, sparsely clothed with silky, suberect setae; thoracic pleurite widely yellow except for darkened posterior margin of propleuron. Hemelytra yellowish green, semitransparent, with uniformly distributed, pale brown suberect setae and sparse, short, silvery pubescence; inner margin of clavus narrowly darkened; membrane pale smoky brown, semitransparent, with a dark spot near posterior corner of vein. Legs long; femora yellowish brown, densely pubescent; trichobothria on fore- and middle femora brown, prominent; tibiae dark brown, with brown spines, tarsi entirely dark brown; lengths of hind femur, tibia and tarsus: 1.68, 2.85-2.88, 0.48; lengths of hind tarsomeres I-III: $0.12-0.15,0.21-0.24,0.20-0.23$. Abdomen pale brown except for darkened parameres. Male genitalia (figs. 68-70): Genital segment uniformly provided with long, spine-like setae apically (fig. 68); left paramere broadened subapically, with blunt-tipped hypophysis (fig. 70); apical part of right paramere flattened, distinctly and roughly toothed (fig. 69).

Female: Unknown.

Dimensions. - ô: Body length 4.17-4.28; head width including eyes $0.69-0.71$; vertex width 0.27 0.29 ; rostral length 1.24-1.25; mesal pronotal length $0.55-0.56$; basal pronotal width 1.03-1.06; width across hemelytra 1.27-1.28.

Distribution. - Japan (Honshu).

\section{Cyllecoris Hahn}

Cyllecoris Hahn, 1834: 97, type species: Cimex agilis Fabricius, 1781, a synonym of Cimex histrionicus Linnaeus, 1767, subsequent designation; Schuh 1995: 98.

Easily recognized by the slender, elongate body, shiny fuscous head, small eyes removed from anterior margin of the pronotum, long antennal segment I much longer than width of the head, and anteriorly constricted pronotum divided into two (anterior and posterior) lobes. Detailed diagnostic characters were provided by Wagner \& Weber (1964), Wagner (1973), Josifov \& Kerzhner (1984), etc. Many authors misspelled the generic name as Cyllocoris!

In Japan two deciduous broadleaf inhabiting species are currently known. They are considered to be waspmimic species as they behave like wasps when captured in insect nets.

\section{Cyllecoris nakanishii Miyamoto}

(figs. 74-75)

Cyllecoris nakanishii Miyamoto, 1969: 79; Miyamoto \& Yasunaga 1989: 162; Kerzhner 1988b: 829; Schuh 1995: 99; Endo et al. 1998: 17.

Diagnosis. - Recognized by the slender body, yellowish brown antennal segment I, dark, shagreened, glabrous pronotum with a mesal pale stripe, sombre yellowish brown hemelytra with obscure stripes, and a dark, anterior stripe of each femur (fig. 74). Length 5.9-6.6; width 1.4-1.5. A detailed description including the male and female genitalia was provided by Miyamoto (1969). The final instar nymph is recognized by the slender body, whitish green general coloration, a dark stripe of each femur, and infuscate apex of the abdomen (fig. 75).

Distribution. - Japan (Hokkaido), Kuril Isls., Russia (Sakhalin).

Biology. - This species is known to be associated with elms, Ulmus japonica Nakai and Ulmus laciniata (Trautv.) Mayr (Ulmaceae).

Material examined. - 42 specimens (HUES, ZMAS) were examined from the following localities: JAPAN: Hokkaido: Moshiri, Horokanai T., Kamikawa; Etanbetsu \& Inoh, Asahikawa C., Kamikawa; Aoyama \& Hattari, Tobetsu T., Ishikari; Hokkaido Univ. Campus, Sapporo C., Ishikari; Takaoka, Tomakomai C., Iburi; Berabonai-Takuhoku, Ashoro T., Tokachi. - KURIL ISLS.: Dubovoe, Kunashiri Is. (ZMAS) - RUSSIA: Novoaleksandrovsk, S. Sakhalin (ZMAS).

\section{Cyllecoris vicarius Kerzhner}

(figs. 76-77)

Cyllecoris vicarius Kerzhner, 1988a: 45; 1988b: 829; Miyamoto \& Yasunaga 1989: 162; Josifov 1992: 122; Lee et al. 1994: 12; Schuh 1995: 100; Endo et al. 1998: 17.

Cyllecoris histrionicus sensu Miyamoto 1969: 82 (nec Linnaeus, 1767).

Diagnosis. - Easily recognized by the large size, reddish antennal segment I, shiny black pronotum with the continuously yellow posterior margin, and reddish corium (fig. 76). Length 7.0-7.5; width 1.9-2.0. Detailed description of the adult with figures of the male genitalia was provided by Kerzhner (1988a). The final instar nymph is easily recognized by the pure white general coloration, black antennal segment I and II, hind tibia and all tarsi, yellowish brown hind femur with a dark stripe, and 3 pairs of characteristic, dark, apical spots on the abdomen (fig. 77).

Distribution. - Japan (Hokkaido, Honshu, Shikoku, Kyushu), Kuril Isls., Russia (Primorskij Kraj, Amur).

Biology. - This species is associated with Quercus crispula Blume (Fagaceae). The final instar nymphs and adults of this univoltine mirid are found in late June. 

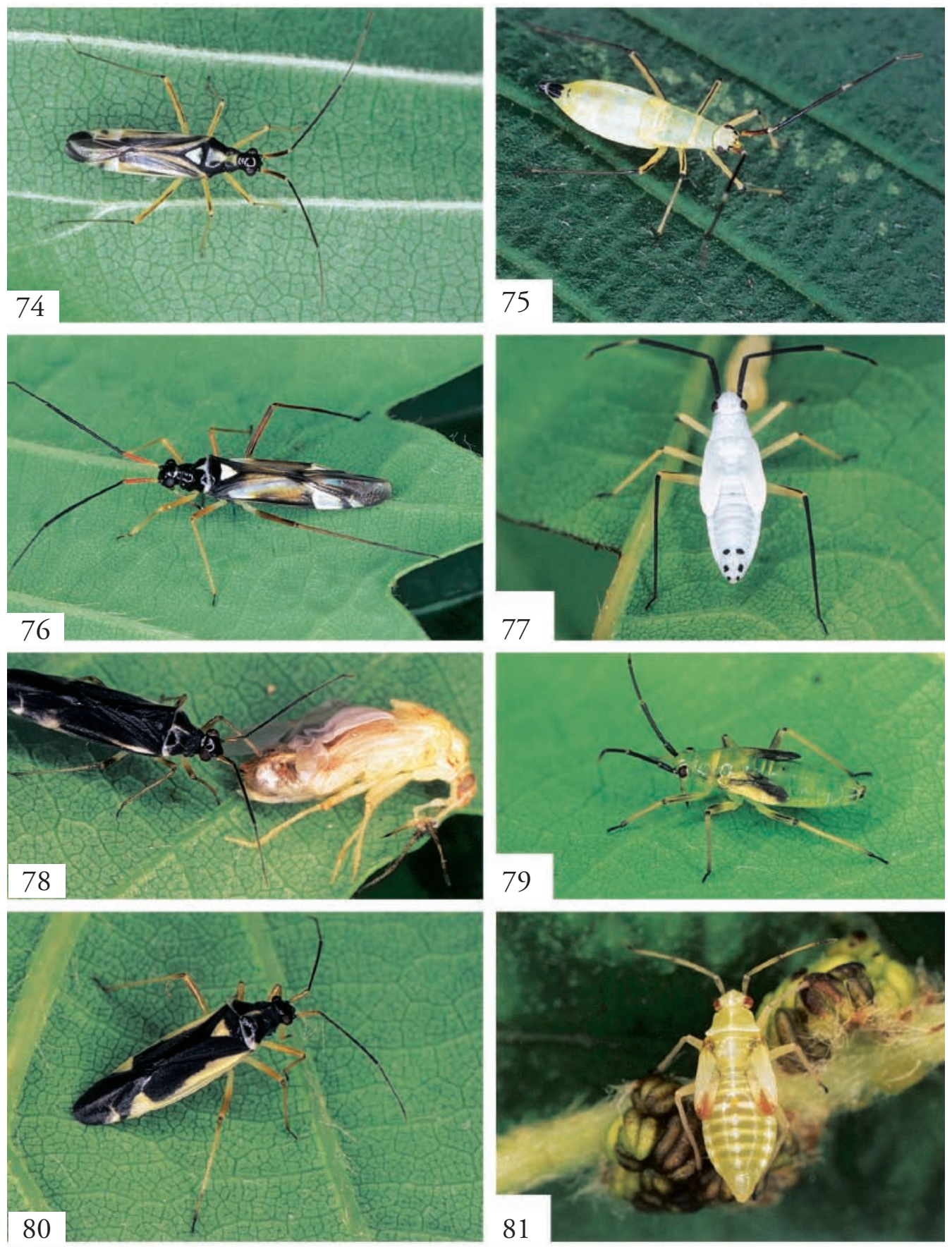

Figs. 74-81. Adults $(74,76,78,80)$ and final instar nymphs $(75,77,79,81)$ of Cyllecoris nakanishii (74-75), C. vicarius (7677), Dryophilocoris saigusai (78-79) and D. miyamotoi $(80-81)$. 
Material examined. - 26 specimens (HUES, ZMAS) were examined from the following localities: JAPAN: Hokkaido: Tokachi-Mitsumata, Kamishihoro T., Tokachi; Aoyama, Tobetsu T., Ishikari; Okusawa, Otaru C., Shiribeshi; Mt. Chisenupuri, 500-600 m alt., Niseko, Shiribeshi. - Honshu: Nagayasawa, Kuroishi C., Aomori Pref.; Kettou, Tsunan T., Niigata Pref.; Jonen-Mitsumata, Nagano Pref.; Uchiyama, Saku C., Nagano Pref. - Shikoku: Yosakoshi-toge, Hongawa Vil., Kochi Pref.; Befu, Monobe Vil., Kochi Pref.; Odamiyama, Ehime Pref. - RUSSIA: Ussurijsk, S. Primorskij Kraj (lectotype $\widehat{\sigma}$, ZMAS); between Malaja Pera and Bolshaja Erageli Rivers, Amur Prov. (3 paralectotypes, ZMAS).

\section{Dryophilocoris Reuter}

Globiceps (Dryophilocoris) Reuter, 1875a: 1: 90, type species: Cyllecoris flavonotatus Boheman, 1852, a synonym of Cimex flavoquadrimaculatus De Geer, 1773, monotypic. Dryophilocoris - Wagner 1952: 135; Schuh 1995: 104.

At first sight similar to Cyllecoris, Dryophilocoris is separable by the shorter head, eyes almost contiguous to the pronotum, basal transverse carina on the vertex, short antenna, always pruinosed anterior lobe of the pronotum, and 3 sclerites of the vesica (figs. 85, 89, 93, sclerites I-III). Detailed diagnostic characters were provided by Wagner \& Weber (1964), Wagner (1973), Josifov \& Kerzhner (1984), etc.

This Palearctic genus is currently composed of 12 species that are deciduous broadleaf inhabitants. Most members occur in the temperate zone of the eastern Eurasia, and in Japan 3 Quercus-inhabiting species have been confirmed. They, without exception, have a univoltine life cycle, and the newly emerged adults appear from late spring to early summer.

\section{Dryophilocoris saigusai Miyamoto}

(figs. 78-79, 82-85)

Dryophilocoris saigusai Miyamoto, 1966: 431; Miyamoto \& Yasunaga 1989; Schuh 1995: 105; Endo et al. 1998: 17.

Diagnosis. - Recognized by the elongate, principally fuscous body, distinctly pubescent pronotum with the pruinosed calli and polished, transversely rugose posterior part, sometimes yellow scutellum in $q$, widely darkened mesial cuneus (fig. 78), widely excavated ventral apical part of the male genital segment, elongate left paramere (figs. 82-84), wide but short mesial branch of the vesical sclerite II, and smooth vesical sclerites I and III (fig. 85). Length 5.7-6.6; width 1.4-1.7. A detailed description including that of the male genitalia was provided by Miyamoto (1966). The final instar nymph is recognized by the pale green body, fuscous antenna, yellow posterior margin of the pronotum, yellow mesonotal wingpad with the infuscate inner part, a fuscous apical stripe on each femur, and dark extreme base of each tibia and dark tarsi (fig. 79).
Distribution. - Japan (Hokkaido, Honshu).

Biology. - Confirmed breeding host of this mirid is Quercus crispula Blume (Fagaceae), and the final instar nymph was found in early June. A just emerged adult of another mirid, Castanopsides potanini (Reuter) of the subfamily Mirinae, was observed as prey in the laboratory (fig. 78).

Material examined. - 13 specimens (HUES) were examined from the following localities in Japan: Hokkaido: Mt. Asahidake, 1,600-1,700 m, Higashikawa T., Kamikawa; Yumoto, Mt. Chisenupuri, Niseko, Shiribeshi; 4-ban River, Tobetsu T., Ishikari. - Honshu: Ohmachi-Aokiko, Nagano Pref.; Mt. Kakezu, Geihoku T., Hiroshima Pref.

\section{Dryophilocoris lucidus sp. $\mathrm{n}$. (figs. 86-89)}

Type material. - Holotype ô, Mt. Gomadan, 1,300 m alt., Nara/Wakayama Pref., 7.vi.1997, T. Yasunaga (HUES). - Paratypes: 43 specimens (HUES) from the following localities in Japan: Honshu: Uchiyama, Saku C., Nagano Pref.; Gonbei-toge, Ina C., Nagano Pref.; Mt. Kiso-hakkai, 1,400-1,650 m alt., Nagano Pref.; Mt. Wasamata, Kamikitayama Vil., Nara Pref.; same as holotype; Hanazono, Mt. Koya, Wakayama Pref. - Kyushu: Bogatsuru, Mts. Kuju, Oita Pref.

Diagnosis. - Allied to the preceding one, this new species is easily distinguished by the very sparse dorsal vestiture and highly polished, glabrous, not wrinkled posterior lobe of the wider pronotum, in addition to significantly different structure of the vesica. $D$. lucidus is also related to D. kanyukovae Josifov \& Kerzhner, 1984 from Korea and the Russian Primor'je, but the latter has the longer antenna, variable orange portions on the pronotum and scutellum, and smooth apex of the vesical sclerite I.

Description. - Body elongate, parallel-sided; dorsal surface dark chestnut brown, with very sparse pubescence. Head shiny fuscous, glabrous, with yellow, narrow basal transverse carina on vertex. Antenna dark brown, slender; lengths of segments I-IV ( $\delta / q)$ : 0.60-0.65/0.63-0.65, $1.86-1.90 / 1.82-1.89, \quad 0.98$ $1.08 / 0.95-0.99,0.34-0.37 / 0.36-0.40$. Rostrum yellowish brown, reaching apex of middle coxa; apical half of segment IV darkened. Pronotum dark chestnut brown, shiny and glabrous on posterior half, with yellow posterior angle, in _ with a yellow, longitudinal, mesal stripe; calli dark greyish brown, pruinosed, with sparse, silky pubescence; mesoscutum and scutellum dark greyish brown, shagreened, somewhat arched, transversely rugose; pleura widely greyish brown, pruinosed, except for propleuron shiny dark brown. Hemelytra dark brown, weakly shagreened; anterolateral part of corium, and base and apex of 


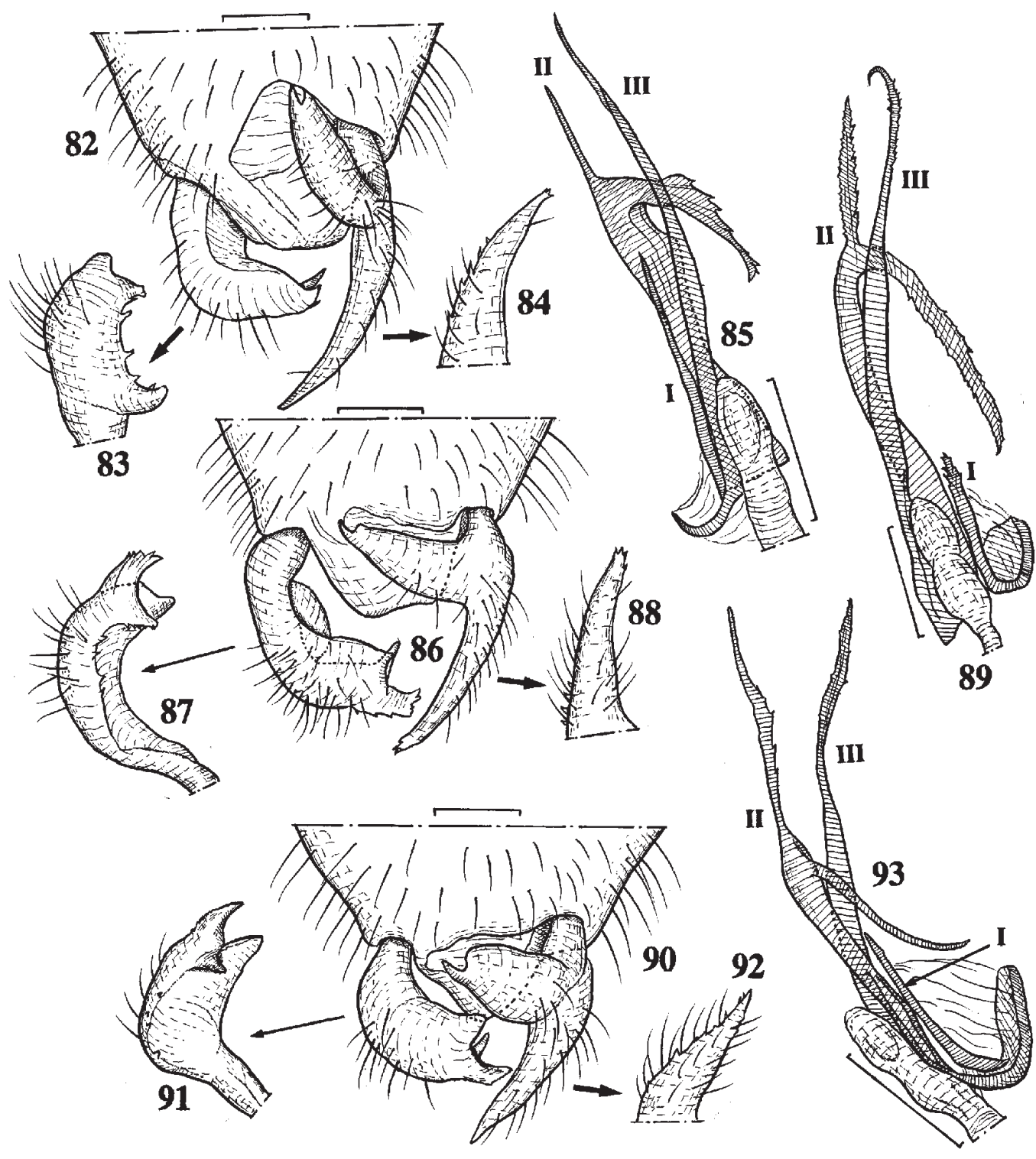

Figs. 82-93. Male genitalia of Dryophilocoris spp. - 82-85, D. saigusai; 86-89, D. lucidus; 90-93, D. miyamotoi. - 82, 86, 90, genital segment with parameres in ventral view; 83, 87, 91, right paramre; 84, 88, 92, sensory lobe of left paramere; 85, 89, 93, vesica. Scales: $0.2 \mathrm{~mm}$. 
cuneus narrowly ( $\widehat{)}$ ) or widely ( + ) yellow; embolium yellow; membrane dark greyish brown, with a pale spot along apex of cuneus. Coxae and legs yellow; femora somewhat reddish; tibial spines pale brown, short; tarsi brown, with darker tarsomeres III; lengths of hind femur, tibia and tarsus ( $0 / 0$ ) : 1.74-1.75/1.80$1.86, \quad 2.72-2.78 / 2.53-2.78, \quad 0.34-0.42 / 0.35-0.40$; lengths of hind tarsomeres I-III $(\delta / q)$ : 0.13 $0.15 / 0.15-0.17,0.16-0.19 / 0.19-0.21,0.24-0.25 / 0.23$ 0.25 . Abdomen unicolorously dark chestnut brown. Male genitalia (figs. 86-89): Ventral surface of genital segment somewhat excavated apically (fig. 86); left paramere long; right paramere with apical toothed processes (fig. 87); vesical sclerite I short, toothed apically; mesial branch of sclerite II long; apex of sclerite III with hooked apex (fig. 89).

Dimensions. - $0 / 9$ : Body length 6.36-6.60/6.637.20; head width including eyes $0.81-0.83 / 0.80$ 0.83 ; vertex width $0.34-0.36 / 0.38-0.40$; rostral length 1.26-1.30/1.34-1.38; mesal pronotal length $0.80-0.88 / 0.90-0.92$; basal pronotal width 1.37 $1.45 / 1.47-1.52$; width across hemelytra 1.581.62/1.58-1.75.

Distribution. - Japan (Honshu, Kyushu).

Biology. - Most specimens of this new mirid were collected on Quercus crispula, which is considered to be the host plant, but nymphs have not been found yet. The newly emerged adults appear in early June.

\section{Dryophilocoris miyamotoi sp. $\mathrm{n}$. (figs. 80-81, 90-93)}

Dryophilocoris sp. - Hiranuma \& Yasunaga 1998: 2 (descriptions of nymphs); Endo et al. 1998: 17.

Type material. - Holotype: $\delta^{\star}$, Mt. Arashiyama, Asahikawa C., Kamikawa, Hokkaido, Japan, 30.v.1998, T. \& M. Yasunaga (HUES). - Paratypes: 273 specimens (HUES) from the following localities of Japan: Hokkaido: Same as the holotype; Ishikari coast, Ishikari C.; 4-ban Riv. \& Aoyama, Tobetsu T., Ishikari; Okusawa Reservoir, Otaru C., Shiribeshi; Shimo- Futamatazawa, Yoichi T., Shiribeshi; Ohnuma, Oshima. - Honshu: Kurokumano-taki, Ajigasawa T., Aomori Pref.; Higashiyama, Shinjo C., Yamagata Pref.; Mikura, Tsunan T., Niigata Pref.; Jonen-Mitsumata, Nagano Pref.; Kisojihara, Nagawa Vil., Nagano Pref.; Abo-toge, Azumi Vil., Nagano Pref.; Yoji, Ina C., Nagano Pref.; Kuzu hot spring, Nagano Pref.; Mt. Wasamata, Kami-kitayama Vil., Nara Pref.; Kusama, Niimi C., Okayama Pref.; Mt. Kakezu, Geihoku T., Hiroshima Pref. - Kyushu: Mt. Shiratori, 900-1,300 m, alt., Izumi Vil., Kumamoto Pref.; Chojabaru, Shirosukosen \& Oike, Mts. Kuju, Oita Pref.
Diagnosis. - Easily recognized by the widely pruinosed pronotum furnished with the densely distributed, suberect setae. The general coloration is variable. In the populations of southwestern Japan (west of the Kii Peninsula), the posterior half of the pronotum is more widely shagreened and provided with much sparsely distributed pubescence, and the pubescence on the hemelytra is also shorter and sparser. Since no significant differences are exhibited in the male genitalia, however, these forms are considered to represent zoogeographical variation. Every instar nymph was described and figured by Hiranuma $\&$ Yasunaga (1998) as Dryophilocoris sp. The final instar nymph of the present new species resembles that of saigusai, from which it can be distinguished by the yellowish green general coloration, pale antennae, orange apex of the mesonotal wingpad and entirely pale tibiae (fig. 81).

Description. - Body elongate, parallel-sided; dorsal surface densely clothed with silky, suberect pubescence. Head shiny dark brown, almost glabrous, with yellow basal transverse carina on vertex. Antenna brown; segment I usually yellowish brown; segment II dark brown, sometimes with paler base; lengths of segments I-IV (ठ/ / $)$ : $0.52-0.62 / 0.53-0.61,1.63$ $1.75 / 1.59-1.83,0.79-0.97 / 0.93-1.07,0.31-0.37 / 0.34-$ 0.37 . Posterior lobe of pronotum widely shagreened, pubescent, with a yellow, longitudinal, mesal stripe and yellow posterior margin; calli greyish brown, pruinosed; mesoscutum dark greyish brown, pruinosed, transversely rugose; scutellum yellow, transversely rugose, in $\delta$ widely fuscous anteriorly; pleura widely greyish brown, pruinosed; propleuron dark brown, with yellow margin. Hemelytra dark brown, somewhat shagreened, densely pubescent; embolium, basal 1/3-1/2 and apex of cuneus, and anterior or sometimes whole ( + ) lateral margin of corium yellow (fig. 80); membrane dark greyish brown, with apical parts of veins and a spot along apex of cuneus pale. Coxae and legs yellow; apical parts of femora sometimes tinged with orange brown; tibial spines pale brown, short; tarsi brown, with darker tarsomeres III; lengths of hind femur, tibia and tarsus ( $8 / 9$ ): 1.58-1.68/1.52$1.73, \quad 2.50-2.65 / 2.21-2.68, \quad 0.31-0.37 / 0.31-0.37$ lengths of hind tarsomeres I-III (t)/ $/ q)$ : 0.14 0.19/0.15-0.18, 0.15-0.19/0.17-0.19, 0.18-0.25/0.180.24 . Abdomen unicolorously dark brown. Male genitalia (figs. 90-93): Ventral surface of genital segment not strongly excavated at apex (fig. 90); left paramere short (fig. 90, 92); apical part of right paramere with two pointed processes (fig. 91); mesial branch of vesical sclerite II smooth (fig. 93).

Dimensions. $-0 / 9$ : Body length 6.30-6.84/6.306.90; head width including eyes $0.79-0.83 / 0.79$ 0.84; vertex width $0.34-0.40 / 0.39-0.43$; rostral 

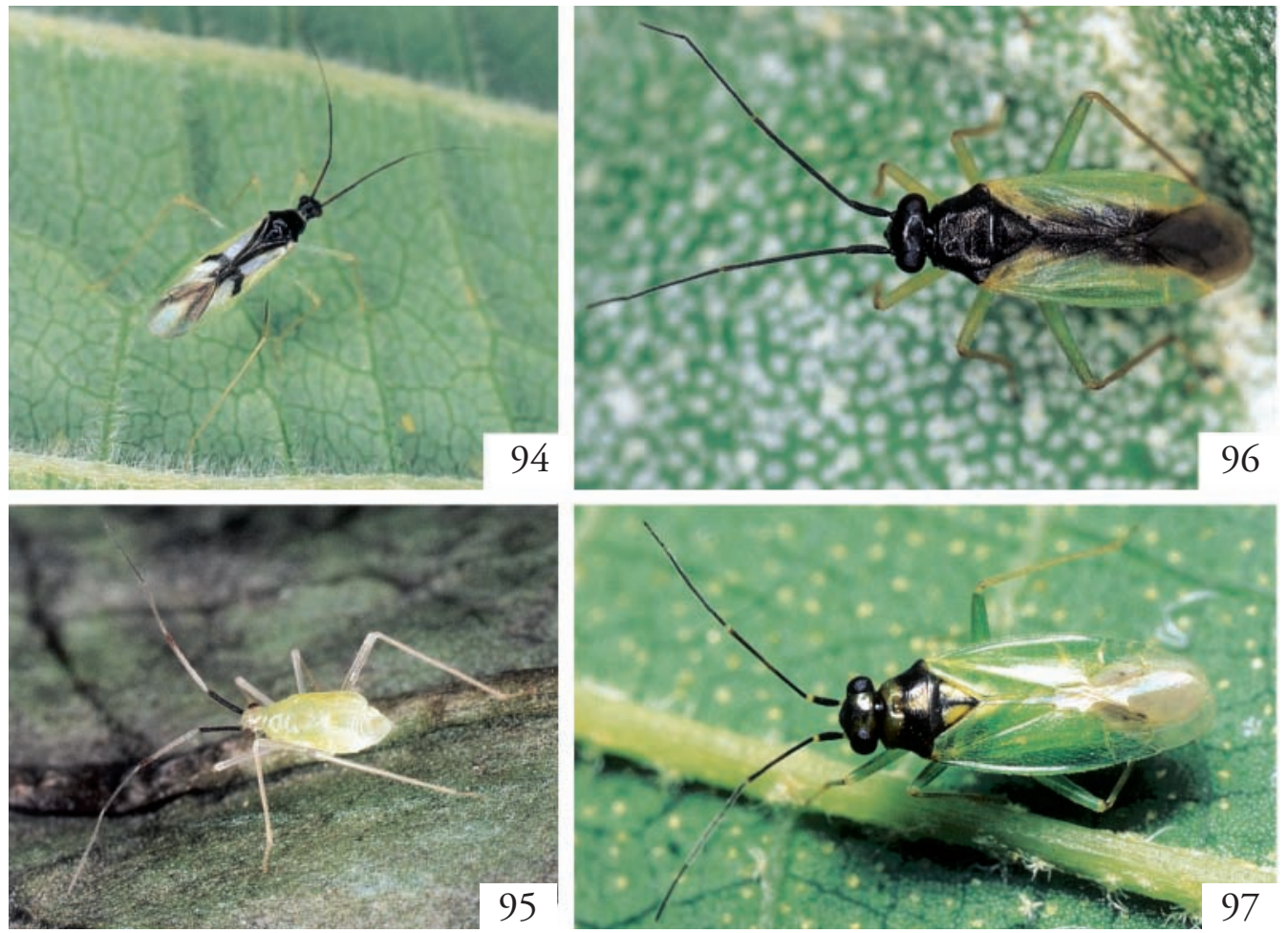

Figs. 94-97. Adults $(94,96,97)$ and final instar nymph (95) of Mecomopsis cruciata (94-95), Cyrtorhinus caricis (96) and C. lividipennis (97).

length 1.26-1.43/1.31-1.41; mesal pronotal length 0.78-0.83/0.79-0.94; basal pronotal width 1.371.43/1.42-1.56; width across hemelytra 1.471.64/1.64-1.75.

Distribution. - Japan (Hokkaido, Honshu, Shikoku, Kyushu).

Biology. - Confirmed breeding hosts of this new species are fagaceous Quercus crispula Blume and Quercus dentata Thunb. et Murray. This mirid has a univoltine life cycle, and emerges in late May in Kyushu and in early June in Hokkaido. The nymphs are predominantly found on the flowers, and exhibit cryptic coloration harmonious with the flowers (fig. 81).

\section{Mecomma Fieber}

Mecomma Fieber, 1858: 313, type species: Capsus ambulans Fallén, 1807, monotypic; Schuh 1995: 142.

Recognized by the moderate size, short and anteriorly flattened head, small eye almost contiguous to pronotum, short antenna, whitish, semitransparent and partly infuscate hemelytra, somewhat twisted left paramere, mesial flat process of right paramere, and simple and apically branched vesical appendage. The female adults are often brachypterous. Detailed diagnostic characters were provided by Wagner \& Weber (1964), Wagner (1973), etc.

Mecomma contains about 30 species in the Holarctic Region and Old World tropics. Only one species is currently known from Japan.

\section{Mecomma japonica Miyamoto}

(figs. 98-100)

Mecomma japonica Miyamoto, 1966: 429; Miyamoto \& Yasunaga 1989: 162; Schuh 1995: 144.

Diagnosis. - Recognized by the characters as mentioned in generic diagnosis, rather large size, fuscous head, pronotum and scutellum, widely infuscate inner part of the clavus, dark apical inner margins of the corium and cuneus, small, pointed teeth on the apical part of the right paramere (fig. 99), and 3-branched apex of the vesical appendage (fig. 100). Length 5.3-5.4; width 1.7-1.8 (ङ). A de- 
tailed description of the male with figures of the dorsal habitus and genitalia was provided by Miyamoto (1966). The fuscous, brachypterous female was recently discovered during examining unsorted collections of NIAS and NSMT, and are described below for the first time.

Description. - Female: Brachypterous. Body black, ovoid, with widened abodmen; dorsal surface shagreened, with uniformly distributed, simple, silky pubescence. Head vertical, slightly narrower than pronotum; vertex with a pair of pale spots along inner margin of eyes. Antenna dark brown, slightly longer than body; segment I, basal 1/4-1/2 of II and basal 1/3-1/2 of III yellowish brown; segment II slightly incrassate towards apex; lengths of segments I-IV: 0.40$0.41,1.15-1.20,1.03-1.10,0.46-0.56$. Rostrum pale brown, nearly reaching apex of hind coxa; segment I and apical part of IV darkened. Pronotum with weak, pruinosed collar and somewhat tumid calli; pleura dark greyish brown. Hemelytra simple in form, noticeably shortened, lacking membrane and distinct veins, with rounded apex that is not exceeding abdominal segment VI. Legs yellowish brown, slightly tinged with red; tarsi pale brown, with darker tarsomeres III; lengths of hind femur, tibia and tarsus: 1.42-1.46, 2.10-2.15, 0.54-0.59; lengths of hind tarsomeres I-III: $0.15-0.18,0.25-0.32,0.24-0.25$. Abdomen shiny fuscous, wider than hemelytra.

Dimensions. - $q$ : Body length 2.89-3.23; head width including eyes $0.85-0.90$; vertex width 0.37 0.39 ; rostral length $1.50-1.52$; mesal pronotal length 0.46-0.50; basal pronotal width 0.90-0.95; width across hemelytra 1.45-1.50; maximum width across abdomen 1.59-1.86.

Distribution. - Japan (alpine areas of north and central Honshu).

Material examined. - Honshu: 10ิ, Mt. Senjo-dake, Nagano Pref., 7.viii.1961, T. Saigusa (holotype, MC); $2 \hat{0}$, Tokusawa, Japan Alps, Nagano Pref., 6.viii.1955, Y. Utsugi (NIAS); 2 \%, Mt. Chokai, Yamagata Pref., 17.ix.1971, M. Tomokuni (NSMT); 2 , Mt. Norikura, Nagano Pref., 7.ix.1951, H. Hasegawa (NIAS).

\section{Mecommopsis Kerzhner, 1979}

Mecommopsis Kerzhner, 1979: 39, type species: M. cruciata Kerzhner, 1979, monotypic; Schuh 1995: 145.

This monotypic genus is easily recognized by the slender body, small eyes removed from the anterior margin of the pronotum, very long antennal segment I even longer than pronotal width, distinct pronotal collar, delicate hemelytra much longer than abdomen, long legs, slender, elongate left paramere (fig. 101), a mesial thumb-like process of right paramere (fig. 102), and membranous vesica with the bifurcate apical sclerite (fig. 103). These characters enable us to distinguish it from the related genus, Mecomma Fieber.

\section{Mecommopsis cruciata Kerzhner}

(figs. 94-95, 101-103)

Mecommopsis cruciata Kerzhner, 1979: 39; 1988b: 831; Miyamoto 1988: 638; Miyamoto \& Yasunaga 1989: 162; Josifov 1992: 122; Lee et al. 1994: 12; Schuh 1995: 145.

Diagnosis. - Recognized by the characters as mentioned in generic diagnosis, shiny black head, pronotum and scutellum, whitish green pronotal collar, and semitransparent hemelytra with the anchor-shaped mesial black marking and fuscous clavus (fig. 94). Length 4.3-5.0; width 1.2-1.3. A redescription is not provided here as Kerzhner (1979) provided a detailed description with figures of the dorsal habitus and male genitalia, and the identity is clear. The final instar nymphs were discovered in July, 1998, and are readily recognized by the entirely whitish green, oval body, conspicuously long, slender antenna and leg, and contrastingly fuscous antennal segment I (fig. 95).

Distribution. - Japan (Hokkaido, Honshu, Kyushu*), S. Kuril Isls., Russia (Primorskij Kraj and Sakhalin), Korea.

Biology. - Confirmed breeding host is Ligularia sp. (Compositae). Both adults and nymphs of this univoltine mirid are found on underside of the large, rounded leaves from mid July to early August.

Material examined. - 106 specimens (HUES, NSMT, USNM, ZMAS) were examined from the following localities: JAPAN Hokkaido: Moshiri, Horokanai T., Kamikawa; Etanbetsu, Asahikawa C., Kamikawa; Mt. Asahidake, 200-800 m alt., Mts. Taisetsu, Kamikawa. - Honshu: Japan Alps, Nagano Pref. - Kyushu: Mt. Shiratori, 1,100-1,300 m alt., Izumi Vil., Kumamoto Pref. (USNM) - KURIL ISLS.: Tret'jakovo, Kunashiri Is. (holotype \& paratypes, ZMAS). - RUSSIA, Primorskij Kraj: Ussurijsk Nature Reserve; Rjazanovka, Khasanskij Dist.

\section{Cyrtorhinus Fieber}

Cyrtorhinus Fieber, 1858: 313, type species: Capsus elegantulus Meyer-Dür, 1843, a synonym of Capsus caricis Fallén, monotypic; Schuh 1995: 100.

This is a small genus composed of 11 species. Most members are distributed in the Old World tropics and subtropics, and Pacific islands. The genus is recognized by the small size, elongate oval body, short head, darkened pronotum, pale hemelytra, developed sensory lobe of the left paramere, apically widened right paramere, and simple form of the vesica. It is liable to be confused with Tytthus Fieber, 1864 of the 


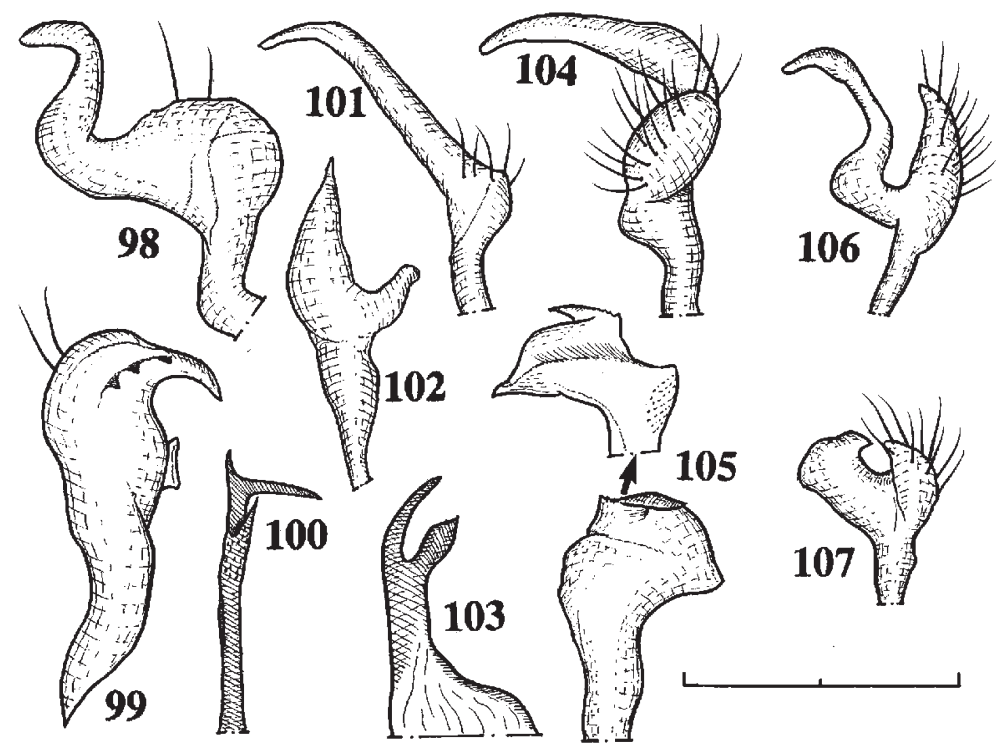

Figs. 98-107.

Male genitalia of Mecomma japonica (98-100), Mecommopis cruciata (101-103), Cyrtorhinus caricis (104105) and $C$. lividipennis (106-107). - 98, 101, 104, 106, left paramere; 99, 102, 105 , 107, right paramere; 100,103 , vesical sclerotized appendage. Scale: $0.2 \mathrm{~mm}$. subfamily Phylinae, from which Cyrtorhinus is separable by the fleshy, apically convergent parempodia between the claws. Many authors have been liable to misspell the generic name as Cyrtorrhinus!

Species of Cyrtorbinus are predominantly predaceous, and some are known to feed preferably on eggs of delphacid leafhoppers.

Cyrtorhinus caricis (Fallén)

(figs. 96, 104-105)

Capsus caricis Fallén, 1807: 102.

Cyrtorhinus caricis - Carvalho 1958: 54; Wagner \& Weber 1964: 336; Wagner 1973: 258; Kerzhner 1988b: 831; Miyamoto \& Yasunaga 1989: 162; Lee \& Kwon 1991: 33; Schuh 1995: 100.

Diagnosis. - Recognized by the dark head, a pair of pale, lateral spots on the vertex, entirely fuscous pronotum and scutellum, pale green and mesally infuscate hemelytra (fig. 96), bulbous sensory lobe of the left paramere (fig. 104), and a hook-shaped apical process of the right paramere (fig. 105). Length 3.34.2; width 1.2-1.5. Redescriptions or diagnostic characters were provided by Wagner \& Weber (1964), Wagner (1973), Kerzhner (1988b), etc.

Distribution. - Japan (Hokkaido, N. Honshu), Holarctic Region.

Biology. - As mentioned by Wheeler \& Henry (1992), this mirid was found on sedges (Carex spp. of the Cyperaceae) in northern Japan.
Material examined. - 22 specimens (BMNH, HUES, ZMUH) were examined from the following localities: JAPAN: Pashikuru-numa, Onbetsu T., Hokkaido; Obuchi-numa \& Noushi-numa, Aomori Pref., N. Honshu - FINLAND: Alandia (BMNH). - SWEDEN: Huddinge, pr. Stockholm (ZMUH). - CANADA: Come-by-chance, SE. Newfoundland (ZMUH); Grand Falls, C. Newfoundland (ZMUH).

\section{Cyrtorhinus lividipennis Reuter}

(figs. 97, 106-107)

Cyrtorhinus lividipennis Reuter, 1885: 199; Carvalho 1956 57; Miyamoto \& Yasunaga 1989: 162; Lee \& Kwon 1991: 33; Yasunaga et al. 1993: 149; Schuh 1995: 101.

Diagnosis. - Recognized by the small size, fuscous pronotum with pale anterior part, pale scutellum with a dark, longitudinal, mesal stripe, wholly pale green hemelytra (fig. 96), long protuberance of the left paramere (fig. 106), and broad, bifurcate apical part of the right paramere (fig. 107). Length: 2.6-3.5; width 0.9-1.3. A detailed redescription was provided by Carvalho (1956), and the ovariole number and structure of the alimentary organs were documented by Miyamoto $(1957,1961)$. Having similar general appearance, habit and habitat, this species is sometimes confused with Tytthus chinensis (Stål) of the Phylinae, from which C. lividipennis is separable by the pale anterior half of the pronotum, greenish hemelytra, and distinct, fleshy, apically convergent parempodia between the claws.

Distribution. - Japan (Honshu, Shikoku, Kyushu, 
Ryukyu Isls.), Taiwan, S. China, Oriental Region, Micronesia.

Biology. - This is a well known, economically important predator preying on eggs of delphacid leafhoppers injurious to rice (Oryza sativa L. of the Gramineae). Zhang (1985) documented that an individual of C. lividipennis can feed on 170-230 delphacid eggs during lifetime. In southern Japan, this mirid is common in paddy fields, and appears to have two or more generations per year. Some delphacid species are known to migrate from continental China to Japan proper across the East China Sea. C. lividipennis has been captured together with delphacid leafhoppers on a Ship on the East China Sea (see below), so that some of Japanese populations of this mirid appear to migrate from China.

Material examined. - 53 specimens (BMNH, HUES, NIAS) were examined from the following localities: JAPAN: Honshu: Saka'ashi, Nachi-Katsu'ura, Wakayama Pref. Shikoku: Mt. Tsukimi, Yasu T., Kochi Pref.; Nishikuma, Monobe Vil., Kochi Pref.; Kitou Vil., Tokushima Pref. Kyushu: Momiki, Izumi Vil., Kumamoto Pref.; Nameshi, Nagasaki C.; East China Sea (on Ship), $129^{\circ} 27^{\prime} \mathrm{E}, 32^{\circ} 15^{\prime} \mathrm{N}$, about $70 \mathrm{~km}$ off the Nomozaki T., Nagasaki Pref. (NIAS) Ryukyus: Yona, Kunigami Vil., Okinawa Is.; Omoto \& Takeda, Ishigaki Is. - PHILIPPINES: Iloilo, Panay Is., Visayas - INDONESIA: Tomohan, Minahasa Pen., N. Sulawesi (Celebes) (BMNH). - MALAYSIA: Bukit Larut, 1,130 m alt., Taiping, Perak - INDIA: Madurai (BMNH) - FIJI: Naduruloulou (BMNH).

\section{Zanchius Distant}

Zanchius Distant, 1904: 477, type species: Z. annulatus Distant, 1904, monotypic; Schuh 1995: 204.

This genus is easily recognized by the pale green general coloration, vertical head, projected frons, anteriorly situated eyes that are distinctly removed from the anterior margin of the pronotum, wide mesoscutum, and delicate, relatively wide and laterally rounded hemelytra. Redescriptions were provided by Linnavuori (1994), Schuh (1974) and Wagner (1973).

Zanchius comprises 30 species in the Old World and Pacific Islands, and 12 species have been reported from the regions adjacent to Japan (Carvalho 1956; Poppius 1915; Zheng \& Liang 1991; Zheng \& Liu 1993; Zou 1987a, 1989). In Japan, only a single species has been known, but 5 new species are added to the Japanese fauna in this paper.

Two monotypic genera, Zonodoropsis and Itacorides, were proposed for Taiwanese species by Poppius (1915) and Miyamoto (1965), respectively. Judging from the original descriptions, these genera are suspected to be synonymous with Zanchius. Since I have not examined the type species of the genera (Zonodoropsis pallens Poppius and Itacorides shirozui Miyamo- to), however, I refrain from synonymizing them here.

The majority of Zanchius species appears to be associated with broadleaf host plants, whereas predation on persimmon leafhoppers by some Zanchius species was observed in China (Zheng \& Liang 1991).

\section{Zanchius tarasovi Kerzhner}

(figs. 108-110, 115-118)

Zanchius tarasovi Kerzhner, 1988a: 49; 1988b: 832; Schuh 1995: 206; Hayashi \& Higashikawa 1997: 39; Endo et al. 1998: 17.

Diagnosis. - Recognized by the largest body among its Japanese congeners, long antennae, strongly curved left paramere, small apical process on the right paramere, and distinctly toothed vesical sclerite I. The final instar nymph is recognized by the oval body, unique head structure, and long antennae and legs (fig. 110).

Redescription. - Body pale green, elongate oval; dorsal surface uniformly clothed with pale, suberect pubescence. Head with a lateral short stripe behind each eye, vertical, bearing sparse, suberect, silky pubescence; vertex mesally with a basal transverse carina; frons weakly and roundly projected; tylus raised, visible in dorsal aspect. Antennae pale brown, somewhat tinged with red, slightly shorter than body; segment I usually with a sanguineous stripe laterally, bearing several brown bristles; lengths of segments IIV (o/ o ): $0.48 / 0.48-0.51,1.96-2.02 / 1.96-2.21$, 1.12-1.20/1.12-1.28, 0.69-0.75/0.72-0.75. Rostrum pale brown, long, reaching hind coxa; apex of segment IV darkened. Pronotum shining, with a short, longitudinal mesal sulcus between calli; mesoscutum and scutellum shining, with pale, suberect pubescence; posterior part of scutellum sometimes with sanguineous mark (fig. 108). Hemelytra pale green, subhyaline, very finely punctate, uniformly clothed with pale, suberect pubescence; apex of clavus and apical inner part of corium sometimes sanguineous; membrane pale brown, semitransparent. Legs generally pale green, sometimes partly tinged with red; tibial spines pale brown; lengths of hind femur, tibia and tarsus (ઠ/ ( ) ): 1.65-1.76/1.77-1.92, 2.52-2.64/2.64$2.86,0.40-0.41 / 0.40-0.44$; lengths of hind tarsomeres I-III (o/ / ) : 0.12-0.14/0.13-0.16, 0.18$0.20 / 0.16-0.18, \quad 0.19-0.21 / 0.15-0.18$. Abdomen uniformly pale green. Male genitalia (figs. 115-118): Left paramere strongly curved at middle, twisted basally (fig. 116); right paramere with a median pointed projection and a small apical process (fig. 115 ); vesical sclerite I broad, with many teeth (fig. 118); sclerite II broadened; sclerite III gradually tapered towards apex (fig. 117).

Dimensions. - o $/ 9$ : Body length 4.56-4.73/4.70- 

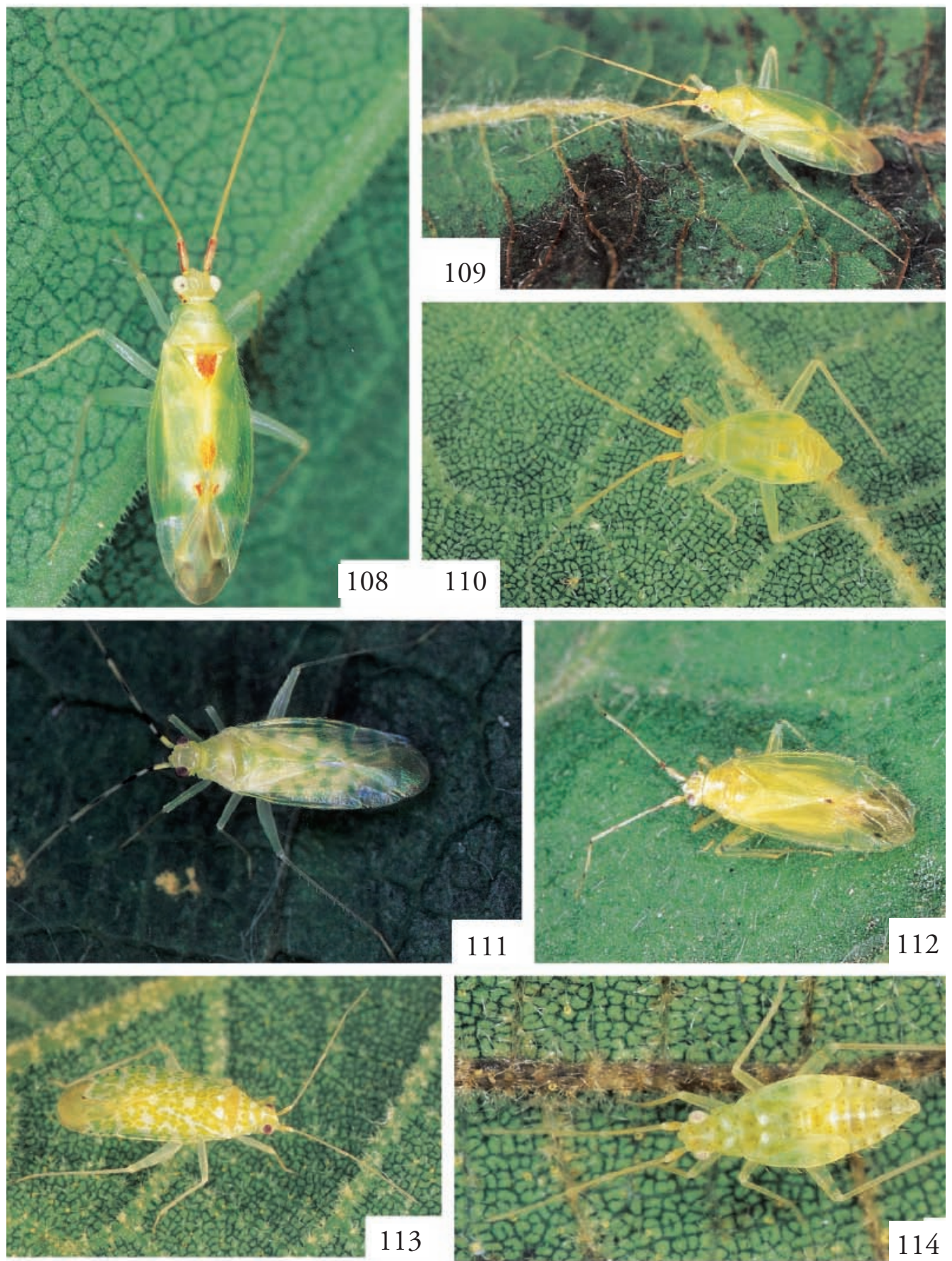

Figs. 108-114. Adults (108, 109,, 111-113) and final instar nymphs (110, 114) of Zanchius tarasovi (108-110), Z. ryukyuensis (111), Z. takahashii (112) and Malacocorisella endoi (113-114). 
5.00; head width including eyes 0.73-0.75/0.74-0.75; vertex width $0.33-0.34 / 0.36$; rostral length $1.44-$ 1.47/1.44-1.49; mesal pronotal length 0.52-0.53 10.57-0.58; basal pronotal width 1.05-1.08/1.05-1.16; width across hemelytra 1.63-1.66/1.72-1.73.

Distribution. - Japan (Hokkaido, Honshu, Shikoku), Russia (S. Primorskij Kraj), China (Hebei Prov.). This species has the northernmost distribution among its congeners.

Biology. - As reported by Endo et al. (1998), this mirid is found on many kinds of deciduous broadleaved trees, such as Juglans ailantifolia Carr. (Juglandaceae), Tilia japonica (Miq.) Simonkai (Tiliaceae), Quercus crispula Blume, Alnus spp. and Salix spp. Both adults and nymphs of this mirid were observed to have preyed on a leafhopper injurious to persimmon in China (Zheng \& Liang 1991). In Japan $Z$. tarasovi is often captured together with many typhlocybinid leafhoppers, so that it seems to be predominantly predaceous.

Material examined. - More than 200 specimens (HUES, IC, ZMAS) from the following localities: JAPAN: Hokkaido: Moshiri-Shirakaba, Horokanai T., Kamikawa; Hattari, Atsuta Vil., Ishikari; Aoyama, Tobetsu T., Ishikari; Hokkaido University Campus, Sapporo C., Ishikari; BerabonaiTakuhoku, Ashoro T., Tokachi; Kohnomai (Yakiyamanosawa), Monbetsu C., Abashiri; Kanehana, Rubeshibe T., Abashiri. - Honshu: Sakaimatsu, Kuroishi C., Aomori Pref. (IC); Washirozawa, Kawauchi T., Aomori Pref. (IC); Shimoyu, Aomori C., Aomori Pref. (IC); Sugadaira, 1,330 m alt., Nagano Pref. - Shikoku: Mt. Tsurugi, Tokushima Pref.; Teragawa, Hongawa Vil., Kochi Pref.; Sameura, Yukimigawa \& Tatsuno, Motoyama T., Kochi Pref. - RUSSIA, Primorskij Kraj: Kievka, Sudzukhinskij (currently Lazovskij) Nature Reserve (lectotype, ZMAS); Kedrovaja Pad', Khasanskij Dist. (3 paralectotypes, ZMAS); Vitjaz', 15 km S. of Sukhanovki, Khasanskij Dist. (3 paralectotypes, ZMAS).

\section{Zanchius quercicola sp. $\mathrm{n}$.}

(figs. 119-123)

Type material. - Holotype ô, Same'ura, Motoyama T., Kochi Pref., Shikoku, Japan, ex Quercus acutissima, 24.vii.1996, Y. Nakatani (HUES). Paratype: 10, Shiramizu, Shounai T., Oita Pref., Kyushu, 27-28.vii.1995, light trap, Y. Nakatani (HUES).

Diagnosis. - Recognized by the small size, clear scarlet lateral stripe of the antennal segment I, sparse vestiture on the hemelytra, smooth apex of the right paramere, weakly curved and basally widened left paramere, and less toothed vesical sclerite I. This new species is a close relative of $Z$. tarasovi, from which it can be distinguished by the significantly smaller body, sparse dorsal vestiture, less projected tylus, shorter antennae and legs, and different structure of the male genitalia.
Description. - Male: Body generally pale green, small, suboval; dorsal surface sparsely clothed with pale pubescence. Head with a scarlet lateral stripe behind each eye, vertical, bearing sparse, silky, suberect pubescence; vertex with a basal transverse carina; frons roundly produced; tylus raised but invisible in dorsal view. Antennae pale brown, somewhat tinged with red; segment I with a clear scarlet lateral stripe and an apical inner spot, bearing several pale, erect bristles; lengths of segments I-IV: $0.43-0.46,1.82$ $1.85,0.96-1.01,0.62-0.72$. Rostrum pale brown, long, slightly exceeding apex of hind coxa; apex of segment IV brown. Pronotum shining, rather short, with a weak, longitudinal mesal sulcus between calli, sparsely clothed with silky pubescence; mesoscutum and scutellum weakly pruinose, almost glabrous. Hemelytra uniformly pale green, semitransparent, with sparsely distributed, silky pubescence. Legs pale green; tibial spines pale brown; apical part of tarsomeres III darkened; lengths of hind femur, tibia and tarsus: $1.56-1.65,2.28-2.40,0.36-0.41$; lengths of hind tarsomeres I-III: $0.12,0.18-0.21,0.15-0.18$. Abdomen entirely pale green. Male genitalia (figs. 119-122): Genital segment with a squared, flat projection (fig. 119); left paramere not strongly curved, with flattened basal part (fig. 121); right paramere smooth apically, lacking apical process (fig. 120); vesical sclerites generally slender (fig. 122); sclerite I less toothed (fig. 123). Female: Unknown.

Dimensions. - of: Body length 3.84-3.96; head width including eyes $0.69-0.77$; vertex width 0.30 0.32 ; rostral length $1.29-1.32$; mesal pronotal length 0.49-0.53; basal pronotal width 1.00-1.08; width across hemelytra 1.44-1.49.

Distribution. - Japan (Shikoku, Kyushu).

Biology. - This new mirid appears to be associated with the oak, Quercus acutissima Carruthers.

\section{Zanchius ryukyuensis sp. $\mathrm{n}$.}

(figs. 111, 124-126)

Type material. - Holotype ô, Yona, Kunigami Vil., Okinawa Is., the Ryukyus, Japan, 20-25.v.1993, light trap, Y. Nakatani (HUES). - Paratypes: 45 specimens (HUES) from the following localities of the Ryukyus, Japan: Okinawa Is.: Same as holotype; Benoki, Kunigami Vil.; Iji; Nanbu-Chinen; Gesashi, Higashi Vil. - Ishigaki Is.: Shiramizu. - Iriomote Is.: Monbanare nr. Otomi.

Diagnosis. - Recognized by the tiny size, dark brown annulations on the antennae, pale green hemelytra irregularly mottled with the green markings, and unique shape of the male genitalia. This new species is allied to $Z$. zoui described on a single female from Yunnan, China by Zheng \& Liu (1993), but 

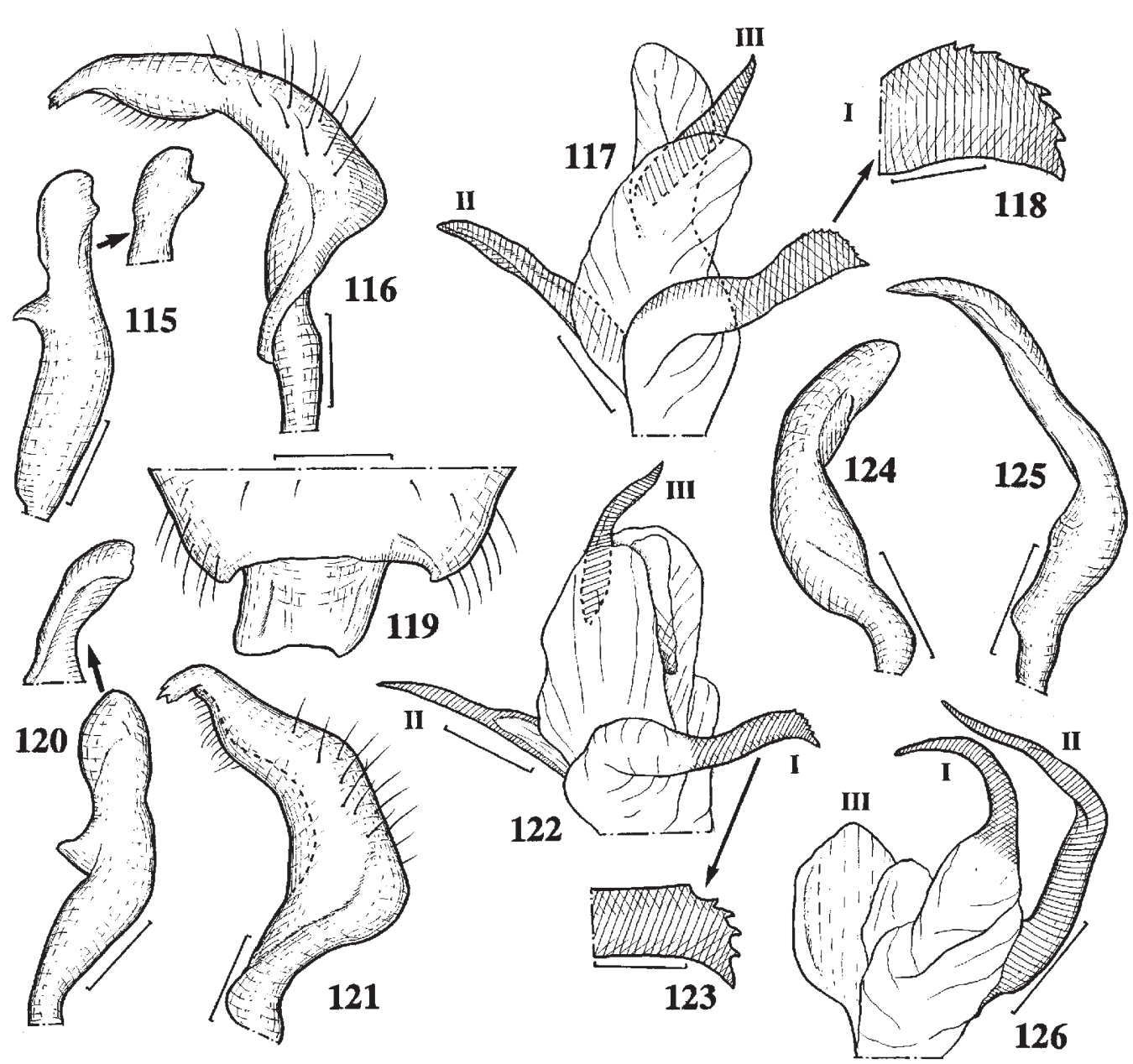

Figs. 115-126. Male genitalia of Zanchius spp. - 115-118, Z. tarasovi; 119-123, Z. quercicola; 124-126, Z. ryukyuensis. - 115, 120,124 , right paramere; $116,121,125$, left paramere; $117,122,126$, vesica; 118,123 , apex of vesical sclerite I; 119 , genital segment in ventral view. Scales: $0.2 \mathrm{~mm}$ for $119,0.1 \mathrm{~mm}$ for $105-117,120-122,124-126,0.05 \mathrm{~mm}$ for $118,123$.

ryukyuensis can be distinguished by the eyes much removed from the pronotum, shorter antenna, longer pronotum, and wholly pale femora. The final instar nymph of ryukyuensis is recognized by the entirely pure pale green, slender body. Description. - Body pale green, small, oblong oval; dorsal surface uniformly clothed with silky, suberect pubescence. Head vertical, with sparse, silky, erect pubescence; vertex with a pair of oval depressions anteriorly, margined by narrow but distinct basal transverse carina; frons rounded; tylus invisible in dorsal view. Antennae yellowish brown; segment I with a dark brown lateral stripe connected with dark apical ring; segment II with two dark brown bands at basal $1 / 3$ and apical $1 / 3$; base of segment III darkened; lengths of segments I-IV (o/q): $0.33-0.34 / 0.34-0.36,1.27$ $1.37 / 1.22-1.32, \quad 0.74-0.77 / 0.76-0.77, \quad 0.72 / 0.74-$ 0.77 . Rostrum pale brown, exceeding apex of hind coxa. Pronotum shining, weakly pruinose, clothed with silky, suberect pubescence; mesoscutum and scutellum rather flat, weakly shagreened, sparsely clothed with silky, suberect pubescence. Hemelytra pale green, subhyaline, weakly shagreened, irregularly speckled with green markings, bearing sparse, silky pubescence; membrane pale brown, semitransparent, with green cells. Legs almost entirely pale green; tibial 
spines pale brown; lengths of hind femur, tibia and tarsus (항): 1.20/1.36-1.42, 1.92-2.00/2.06-2.14, 0.40-0.44/0.40-0.45; lengths of hind tarsomeres I-III (ઠ)/ ㅇ): $0.10-0.12 / 0.10-0.14,0.19-0.22 / 0.16-0.21$, $0.19-0.22 / 0.19-0.21$. Abdomen generally pale green. Male genitalia (figs. 124-126): Left paramere long, slender, curved near its base, with tapered apex (fig. 125); right paramere blunt-tipped, roundly curved at middle (fig. 124); vesical sclerite I hooked, not toothed; sclerite II elongate, curved at middle; sclerite III reduced, becoming a flattened, weakly sclerotized plate (fig. 126).

Dimensions. - o/ 9 : Body length 3.16-3.41/3.483.60; head width including eyes $0.57-0.63 / 0.57$ 0.60 ; vertex width $0.24-0.27 / 0.27-0.29$; rostral length 1.24-1.25/1.41-1.44; mesal pronotal length $0.40-0.41 / 0.38-0.44$; basal pronotal width 0.86 $0.89 / 0.84-0.89$; width across hemelytra 1.121.23/1.20-1.25.

Distribution. - Japan (the Ryukyus: Okinawa, Ishigaki and Iriomote Isls.).

Biology. - The collection records suggest that $Z$. ryukyuensis has two or more generations per year; newly emerged adults were collected in March, May and November. Both adults and nymphs of this new species were found on Macaranga tanarius (L.) Muell. Arg. (Euphorbiaceae) together with a typhlocybinid leafhopper, Davmata (or Tautoneura) sp. (Cicadellidae, Typhlocybinae) that is considered as prey.

\section{Zanchius nakatanii sp. n.}

Type material. - Holotype $q$, Yona, Kunigami Vil., Okinawa Is., the Ryukyus, Japan, 2025.vii.1993, light trap, Y. Nakatani (HUES). Paratypes (HUES): 49 , same data as for holotype; 19 , Naze C., Amami-Oshima Is., Ryukyus, 17.v.1999, K. Takahashi.

Diagnosis. - Easily recognized by the distinct dark setae on dorsum, subtriangularly projected frons, two sanguineous bands on the antennal segment II, dark brown base of the antennal segment III, and many green circular spots on the hemelytra. These characters enable us to distinguish this new species from other congeners.

Description. - Female: Body pale green, oblongoval; dorsal surface provided with silky, suberect pubescence and distinct, dark, erect setae. Head somewhat pruinose, vertical, with silky, erect pubescence; vertex with a distinct, basal transverse carina; frons tumid, subtriangularly projected; tylus raised, almost equal in height to frons. Antennae yellow; segment I tinged with red laterally; segment II with two sanguineous bands at middle and base; base of segment III dark brown; lengths of segments I-IV: 0.33-0.36,
0.96-1.01, 0.55-0.60, 0.55-0.56. Rostrum pale brown, reaching or slightly exceeding apex of hind coxa. Pronotum weakly pruinose, somewhat carinate laterally, sparsely clothed with dark, erect setae and silky pubescence; calli weak; mesoscutum rather flat, bearing several, silky setae; scutellum provided with dark, erect setae. Hemelytra pale green, somewhat shagreened, semitransparent, with many green circular spots on clavus and corium, bearing dark, erect setae and silky, suberect pubescence; clavus without dark setae; cuneus narrowly margined by basal green band, lacking dark setae; membrane pale brown, semitransparent, with partly green veins and cells. Legs entirely pale brown; lengths of hind femur, tibia and tarsus: $0.98-1.13,1.65-1.68,0.31-0.34$; lengths of hind tarsomeres I-III: $0.07-0.09,0.12-$ $0.14,0.14-0.18$. Abdomen pale brown. Male: Unknown.

Dimensions. - $q$ : Body length 2.92-3.08; head width including eyes $0.48-0.51$; vertex width 0.21 0.23 ; rostral length 1.15-1.16; mesal pronotal length 0.24-0.27; basal pronotal width 0.69-0.77; width across hemelytra 1.12-1.20.

Distribution. - Japan (Okinawa and Amami-Oshima Isls.).

\section{Zanchius takahashii sp. n.}

(figs. 112, 127-129)

Type material. - Holotype $\hat{\sigma}$, Hirakubo, Ishigaki Is., Ryukyus, Japan, 6.ii.1993, K. Takahashi (HUES). - Paratypes (HUES): Ryukyus: Ishigaki Is.: $19, \mathrm{Mt}$. Buzama, 5.xii.1998, K. Takahashi; 10 , $1 \%$, same data as for holotype; 3 q, Ban'na Park, 4.iii.1999, T. Yasunaga; $2 q$, Shiramizu, 7.iii.1999, T. Yasunaga; 1, Maesato, 7.ii.1998, K. Takahashi; 2 옹 Itona, 9.v.1993, T. Yasunaga. - Iriomote Is.: 1 \% , Mombanare, 11.v.1993, T. Yasunaga; 1ㅇ, Komi, 13.v.1993, T. Yasunaga.

Diagnosis. - Recognized by the small, suboval body, short antenna, and characteristic dark spots on inner corner of the corium and small cell of the membrane (fig. 112). Similar in general appearance to the Taiwanese Zonodoropsis pallens Poppius, 1915, from which takahashii is easily distinguished by the reddish annulations on the antennal segment II, dark extreme bases of the antennal segments III and IV, and small dark spots on inner corner of the corium and small cell of the membrane. The final instar nymph of takahashii is recognized by the rather slender, pale green body with somewhat brownish, setose abdominal terga.

Description. - Body generally pale green, tiny, oval, slightly elongate in $\hat{\delta}$; dorsal surface sparsely clothed with simple, pale pubescence. Head vertical, with silky, erect pubescence; eyes small, vertex flat, 


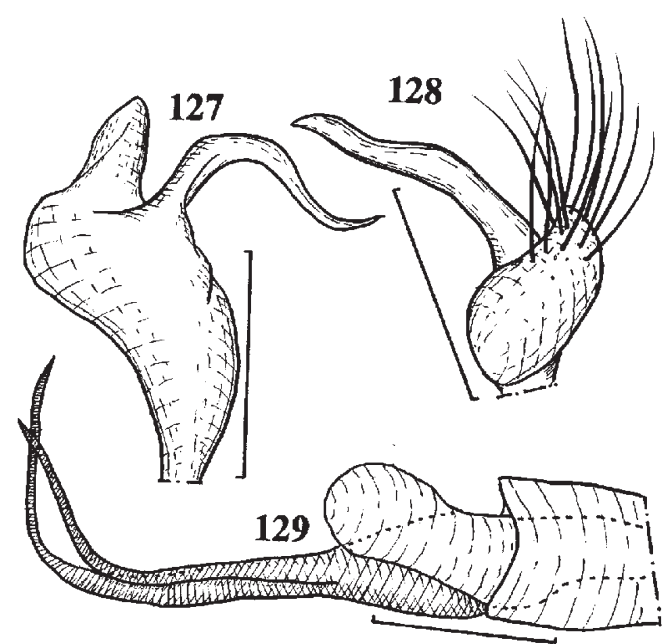

Figs. 127-129. Male genitalia of Zanchius takahashii 127 , right paramere; 128 , left paramere; 129 , vesica. Scales: $0.1 \mathrm{~mm}$.

with basal transverse carina laterally continuing to posterior margins of eyes; frons subtriangularly projected, concealing tylus in dorsal view. Antenna yellow, with silky pubescence; segment II with 2 pale red annulations at base and apical 2/3; extreme bases of filiform segments III and IV darkened; lengths of segments I-IV (o/ $/ 9)$ : $0.25-0.26 / 0.25-0.27,0.85$ 0.86/0.90-0.92, 0.39-0.40/0.44-0.45, 0.36-0.37/0.340.40 . Rostrum pale brown, slightly exceeding apex of middle coxa. Pronotum short, wide; calli flat; mesoscutum somewhat swollen; scutellum flat, weakly shagreened. Hemelytra pale green, subhyaline, flat and wide; inner margin of corium with a brown spot behind apex of clavus; extreme apex of embolium deep green; apical lateral part of cuneus sometimes with deep green spot; membrane sombre yellowish brown, semitransparent, with a dark spot on smaller cell. Leg yellowish brown; tibial spines pale brown; lengths of hind femur, tibia and tarsus ( $\delta / q$ ): $0.76-0.81 / 0.83$ $0.88, \quad 1.28-1.30 / 1.26-1.35, \quad 0.19-0.21 / 0.18-0.21$; lengths of hind tarsomeres I-III $(\delta / q)$ : 0.06 0.07/0.06-0.07, 0.09-0.10/0.08-0.11, 0.11-0.13/0.120.13 . Abdomen almost unicolorously yellowish brown. Male genitalia (figs. 127-129): Parameres rather symmetrical in form; left paramere with conspicuously long setae (fig. 128); right paramere with elongate, curved hypophysis (fig. 127); vesica with pointed, bifurcate, apically curved sclerite (fig. 129).

Dimensions. - $\delta / q$ : Body length 2.97-3.06/3.003.15; head width including eyes $0.44-0.46 / 0.45-0.46$; vertex width $0.15-0.17 / 0.19-0.21$; rostral length $0.73 / 0.79-0.81$; mesal pronotal length 0.22 -
0.24/0.25-0.27; basal pronotal width 0.63-0.69/0.660.70 ; width across hemelytra 0.95-0.97/1.10-1.14.

Distribution. - Japan (Ryukyus: Ishigaki and Iriomote Isls.).

Biology. - This new species was found on Pueraria sp. (Leguminosae) and Pipturus arborescens (Link) C. B. Rob. (Urticaceae), with which numerous typhlocybinid leafhoppers (e.g., Anufrievia sp., Limassolla sp.) were associated. The final instar nymphs were found on Macaranga tanarius with a typhlocybinid leafhopper, Davmata (or Tautoneura) sp. Presumably, Z. takahashii preys on these leafhoppers.

\section{Zanchius gigantoculus sp. $\mathrm{n}$.}

(figs. 130, 132-134)

Type material. - Holotype: $\hat{\delta}$, Mt. Yuwandake, Uken Vil., Amami-Oshima Is., Ryukyus, Japan, 29.v.1993, T. Yasunaga (HUES). - Paratypes (HUES): JAPAN, Ryukyus: $10^{\pi}$, same data as for holotype; 19 , Yona, Kunigami Vil., Okinawa Is., 20-25.v.1993, light trap, Y. Nakatani; $10,5 \%$, same data except for 15-18.v.1998; 10 , Okuni-Rindo, Kunigami Vil., Okinawa Is., 14.v.1998, light trap, Y. Nakatani.

Diagnosis. - Recognized by the generally pale green dorsum with white markings on the hemelytra, large eyes, smooth base of the vertex, ventral apical sanguineous spot of the antennal segment I, sanguineous extreme apices of the antennal segments II and III, and partly punctate corium, cuneus and membrane cells. This new species is distinct in having a parallel-sided body, conspicuously enlarged eyes in the male, reduced basal transverse carina of the vertex and pronotal collar, punctate hemelytra and membrane cell (fig. 130), strong projection on the male genital segment (fig. 129), basally developed left paramere (fig. 133), tiny right paramere, and 4 sclerites on the vesica (fig. 134, sclerites 1-4). Similar male genital structure is exhibited in $Z$. vittelinus described from China by Zou (1989), and it is considered to be a sister species of gigantoculus.

Description. - Body generally pale or yellowish green, elongate oval, parallel-sided; dorsal surface shiny, sparsely pubescent. Head vertical; eyes prominent, conspicuously projected in $\hat{\delta}$, distinctly removed from anterior margin of pronotum; vertex lacking basal transverse carina, with a pair of rounded depressions; frons weakly projected; tylus rather flat, invisible in dorsal view. Antennae yellow; segment I with a ventral apical sanguineous spot, shorter than mesal length of head; extreme apices of segments II and III narrowly sanguineous; lengths of segments IIV (ð/ ( ) ): 0.33-0.38/0.33-0.34, 1.45-1.55/1.29-1.37, 1.05-1.11/1.00-1.04, 0.55-0.71/0.67-0.72. Rostrum reaching apex of hind coxa. Pronotum weakly sha- 

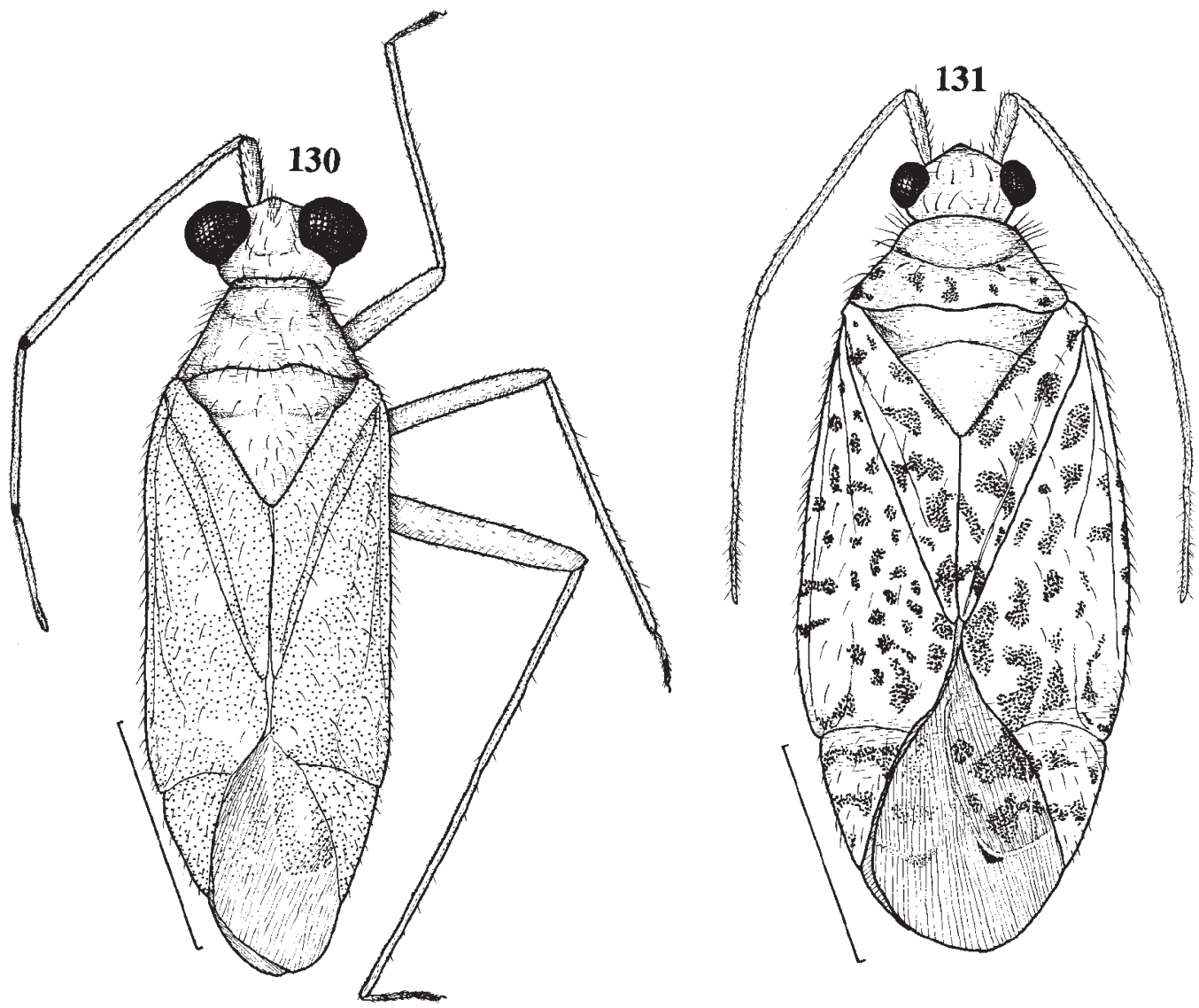

Figs. 130, 131. Dorsal habitus of Zanchius gigantoculus, male (127) and Malacocorisella endoi, female (128). Scales: $1.0 \mathrm{~mm}$.

greened posteriorly, narrow, with sparse, silky, suberect pubescence; calli shiny; collar almost completely reduced; mesoscutum and scutellum bearing silky, suberect setae; mesoscutum wide, about as wide as pronotum; scutellum large. Hemelytra subhyaline, pale green, sparsely provided with silky, suberect pubescence along veins; corium with two white markings at middle and apex, finely punctate along radius; clavus white between claval vein and suture; lateral margin of cuneus and membrane cells punctate; membrane pale brown, semitransparent, with pale green cells. Legs yellow; tibial spine pale brown; tarsomeres III dark brown; lengths of hind femur, tibia and tarsus (o/ $\%$ ): 1.39-1.50/1.22-1.44, 2.28$2.40 / 1.99-2.21, \quad 0.38-0.39 / 0.31-0.41$; lengths of hind tarsomeres I-III ( $\delta / q)$ : 0.09-0.13/0.10-0.12, $0.18-0.20 / 0.13-0.16, \quad 0.17-0.19 / 0.13-0.16$. Male genitalia (figs. 128-130): Genital segment with a prominent, right lateral projection (fig. 129); right paramere oval, tiny; left paramere developed basally, with slender and apically hooked hypophysis (fig. 130); vesica with 4 sclerotized appendages (fig. 134, 1-4) - apical broad pointed sclerite (1), elongate broad sclerite (2) and long thin sclerite (3), and mesial spinulate sclerite (4).

Dimensions. - o/ 9 : Body length 3.72-3.84/3.434.04; head width including eyes $0.72-0.77 / 0.62$ 0.68 ; vertex width $0.24-0.25 / 0.25-0.29$; rostral length 1.24-1.35/1.20; mesal pronotal length 0.45 $0.48 / 0.40-0.46$; basal pronotal width 0.90 $0.93 / 0.81-0.92$; width across hemelytra 1.20 1.31/1.10-1.30.

Distribution. - Japan (Ryukyus: Amami-Oshima and Okinawa Is.).

Biology. - This new species was collected on flowers of an undetermined evergreen broadleaved tree, and by light traps. No other information is available on the biology. 


\section{Malacocorisella gen. $\mathrm{n}$.}

Type species. - Malacocorisella endoi Yasunaga sp. n. Diagnosis. - Recognized by the small size, oval body, small eye removed from the pronotum, smooth vertex, short antenna, widely exposed mesoscutum (figs. 113, 131), and peculiar male genital structure as described below (figs. 135-138).

Description. - Body oval, small; dorsal surface sparsely clothed with brown, suberect setae. Head vertical, bearing pale, erect pubescence; eyes small, distinctly removed from anterior margin of pronotum; vertex smooth, wide, lacking basal transverse carina; frons roundly projected. Antennae short. Rostrum slightly exceeding apex of middle coxa. Pronotum short, bearing brown, suberect setae, with a transverse suture along posterior margin of calli; collar reduced; mesoscutum strongly exposed, about as wide as pronotum, obliquely carinate laterally, with sparse, brown setae; scutellum arched, pruinose, bearing sparse, brown setae. Hemelytra somewhat pruinose, uniformly clothed with pale brown, suberect setae. Male genitalia (figs. 135-138): Genital segment sharply excavated, without any noticeable processes (fig. 135); left paramere broad, with straight hypophysis (fig. 136); right paramere twisted apically, terminated in sharp apex (fig. 137); vesica with two long sclerites that are connected with phallobase by very flexible membranous tubes (fig. 138).

Etymology. - From the Palearctic genus Malacocoris Fieber, which is considered to be a close relative of this new genus; gender feminine.

Discussion. - The present new genus resembles Malacocoris Fieber, 1858, known by 3 species from Europe, Burma and India, respectively, but is distinct in having a small and oval body, smooth vertex, short antennae and legs, and very unique male genitalia.

Malacocorisella is known by a single, temperate species associated with walnut.

\section{Malacocorisella endoi sp. n.}

(figs. 113-114, 131, 135-138)

Type material. - Holotype ${ }^{\star}$, Aoyama, Tobetsu T., Ishikari, Hokkaido, Japan, ex Juglans ailantifolia, 611.viii.1997, R. Endo (HUES). - Paratypes: 128 specimens (HUES) from the following localities of Japan: Hokkaido: Same as holotype; Hattari, Atsuta Vil., Ishikari. - Honshu: Misato T. \& Koya-Hanasaka, Wakayama Pref. - Shikoku: Yusuhara, Kochi Pref.; Yukimigawa \& Same'ura, Motoyama T., Kochi Pref.

Diagnosis. - Easily recognized by the oval body, small eyes, strongly exposed mesoscutum, and dense, irregular green spots on the hemelytra and membrane cells (figs. 113, 131). The final instar nymph is recog- nized by the pale green, elongate oval body similar to that of the adult, green apical annulations of the hind femur, and rows of small, brown spots along posterior margins of the abdorminal terga (fig. 114).

Description. - Body pale green. Head with an obscure stripe behind each eye. Antennae uniformly yellowish brown; segment I bearing brown, suberect setae; lengths of segments I-IV (o/ / + ): 0.28-0.29 /0.28-0.30, 1.08-1.18/1.00-1.04, $0.64-0.72 / 0.64-0.65, \quad 0.45-0.48$ 10.48-0.51. Pronotum pruinose, with several green spots posteriorly. Hemelytra and membrane cells pale green, somewhat pruinose, densely and irregularly mottled with many green spots; membrane pale brown, semitransparent, with a dark spot at posterior apex of veins. Legs pale green; hind femur with several green spots; tibial spines pale brown; apices of tarsomeres III brown; lengths of hind femur, tibia and tarsus ( $\delta / \%): 1.10$ $1.18 / 1.17-1.20,1.72-1.80 / 1.82-1.90,0.33-0.36 / 0.33-$ 0.39 ; lengths of hind tarsomeres I-III ( $\mathrm{o} / \mathrm{P})$ : 0.10 0.12/0.09-0.12, 0.14-0.16/0.15-0.17, 0.14-0.17/0.14 -0.18 . Abdomen unicolorously pale green. Male genitalia as mentioned in generic description.

Dimensions. - o / 9 : Body length 3.33-3.36/3.483.60; head width including eyes $0.62-0.63 / 0.57$ 0.60 ; vertex width $0.26-0.27 / 0.28-0.32$; rostral length 1.08-1.11/1.15-1.20; mesal pronotal length $0.38-0.41 / 0.38-0.39$; basal pronotal width 0.91 $0.94 / 0.88-0.92$; width across hemelytra 1.441.47/1.46-1.52. $\mathrm{ku})$

Distribution. - Japan (Hokkaido, Honshu, Shiko-

Biology. - This new species was confirmed to be associated strictly with a Japanese walnut, Juglans ailantifolia Carr. One generation per year is assumed for $M$. endoi, and the newly emerged adults appear in early August.

\section{Pseudoloxops Kirkaldy}

Pseudoloxops Kirkaldy, 1905: 268, type species: Capsus coccineus Meyer-Dür, 1843, monotypic (nom. n. for Loxops Fieber, 1858: 314, preocc. by Loxops Cabanis, 1847 , Aves); Schuh 1995: 184.

This genus currently comprises 35 species ( 9 Afrotropical, 17 Indo-Pacific and 9 Palearctic) that are, without exception, easily recognized by the unique coloration. A single species, $P$. coccineus, was reported from North America, but it is considered to have been accidentally introduced with European ash nursery stock (Wheeler \& Henry 1992). In Japan 4 species occur, and are readily distinguished from one another by the superficial appearance alone. Although some external diagnostic characters are unique to Pseudoloxops as redescribed by Linnavuori (1994) and Wagner (1973), it is difficult to explain the genus as a monophyletic 


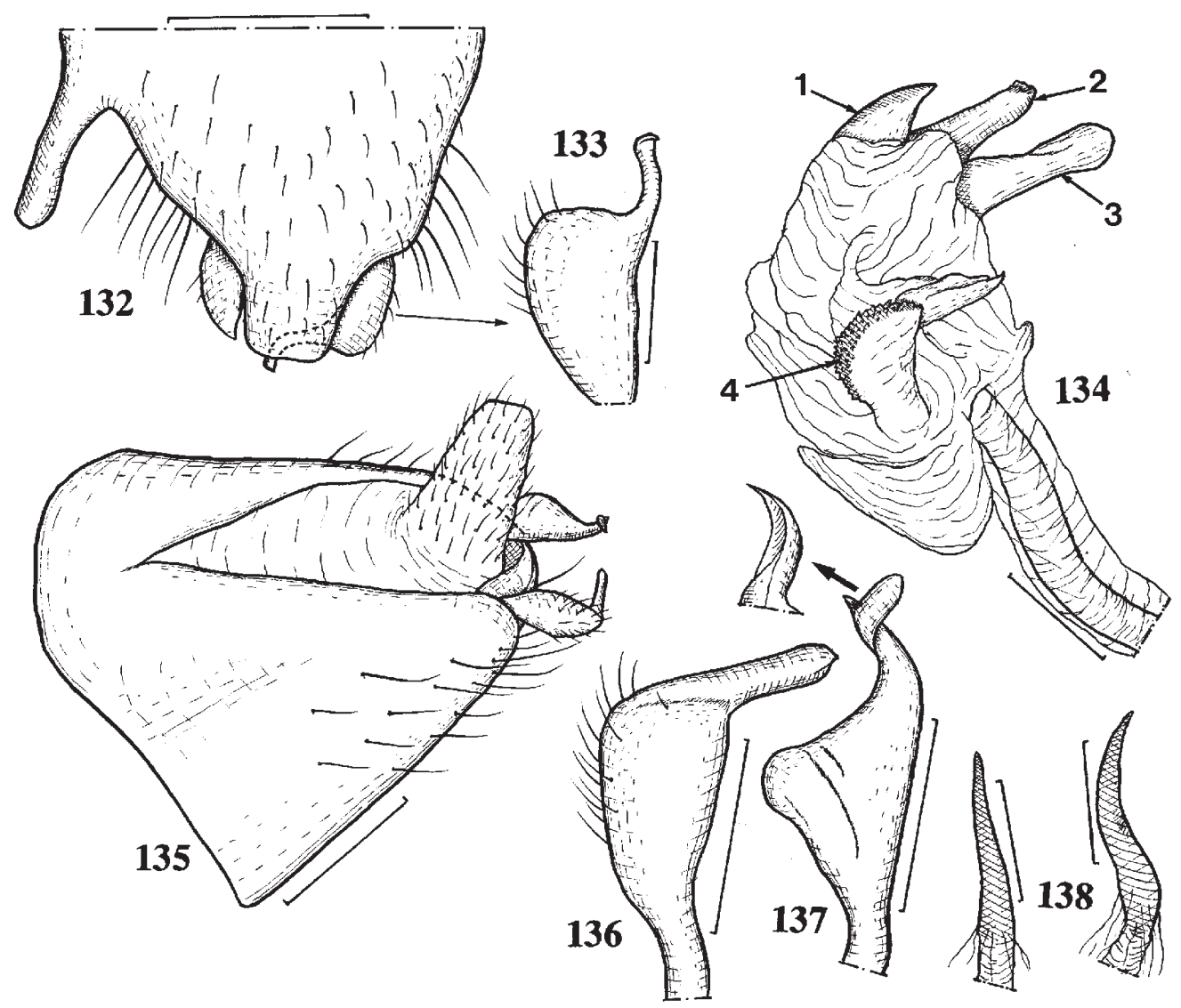

Figs. 132-138. Male genitalia of Zanchius gigantoculus (132-134) and Malacocorisella endoi (135-138). - 132, genital segment in ventral view; 135, the same, in left dorsolateral view; 133, 136, left paramere; 137 , right paramere; 134, vesica; 138 , vesical sclerites. Scales: $0.2 \mathrm{~mm}$ for 132, 135, $0.1 \mathrm{~mm}$ for 133-134, 136-138.

group because of the great interspecific variation exhibited in the male genitalia. A much broader survey on characters is required to correctly redefine Pseudoloxops.

The majority of Pseudoloxops species appear to be associated with broadleaved host plants, whereas predation was observed in a European species, P. coccineus Meyer-Dür (Wheeler \& Henry 1992).

\section{Pseudoloxops miyatakei Miyamoto}

(figs. 139, 145-146)

Pseudoloxops miyatakei Miyamoto, 1969: 75; Schuh 1995: 185; Yasunaga 1997: 11.

Diagnosis. - Recognized by the comparatively large size, uniformly distributed dark spots on the widely scarlet dorsum, mesally yellowish hemelytra, entirely yellow femur (fig. 139), two characteristic processes on the genital segment (fig. 145) (in the original description, these processes were referred to as 'a sharp median projection on hind margin of ventral wall' and 'erect spatula-shaped projection'), remarkably widened sensory lobe of the left paramere (fig. 146), and 3-branched apical appendage of the vesica. Length 3.5-4.1; width 1.4-1.6. Detailed descriptions of male and female adults were provided by Miyamoto (1969) and Yasunaga (1997), respectively.

Distribution. - Japan (Honshu, Shikoku, Kyushu).

Biology. - The only information is that this rare mirid is occasionally attracted to light.

Material examined. - 8 specimens (HUES) were examined from the following localities: Honshu: Mt. Haguro, Haguro T., Yamagata Pref.; Mt. Wasamata, Kamikitayama Vil., Nara Pref. - Shikoku: Befu, Monobe Vil., Kochi Pref. - Kyushu: Shiramizu, Shonai T., Oita Pref. 

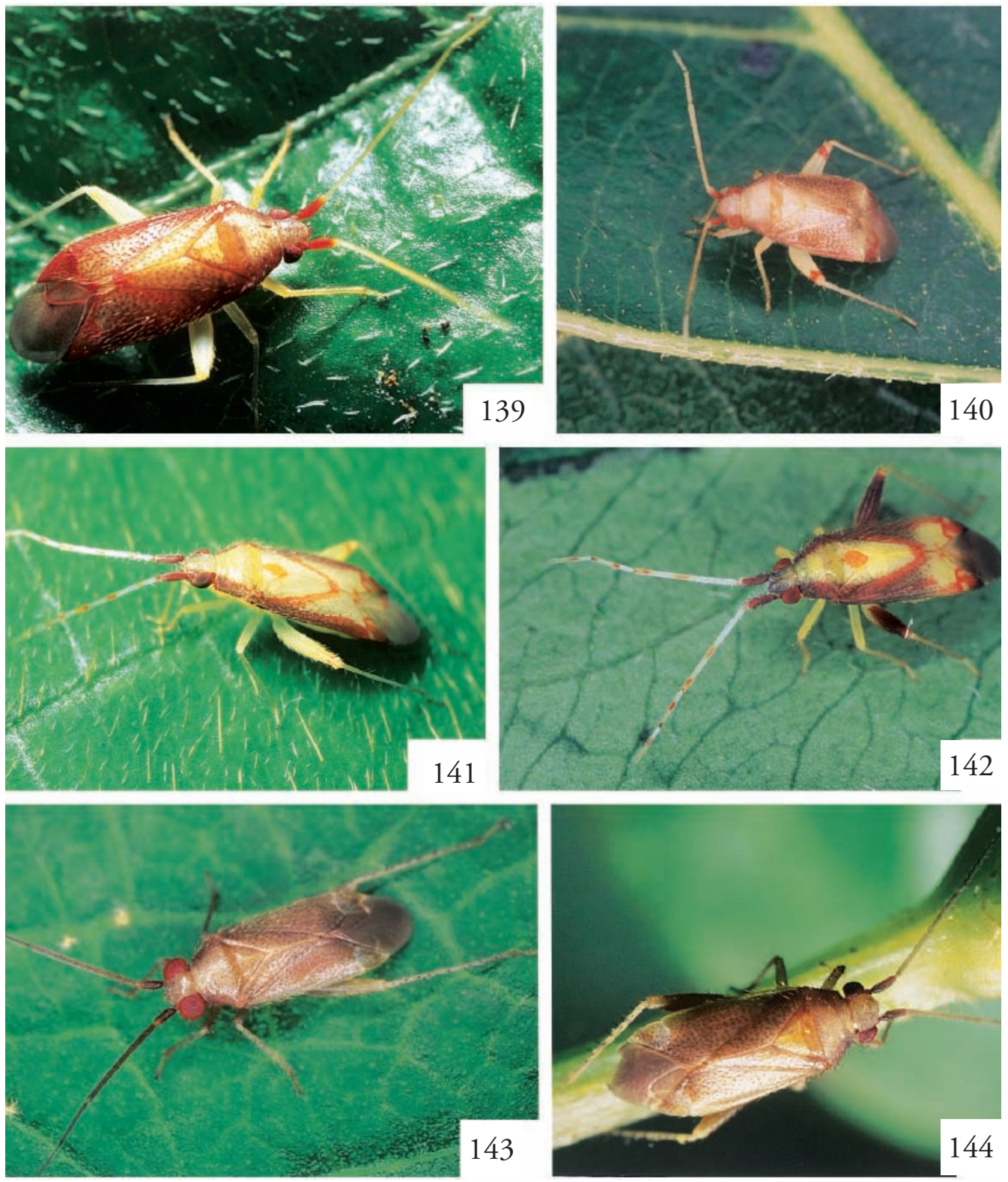

Figs. 139-144. Male (142, 143) and female (139-141, 144) adults of Pseudoloxops miyatakei (139), P. miyamotoi (140), P. imperatorius (141), P. takaii (142), and Pseudoloxopidea pinicola (143-144). 
Pseudoloxops miyamotoi Yasunaga

(figs. 140, 147-149)

Pseudoloxops miyamotoi Yasunaga, 1997: 15.

Diagnosis. - Easily ecognized by the small, oval body, rounded frons, noticeably shortened antennal segment I, well developed hind femur provided with an apical sanguineous spot (fig. 140), a pointed, subapical process of the left paramere (fig. 148), and birdhead-shaped right paramere (fig. 149). Length 2.9-3.2; width 1.2-1.4. A detailed description was provided by Yasunaga (1997). Its close relative appears to be a Chinese P. guttatus Zou, judging from the affinity of the parameres, but the latter significantly differs in the coloration and structure, in addition to being associated with the Rosaceae and Rhamnaceae host plants (Zou 1987b).

Distribution. - Japan (Honshu*, Kyushu).

Biology. - This mirid is associated strictly with the oak, Quercus acutissima Carruthers, and has a univoltine life cycle. The newly emerged adults usually appear from late July to early August.

Material examined. $-1 \delta$, Mt. Mikusa, Inagawa T., Hyogo Pref., 17.vii.1997, Y. Nakatani (HUES); 30 , 24 , Konoura, Sotome T., Nishisonogi-gun, Nagasaki Pref., Kyushu, on Quercus acutissima, 1-4.viii.1996, T. Yasunaga (holotype \& paratypes, HUES).

\section{Pseudoloxops imperatorius (Distant)}

(fig. 141)

Aretas imperatorius Distant, 1909: 451.

Pseudoloxops imperatorius - Carvalho 1958: 128; Schuh 1995: 185.

Diagnosis. - Recognized by the elongate oval body, oblique head, small eyes, widely sanguineous antennal segment I, pale red annulations of the yellow segments II, III and IV, yellow pronotum with sanguineous lateral margins, pale red, mesial, ovoid mark on the scutellum, M-shaped sanguineous mark on the yellow hemelytra, and almost entirely yellow legs (fig. 141).

Redescription. - Female: Body elongate oval, subparallel-sided; dorsal surface yellow with sanguineous marks, shining, densely clothed with brown, suberect setae. Head yellow, sometimes tinged with red in front, with silky setae. Antenna creamy yellow; segment I widely sanguineous, with stiff, suberect setae and silky, erect pubescence; segment II, III and IV each with a few, pale red annulations, bearing silky pubescence; lengths of segments I-IV: 0.37-0.38, 1.21-1.22, 0.46-0.48, 0.41-0.46. Rostrum yellow, reaching apex of middle coxa; apical part of segment IV darkened. Pronotum widely shiny yellow mesally, sanguineous and spotted laterally; mesoscutum creamy yellow; scutellum creamy yellow with a pale red, ovoid mark mesially; pleura creamy yellow. Hemelytra yellow mesally, with small, obscure spots laterally; base of clavus, basal half and each margin of corium, embolium and cuneus sanguineous; lateral bases of cuneus yellow; membrane pale greyish brown, semitransparent, with apically sanguineous veins. Leg almost unicolorously yellow; apex of hind femur sometimes narrowly red; tibial spines pale brown; lengths of hind femur, tibia and tarsus: 1.23$1.27,1.58-1.75,0.28-0.30$; lengths of hind tarsomeres I-III: $0.10-0.13,0.13-0.16,0.18-0.22$. Abdomen yellow; valvulae darkened apically.

Male: Unknown.

Dimensions. - $q$ : Body length 3.33-3.69; head width including eyes $0.57-0.59$; vertex width 0.30 0.31; rostral length 0.83-0.94; mesal pronotal length 0.31-0.32; basal pronotal width $0.79-0.84$; width across hemelytra 1.10-1.23.

Distribution. - Japan (Shikoku, Okinawa Is. and Ishigaki Is.), Sri Lanka; it is considered to be distributed widely over the regions between southern Japan and Sri Lanka.

Material examined. - JAPAN: Shikoku: 2 , , Cape Muroto, Kochi Pref., 27.v.1997, light trap, I. Yamashita (HUES). Ryukyus: 1 , Okunirindo, Kunigami Vil., Okinawa Is., 14.v.1998, light trap, Y. Nakatani (HUES); 1 \%, Hiji, Kunigami Vil., Okinawa Is., 19.v.1998, light trap, Y. Nakatani (HUES); 1 으, Ura, Okinawa Is., 27.vi.1992, M. Hayashi (HUES) - SRI LANKA: 19 , Peradeniya, Ceylon, 4-05, Distant Coll./1911-383 (holotype, BMNH).

\section{Pseudoloxops takaii Yasunaga}

(figs. 142, 150-152)

Pseudoloxops takaii Yasunaga, 1997: 12.

Diagnosis. - Recognized by the slender and small body, mesally yellowish dorsum that lacks dark spots, widely reddish brown apical part of the hind femur (fig. 142), dark, apical spines of the male genital segment (fig. 150), widened left paramere with slender hypophysis (fig. 151), and elongate right paramere (fig. 152). Length 3.0-3.7; width 1.0-1.4. The final instar nymph is easily recognized by the unique general coloration quite similar to that of adult. Detailed descriptions of both adult and final instar nymph were provided by Yasunaga (1997). Closely allied to imperatorius, takaii is easily distinguished from it by the narrower mesal yellow part on the dorsum and widely reddish apical part of the hind femur.

Distribution. - Japan (Shikoku*, the Ryukyus: Okinawa, Ishigaki and Iriomote* Isls.).

Biology. - Confirmed breeding host plants of takaii are Quercus (Cyclobalanopsis) sp., Castanopsis sp. (Fagaceae) and Styrax japonica Sieb. et Zucc. (Styracaceae), from which final instar nymphs were collect- 
ed. Collection records suggest the possibility of bi- or multivoltine life cycles for $P$. takaii, since teneral adults were collected in January and May.

Material examined. - 26 specimens including types (HUES) from the following localities of Japan: Shikoku: Kanda, Kochi C., Kochi Pref. - Ryukyus: Okinawa Is.: Yona, Kunigami Vil. (paratypes). - Ishigaki Is.: Mt. Banna (paratype); Ban'na Park; Shiramizu; without detailed locality data (paratypes); Mt. Omoto (paratypes); Omoto-Takeda (holotype \& paratypes); Miyara. - Iriomote Is.: SonaiShirahama.

\section{Pseudoloxopidea gen. $\mathrm{n}$.}

Type species. - Pseudoloxopidea pinicola Yasunaga, sp. n.

Diagnosis. - Recognized by the unicolorously pale brown general coloration, small size, regularly distributed dark spots on the dorsum, short, vertical head, very short antennal segment I (figs. 143, 144), apical spine-like setae of the male genital segment (fig. 154), slender parameres, and 3 apical spiculi of the vesica (fig. 155).

Description. - Body almost unicolorously pale brown, small, elongate oval, subparallel-sided; dorsal surface moderately shining, uniformly provided with dark, small spots each bearing a simple, suberect seta. Head short, vertical, flattened in front, with dark, erect setae. Antennal segment I very short, shorter than eye length, bearing several, dark, erect spines. Rostrum reaching apex of middle coxa. Pronotum rather narrow, with narrow collar; calli indistinct; mesoscutum wide; scutellum weakly arched. Hind tibia with large dark spots at bases of brown, prominent spines. Male genitalia (figs. 153-155): Genital segment with distinct, pale, spine-like setae apically (fig. 154); parameres slender; right paramere with apical teeth (fig. 153); vesica membranous, with 3 distinct, horn-like spiculi (fig. 155).

Etymology. - From the generic name Pseudoloxops Kirkaldy, to which this new genus is allied; gender feminine.

Discussion. - This new genus is allied to Pseudoloxops, from which it can be distinguished by the characters as diagnosed above. Especially, the structures of head and male genitalia of Pseudoloxopidea are distinctly different from those exhibited in Pseudoloxops.

Pseudoloxopidea is represented by a subtropical, pine-inhabiting species.

Pseudoloxopidea pinicola sp. $\mathrm{n}$.

(figs. 143-144, 153-155)

Type material. - Holotype đ̊, Mt. Bansei (Maese),
Ishigaki Is., Ryukyus, Japan, 20.xi.1997, T. Yasunaga (HUES). - Paratypes: 45 specimens (HUES) from the following localities of the Ryukyus, Japan: Okinawa Is.: Sate, Yona \& Mt. Terukubi, Kunigami Vil. Ishigaki Is.: Omoto; Mt. Omoto; Maesato Reservoir; same as holotype. - Iriomote Is.: Komi, Funaura, Shirahama \& Mt. Uehara.

Diagnosis. - Recognized by the characters as diagnosed in the generic diagnosis. This small species may be confused with certain species of the Phylinae, from which $P$. pinicola is distinguished by the fleshy, apically convergent parempodia between the claws.

Description. - Body almost uniformly pale brown, partly slightly reddish. Head pale brown; vertex $0.36-$ $0.40\left(\delta^{\star}\right) / 0.48-0.51$ ( + ) times as wide as head. Antenna pale brown; segment I brown or reddish brown; lengths of segments I-IV ( $₫ /$ o ) : 0.26-0.27/0.28-0.32, $1.12-1.18 / 1.10-1.24, \quad 0.45-0.49 / 0.47-0.57, \quad 0.25$ $0.32 / 0.33-0.38$. Rostrum pale brown; apical part of segment IV darkened. Spots on mesal part of pronotum, mesoscutum and scutellum sometimes reduced. Basal margin of cuneus pale; membrane pale greyish brown. Leg pale brown; tibia with dark spots; lengths of hind femur, tibia and tarsus ( $\delta / \%$ ): 0.98-1.02/1.06$1.11, \quad 1.31-1.38 / 1.40-1.52, \quad 0.30-0.32 / 0.30-0.32$; lengths of hind tarsomeres I-III ( $₫ / q)$ : $0.11-0.13 / 0.10$ $0.13,0.15-0.18 / 0.16-0.18,0.17-0.19 / 0.18-0.19$. Abdomen pale brown, somewhat tinged with red laterad. Male genitalia as mentioned in generic description.

Dimensions. - $\delta / q$ : Body length 3.03-3.24/3.093.45 ; head width including eyes $0.63-0.67 / 0.62$ 0.68 ; vertex width $0.22-0.27 / 0.31-0.33$; rostral length $0.76-0.80 / 0.79-0.81$; mesal pronotal length $0.38-0.43 / 0.37-0.40$; basal pronotal width 0.77 $0.80 / 0.79-0.89$; width across hemelytra 0.95 1.04/0.95-1.16.

Distribution. - Japan (Ryukyus: Okinawa, Ishigaki and Iriomote Isls.).

Biology. - This new species was collected from a subtropical pine, Pinus luchuensis Mayr (Pinaceae) that is regarded as the breeding host, and is frequently attracted to light. The collection records suggest that this mirid has two or more generations per year.

Key to JAPANESE GENERA, SUbGeNERA AND SPECIES OF ORTHOTYLINI

1. Pronotum strongly constricted at calli, forming distinct anterior and posterior lobes ................. 2

- Pronotum almost uniform, not constricted at calli

2. Eyes not touching anterior margin of pronotum; vertex smooth; antennal segment I much longer than head width ..............................3 (Cyllecoris)

- Eyes almost contiguous to anterior margin of 


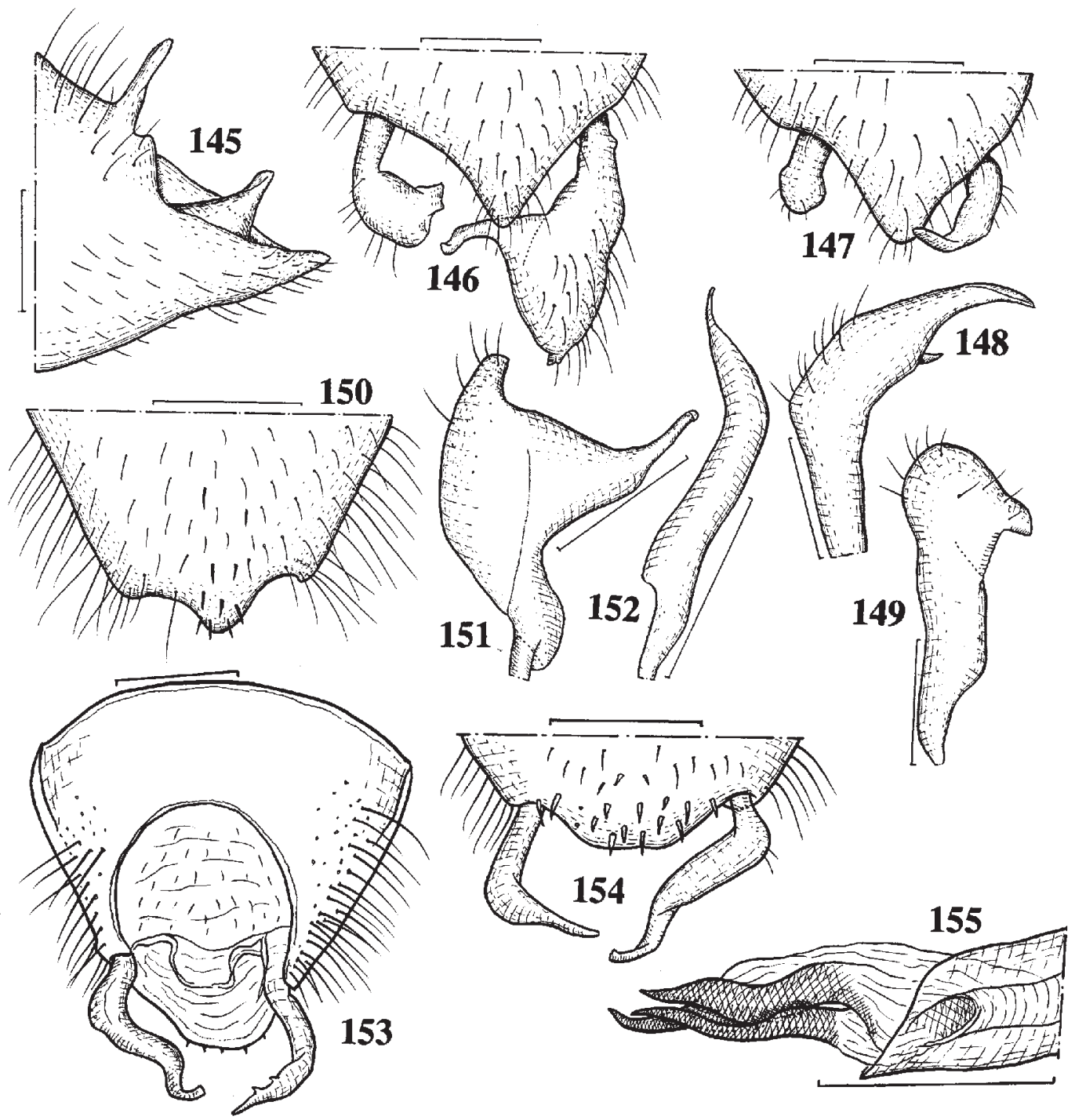

Figs. 145-155. Male genitalia of Pseudoloxops miyatakei (145-146), P. miyamotoi (147-149), P. takaii (150-152) and Pseudoloxopidea pinicola (153-155). - 145, genital segment in left lateral view; 150, the same, in ventral view; 153, the same, with parameres in dorsal view; 145, 147, 154, the same, with parameres in ventral view; 148, 151, left paramere; 149, 152, right paramere; 155 , vesica. Scales: $0.2 \mathrm{~mm}$ for $145-147,150-155,0.1 \mathrm{~mm}$ for $148-149$. 
pronotum; vertex with a transverse carina basally; antennal segment I shorter than head width ...... ..4 (Dryophilocoris)

3. Body larger, longer than $7 \mathrm{~mm}$ and wider than $1.9 \mathrm{~mm}$; antennal segment I tinged with red; pronotum polished, very shiny with continuously pale posterior margin; oak inhabitant

Cyllecoris vicarius

- Body shorter and slenderer, shorter than $6.6 \mathrm{~mm}$ and narrower than $1.5 \mathrm{~mm}$; antennal segment I dark brown; pronotum widely shagreened or pruinosed, with dark and mesally pale posterior margin; elm inhabitant C. nakanishii

4. Pronotum behind calli pruinosed Dryophilocoris miyamoto $i$

- Pronotum behind calli shiny, polished, not pruinosed

5. Pronotum distinctly pubescent .......... D. saigusai

- Pronotum almost glabrous ............... D. lucidus

6. Pronotum and hemelytra more or less with scattered, dark, small spots (figs. 139-144) ............7

- Pronotum and hemelytra lacking such spots ...11

7. Hemelytra unicolorously pale brown Pseudoloxopidea pinicola

- Hemelytra bicolorous, sanguineous or reddish brown laterally and yellow or pale brown mesally 8 (Pseudoloxops)

8. Pronotum and scutellum uniformly furnished with dark, small spots (fig. 139).....

\section{Pseudoloxops miyatakei}

- At least mesal parts of pronotum and scutellum lacking dark, small spots ...9

9. Antennal segments II and III unicolorously pale brown; pronotum and hemelytra pale reddish brown laterally; scutellum entirely pale brown (fig. 140) ...................................... miyamotoi

- Antennal segment II and III with 3-4 reddish rings; lateral parts of pronotum and hemelytra sanguineous or deep red; scutellum yellow, with oval, reddish mark mesially (figs. 141, 142) .. 10

10. Hind femur entirely yellow, or sometimes narrowly pale red at apex (fig. 141)...P. imperatorius

- More than apical half of hind femur deep red (fig. 142) P. takaii

11. Eyes situated anteriorly, distinctly removed from pronotum as in figs. 130, 131

- Eyes contiguous or subcontiguous to pronotum .

12. Antennal segment I very long, much longer than pronotal width (fig. 94) ... Mecommopsis cruciata

- Antennal segment I apparently shorter than pronotal width .. 13

13. Antenna entirely pale, without any annulation or stripe ............................. Malacocorisella endo $i$

- Antenna somewhere with red or dark spot, annulation or stripe 14 (Zanchius)
14. Body suboval, less than 3 times as long as maximum width; inner corner of corium and small membrane cell each with a dark brown spot (fig. 112) Zanchius takahashii

- Body elongate oval, more than 3 times as long as maximum width; corium and membrane without dark spots 15

15. Pronotum with both dark and pale setae ............ Z. nakatanii

- Pronotum only with simple, pale setae ........ 16

16. Head with a scarlet lateral stripe or spot behind each eye ................................................ 17

- Head without any marking behind eye ......... 18

17. Body larger, more than $4.5 \mathrm{~mm}$ in length; tylus projected ...................................... Z. tarasovi

- Body smaller, less than $4 \mathrm{~mm}$; tylus less projected

18. Apical part of antennal.................... quercicola guineous, ventral spot; extreme apex of segment II reddish Z. gigantoculus

- Antennal segment I with a black lateral stripe; segment II with 4 black annulations

Z. ryukyuensis

19. Hemelytra with both simple setae and silvery pubescence ................................................. 20

- Hemelytra with simple, pale or brown setae . 23

20. Antennal segment I short, less than $0.3 \mathrm{~mm}$ in length...............21 (Orthotylus (Melanotrichus))

- Antennal segment I long, more than $0.4 \mathrm{~mm} . . .$. .22 (Blepharidopterus)

21. Body smaller, less than $3.2 \mathrm{~mm}$ in length; silvery pubescence on hemelytra uniformly distributed... Orthotylus (Melanotrichus) parvulus

- Body larger, more than $3.5 \mathrm{~mm}$; hemelytra with patches of silvery pubescence (fig. 43)

O. (M.) flavosparsus

22. Antennal segments I and II pale brown; pronotum entirely pale (fig. 44)

Blepharidopterus ulmicola

- Antennal segment I and II, and posterior margin of pronotum dark brown B. striatus

23. Pronotum entirely pale green (or fading to yellow or pale brown in old specimens) ...................24

- Pronotum entirely or partly blackish, brownish or reddish ................................................ 27

24. Extreme base of hind tibia with a dark knee spot (fig. 5) Orthotylus (O.) japonicus

- Hind tibia lacking knee spot ........................ 25

25. Anterior margin of scutellum and membrane veins infuscate O. (O.) kurilensis

- Scutellum and membrane veins pale (figs. 3, 39)

26. Rostrum short, not exceeding apex of middle coxa ................................ O. (O.) interpositus

- Rostrum long, exceeding apex of hind coxa ....... ..O. (Kiiorthotylus) gotohi 
27. Pronotum, scutellum and hemelytra almost unicolorously reddish brown or dark brown (fig. 41) O. (Yamatorthotylus) xanthopoda

- Pronotum, scutellum and/or hemelytra bicolorous 28

28. Hemelytra unicolorously pale green (fig. 97)...... Cyrtorhinus lividipennis

- Corium and clavus more or less infuscate ..... 29

29. Pronotum and scutellum entirely fuscous ..... 30

- Pronotum and scutellum always with pale parts. ...31

30. Body elongate in $\hat{\delta}$, more than $5 \mathrm{~mm}$ in length; female brachypterous; apex of cuneus infuscate . Mecomma japonica

- Body small, less than $4 \mathrm{~mm}$, always macropterous; cuneus entirely pale green (fig. 96)

Cyrtorhinus caricis

31. Scutellum pale, with mesal dark spot; clavus whitish green, narrowly infuscate along inner margin ..... Orthotylus (Pseudorthotylus) bilineatus

- Scutellum entirely dark, sometimes pale mesally; clavus widely or entirely infuscate (fig. 1) ..... 32

32. Body larger, more than $5.2 \mathrm{~mm}$ in length; pronotum more than $1.4 \mathrm{~mm}$ in width.

O. (O.) pallens

- Body smaller, less than $4.8 \mathrm{~mm}$; pronotum less than $1.3 \mathrm{~mm}$ O. (O.) fuscipennis

\section{ACKNOWLEDGements}

Special thanks are due to Dr. S. Miyamoto (Fukuoka City) for continuous advice and encouragement. I am also much indebted to Dr. I. M. Kerzhner (ZMAS) and Dr. N. N. Vinokurov (Siberian Branch of Russian Academy of Sciences, Yakutsk) for valuable suggestion and Russian translation. My cordial thanks are due to Dr.I.M. Kerzhner (ZMAS), Dr. T. J. Henry (USNM), Dr. L. Hulden (ZMUH), and Mr. M. D. Webb (BMNH) for permission to examine valuable material. I wish to thank Mr. M. Takai (Kochi Agricultural Research Center, Nankoku) for offering some excellent photographs used in this paper and Prof. M. Hayashi (Saitama Univ., Urawa) for identification of the typhlocybinid leafhoppers. I greatly acknowledge the following individuals for loan or donation of material, and/or kind assistance in the field: Dr. S. Miyamoto, Dr. T. J. Henry (USNM), Dr. A. G. Wheeler, Jr. (Clemson Univ., SC, USA), Drs. N. Kurzenko, A. Lelej, Y. Tshuistjakov, V. Makarkin, A. Egorov and E. Kanyukova (Russian Academy of Sciences, Vladivostok), Prof. M. Suwa and Dr. M. Ohara (SEHU), Mr. S. Gotoh and Mrs. M. Gotoh (Tanabe City), Prof. M. Hayashi, Drs. M. Tomokuni and S. Nomura (NSMT), Dr. T. Matsumura and Mr. K. Konishi (NIAS), Messrs. T. Kawasawa, M. Kawamura, M. Takai, T. Befu and I. Yamashita (Kochi
Pref.), Drs. K. Takahashi and K. Kohno (JIRCAS, Okinawa Subtropical Station, Ishigaki), Dr. Y. Sawada (Museum of Nature and Human Activities, Hyogo), Mr. S. Sakurai (Niigata City), Mr. M. Nozawa (Saitama Pref.), Mr. M. Wataji (Takuhoku Highschool, Sapporo), Mr. T. Ichita (Aomori Pref.), Mr. K. Watanabe (Yamagata Pref.), Dr. Y. Nakatani (National Institute of Agro-Environmental Sciences, Tsukuba), Mr. A. Yamamoto (Otaru City Museum), Mr. S. Ide (Kurume City), Dr. K. Yoshizawa (Kyushu Univ., Fukuoka), Ms. Y. Todo, and Messrs. A. Hiranuma, R. Endo, A. Makino and S. Yamashita (Sapporo City), and my wife, Miho-Arare.

\section{REFERENCES}

Butler, E. A., 1923. A Biology of the British Hemiptera-Heteroptera. - H. F. \& G. Witherby, London, viii+682 pp.

Carvalho, J. C. M., 1956. Insects of Micronesia: Miridae. Bernice P. Bishop Museum, Insects of Micronesia 7: 1-100.

Carvalho, J. C. M., 1958. Catalogue of the Miridae of the world. Part III. - Arquivos do Museo Nacional, Rio de Janeiro 47: 1-161.

Carvalho, J. C. M., 1980. Analecta Miridologica, IV: Observations on type specimens in the National Museum of Natural History, Budapest, Hungary (Hemiptera, Miridae). - Revista Brasileira de Biologica 40: 649-658.

Distant, W. L., 1904. The fauna of British India, including Ceylon and Burma. Rhynchota Vol. II, part 2. - Taylor \& Francis, London, pp. 243-503.

Endo, R., T. Yasunaga \& N. N. Vinokurov, 1998. Plant bugs (Heteroptera, Miridae) collected in Tobetsu Town, Hokkaido, Japan. - Rostria 47: 15-22. [In Japanese with English summary]

Fallén, C. F., 1807. Monographia Cimicum Sveciae. - Hafniae, $122 \mathrm{pp}$.

Fieber, F. X., 1858. Criterien zur generischen Theilung der Phytocoriden (Capsini aut.). - Wiener entomologische Monatschrift 2: 289-327, 329-347, 388, 1 pl.

Hahn, C. W., 1834. Die Wanzenartigen Insecten. - Nürnberg 2: 33-120.

Hayashi, M., \& O. Higashikawa, 1997. HomopteraAuchenorrhyncha and Heteroptera (Insecta, Rhynchota) from Sugadaira, central Honshu, Japan. - Bulletin of Sugadaira Montane Research Center, University of Tsukuba 14: 15-56.

Henry, T. J., \& A. G. Wheeler, Jr., 1988. Family Miridae Hahn, 1833 (= Capsidae Burmeister, 1835). The plant bugs, pp. 251-507. - In Henry, T. J. \& R. C. Froeschner (eds.), Catalogue of the Heteroptera, or True Bugs of Canada and the Continental United States. - E. J. Brill, Leiden \& New York, xix+958 pp.

Hiranuma, A. \& T. Yasunaga, 1998. The nymphal period of mirid bugs (Heteroptera, Miridae). - Rostria 47: 1-14. [In Japanese with English summary]

Josifov, M., 1976. Drei neue Orthotylus-Arten aus Korea. Reichenbachia 16: 143-146.

Josifov, M., 1992. Contribution to a knowledge of the family Miridae of North Korea (Heteroptera). - Insecta Koreana 9: 115-128.

Josifov, M. \& I. M. Kerzhner, 1984. Zur Systematik der Gattung Dryophilocoris Reuter, 1875 (Heteroptera, Miri- 
dae). - Reichenbachia 22: 215-226.

Kelton, L. A., 1980. The plant bugs of the Prairie Provinces of Canada. Heteroptera: Miridae. - The Insects and Arachnids of Canada Part 8. - Agriculture Canada, Ottawa, Ontario, 408 pp.

Kerzhner, I. M., 1972. Novye i maloizvestnye Poluzhestkokrylye (Heteroptera) s Dal'negoVostoka SSSR [New and little known Heteroptera from the Soviet Far East]. Trudy zoologitseskogo Instituta Akademija Nauk SSSR 52: 276-295. [In Russian]

Kerzhner, I. M., 1977. Novye i maloizvestnye vidy Poluzhestkokrylykh (Heteroptera) s Dal'nego Vostoka SSSR [New and little known species of Heteroptera from the Soviet Far East]. - Trudy zoologitcheskogo Instituta Akademija Nauk SSSR 57: 6-35. [In Russian]

Kerzhner, I. M., 1978. Poluzhestkokrylye (Heteroptera) Sakhalina i Kuril'skikh Ostrovov [Heteroptera of Sakhalin and Kuril Islands]. Trudy biologo - pochvennogo Instituta, Novaja serija, 50: 31-57. Akademija Nauk SSSR, Vladivostok. [In Russian]

Kerzhner, I. M., 1979. Novye Poluzhestkokrylye (Heteroptera) s Dal'nego Vostoka SSSR [New Heteroptera from the Soviet Far East]. - Trudy zoologitseskogo Instituta Akademija Nauk SSSR 81: 14-65. [In Russian]

Kerzhner, I. M., 1988a(1987). Novye i maloizvestnye poluzhestkokrylye Nasekomye s Dal'nego Vostoka SSSR [New and little known heteropterous insects from the Soviet Far East]. - Akademija Nauk SSSR, Vladivostok, 83 pp. [In Russian]

Kerzhner, I. M., 1988b. Sem. Miridae (Capsidae) - Slepnjaki. - Opredelitel' Nasekomykh Dal'nego Vostoka SSSR [Keys to the insects of the Soviet Far East] 2: 778-857. Nauka, Leningrad. [In Russian]

Kerzhner, I. M., 1997a. A new species of Orthotylus from the Kuril Islands (Heteroptera: Miridae). - Zoosystematica Rossica 5: 212.

Kerzhner, I. M., 1997b. Type specimens of some Palaearctic Miridae in the Zoological Museum, Helsinki (Heteroptera). - Zoosystematica Rossica 6: 115-121.

Kirkaldy, G. W., 1905. Neue und wenig bekannte Hemiptera. - Wiener Entomologische Zeitung 24: 266268.

Kirkaldy, G. W., 1906. List of the genera of the Pagiopodous Hemiptera-Heteroptera with their type species, from 1758 to 1904 (and also of the aquatic and semi-aquatic Trochalopoda). - Transactions of the American entomological Society 32: 117-156, 156a, 156 b.

Kolenati, F. A., 1845. Meletemata entomologica - Fasc.ii.Hemiptera Caucasi Tessaratomidae, monographice dispositae. - Petropoli, pp. 1-132, pls. 7-11.

Lee, C. E. \& Y. J. Kwon, 1991. Annotated check list of Hemiptera from Korea. Part III, Cimicomorpha 2: Miridae. - Nature and Life, Taegu (Korea) 21: 23-38.

Lee, C. E., S. Miyamoto \& I. M. Kerzhner, 1994. Additions and corrections to the list of Korean Heteroptera. - Nature and Life, Taegu (Korea) 24: 1-34.

Leston, D., 1957. Cyto-taxonomy of Miridae and Nabidae. Chromosoma 8: 609-616.

Linnavuori, R., 1994. Orthotylinae of West, Central and North-East Africa (Heteroptera). - Acta zoologica fennica 193: 1-84.

Liu, G.-Q. \& L.-Y. Zheng, 1994. Two new species of genus Pseudoloxops Kirk. from China (Insecta: Heteroptera: Miridae). - Reichenbachia 30: 119-122.

Matsumura, S., 1911. Erster Beitrag zur Insekten Fauna von
Sachalin. - Journal of College of Agriculture, Tohoku Imperial University 4: 1-145.

Matsumura, S., 1917. Ohyo-Konchu-Gaku [Applied Entomology]. - Keiseisha, Tokyo, 11+731+12 pp. [In Japanese]

Miyamoto, S., 1957. List of ovariole numbers in Japanese Heteroptera. - Sieboldia, Fukuoka 2: 69-82.

Miyamoto, S., 1961. Comparative morphology of alimentary organs of Heteroptera, with the phylogenetic consideration. - Sieboldia, Fukuoka 2: 197-250.

Miyamoto, S., 1965. Heteropterous insects of Formosa collected by Dr. Shirozu and others.-Special Bulletin of Lepidopterological Society of Japan 1: 227-238.

Miyamoto, S., 1966. Five new species of Miridae from Japan (Hemiptera, Heteroptera). Sieboldia, Fukuoka 3: 427-438.

Miyamoto, S., 1969. Some Orthotylinae from Japan (Hemiptera-Heteroptera: Miridae). -Sieboldia, Fukuoka 4: 75-83.

Miyamoto, S., 1977. On the scientific names of Japanese Heteroptera. - Rostria 28: 231-234. [In Japanese]

Miyamoto, S., 1988. Some mirids new to Japan (Heteroptera: Miridae). - Rostria 39: 637-638. [In Japanese]

Miyamoto, S. \& T. Yasunaga, 1989. Heteroptera, pp. 151188. - In Hirashima, Y. (ed.), A Check List of Japanese Insects I. - Fukuoka, xi+540 pp.

Muramoto, N., 1975. Notes on the chromosomes and sex ratio of Orthotylus flavosparsus Sahlberg (Miridae, Heteroptera). Rostria 25: 161-165.

Poppius, B., 1914. Die Miriden der Äetiopischen Region II - Macrolophinae, Heterotominae, Phylinae. - Acta Societatis Scientiarum fennicae, Helsingfors 44(3): 1-136.

Poppius, B., 1915(1914). H. Sauter's Formosa = Ausbeute: Nabidae, Anthocoridae, Termatophylidae, Miridae, Isometopidae und Ceratocombidae (Hemiptera). Archiv für Naturgeschichte $80 \mathrm{~A}(8)$ : 1-80.

Reuter, O. M., 1875a. Revisio critica Capsinarum praecipue Scandinaviae et Fenniae. - Akademisk Afhandling, Helsingfors, $101+190 \mathrm{pp}$.

Reuter, O. M., 1875b. Genera Cimicidarum Europae. - Bihang till Kongliga Svenska Vetenskaps-Akademiens Händlingar - 3: 1-66.

Reuter, O. M., 1879. Diagnoses Hemipterorum novorum. - Öfversigt Finska Vetenskaps Societatens Förhandlingar 21: 30-41.

Reuter, O. M., 1883. Hemiptera Gymnocerata Europae. Hémiptères Gymnocérates d'Europe, du bassin de la Méditerranée et de l'Asie Russe III. - Acta Societatis Scientiarum fennicae, Helsingfors 14: 313-496.

Reuter, O. M., 1885. Species Capsidarum quas legit expeditio danica Galateae descripsit. - Entomologisk Tidskrift 5: 195-200.

Sahlberg, C. R., 1841. Nova species generis Phytocoris ex ordine Hemipterorum descripta. - Acta Societatis Scientiarum fennicae, Helsingfors 1: 411-412.

Schmidt, K., 1938. Eine neue Orthotylus-Art. - In Stichel, W. Illustrierte Bestimmungstabellen der Deutschen Wanzen (Hemiptera-Heteroptera) 16: 468-469. Stichel, Berlin- Hermsdorf.

Schuh, R. T., 1974. The Orthotylinae and Phylinae (Heteroptera: Miridae) of South Africa with a phylogenetic analysis of the ant-mimetic tribes of the two subfamilies for the world. - Entomologica Americana 47: 1-332.

Schuh, R. T., 1995. Plant bugs of the world (Insecta: Heteroptera: Miridae). Systematic catalog, distributions, host list and bibliography. - The New York Entomological 
Society, xii+1329 pp.

Southwood, T. R. E., 1953. The morphology and taxonomy of the genus Orthotylus Fieber (Hem., Miridae), with special reference to the British species. - Transactions of the Royal entomological Society of London 104: 415-449.

Southwood, T. R. E. \& D. Leston, 1959. Land and water bugs of British Isles. - Frederic Warne \& Co. Ltd., London \& New York, ix+436 pp.

Todo, Y. \& T. Yasunaga, 1996. The plant bugs collected on willow (Salix spp.) in Hokkaido, Japan. - Rostria 45: 4147. [In Japanese with English summary]

Vinokurov, N. N. \& E.V..Kanyukova, 1995. Poluzhestkokrylye Nasekomye (Heteroptera) Sibiri [Heteropterous insects of Siberia]. - Novosibirsk, Nauka, 237 pp. [In Russian]

Wagner, E., 1952. Blindwanzen oder Miriden. - Tierwelt Deutschlands 41: iv +218 .

Wagner, E., 1973. Die Miridae Hahn, 1831, des Mittelmeerraumes und der Makaronesischen Inseln (Hemiptera, Heteroptera). Teil 2. - Entomologische Abhandlungen, Dresden, 39 supplement: 1-421.

Wagner, E. \& H. H. Weber, 1964. Hétéroptères, Miridae. - Faune de France 67: 1-591.

Wheeler, Jr., A. G. \& T. J. Henry, 1992. A synthesis of the Holarctic Miridae (Heteroptera): distribution, biology, and origin, with emphasis on North America. - ESA, Lanham, Maryland, $282 \mathrm{pp}$.

Yasunaga, T., 1992. Stomorhina obsoleta (Dip.: Calliphoridae) 'captured' by adhesive hairs of young haricot bean. Pulex 80: 7-8. [In Japanese.]

Yasunaga, T., 1993. A new orthotyline plant bug (Heteroptera: Miridae), associated with Rhododendron macrosepalum (Ericaceae) in the Kii Peninsula, Japan. Bulletin of biogeographical Society of Japan 48: 56-59.
Yasunaga, T., 1996. Predation observed on Orthotylus pallens (Matsumura) (Heteroptera, Miridae, Orthotylinae). - Rostria 45: 48-50. [In Japanese with English summary]

Yasunaga, T., 1997. Species of the orthotyline genus Pseudoloxops Kirkaldy from Japan (Heteroptera: Miridae). - Bulletin of biogeographical Society of Japan, 52: 11-18. Yasunaga, T., S. Miyamoto \& I. M. Kerzhner, 1996. Type specimens and identity of the mirid species described by Japanese authors in 1906-1917 (Heteroptera: Miridae). Zoosystematica Rossica 5: 91-94.

Zhang, W.-Q., 1985. Cyrtorrhinus lividipennis Reuter. - In Zhang, S.-M. (ed.), Economic insect fauna of China. Fasc. 31. Hemiptera (1), p. 200. - Science Press, Beijing, $\mathrm{x}+242 \mathrm{pp}$

Zheng, L.-Y. \& L.-J. Liang, 1991. Mirid bugs preying on persimmon leafhoppers from China (Hemiptera: Miridae). - Acta Scientiarum naturalium Universitatis Nankaiensis 3: 84-87.

Zheng, L.-Y. \& G.-Q. Liu, 1993. Two new species of genus Zanchius Dist. (Insecta: Hemiptera: Heteroptera: Miridae). - Reichenbachia 30: 17-20.

Zou, H.-G., 1987a. Descriptions of two new species of Zanchius from China (Hemiptera: Miridae). - Acta Zootaxonomica Sinica 12: 297-300

Zou, H.-G., 1987b. Two new species of Pseudoloxops Kirk. from China (Hemiptera: Miridae). Acta Zootaxonomica Sinica 12: 389-392.

Zou, H.-G., 1989. New species and new records of Miridae from China. - Acta Zootaxionomica Sinica 14: 327-331.

Received: 12 February 1999

Accepted: 19 May 1999 